\title{
A polypeptide D-TTK001 targeting HBx controls cccDNA against HBV
}

\section{Xiaodong Zhang ( $\nabla$ zhangxiaodong@tjmuch.com )}

Tianjin Cancer Institute, Tianjin Medical University Cancer Institute and Hospital

\section{Hongfeng Yuan}

Tianjin Cancer Institute, Tianjin Medical University Cancer Institute and Hospital

\section{Shuai Zhang}

Department of Cancer Research, College of Life Sciences, Nankai University

\section{Shuqin Zhang}

Department of Cancer Research, College of Life Sciences, Nankai University

\section{Lina Zhao}

Department of Cancer Research, College of Life Sciences, Nankai University

\section{Hongwei Gao}

School of Life Sciences, Ludong University

\section{Guang Yang}

Tianjin Cancer Institute, Tianjin Medical University Cancer Institute and Hospital

\section{Xuezhi Zhang}

Department of Cancer Research, College of Life Sciences, Nankai University

\section{Haolin Yun}

Department of Cancer Research, College of Life Sciences, Nankai University

\section{Changliang Shan}

Nankai University

\section{Yunxia Liu}

Nankai University

\section{Yu Geng}

Department of Cancer Research, College of Life Sciences, Nankai University

\section{Wei Zheng}

Department of Cancer Research, College of Life Sciences, Nankai University

\section{Xiuzhu Gao}

Department of Hepatology, the First Hospital, Jilin University

\section{Xiaomei Wang}

Department of Hepatology, the First Hospital, Jilin University

\section{Ying Yuan}

Tianjin Cancer Institute, Tianjin Medical University Cancer Institute and Hospital

\section{Zhenchuan Miao}


Beijing Vitalstar Biotechnology Co. Ltd.

\section{Ming Yin}

Beijing Vitalstar Biotechnology Co. Ltd.

\section{Man Zhao}

Nankai University

\section{Yufei Wang}

Department of Cancer Research, College of Life Sciences, Nankai University

Jiapei Wang

Department of Cancer Research, College of Life Sciences, Nankai University

\section{Junqi Niu}

Department of Hepatology, the First Hospital, Jilin University

\section{Biological Sciences - Article}

Keywords: HBV, covalently closed circular DNA, HBV X protein, D-TTK001

Posted Date: December 1st, 2020

DOl: https://doi.org/10.21203/rs.3.rs-100428/v1

License: (1) (1) This work is licensed under a Creative Commons Attribution 4.0 International License. Read Full License 
3 Hongfeng Yuan ${ }^{1,2,6}$, Shuai Zhang ${ }^{2,6,7}$, Shuqin Zhang ${ }^{2}$, Lina Zhao ${ }^{2}$, Hongwei Gao ${ }^{3}$, Guang Yang ${ }^{1,2}$,

4 Xuezhi Zhang ${ }^{2}$, Haolin Yun ${ }^{2}$, Changliang Shan², Yunxia Liu ${ }^{2}$, Yu Geng ${ }^{2}$, Wei Zheng ${ }^{2}$, Xiuzhu

$5 \mathrm{Gao}^{4}$, Xiaomei Wang ${ }^{4}$, Ying Yuan ${ }^{2}$, Zhenchuan Miao ${ }^{5}$, Ming Yin ${ }^{5}$, Man Zhao ${ }^{2}$, Yufei Wang 2 ,

6 Jiapei Wang 2 , Junqi Niu ${ }^{4 *}$, Xiaodong Zhang ${ }^{1,2} *$

7 1. Tianjin Cancer Institute, Tianjin Medical University Cancer Institute and Hospital, Tianjin, P.R.

8 China.

2. Department of Cancer Research, College of Life Sciences, Nankai University, Tianjin 300071,

P.R. China.

3. School of Life Sciences, Ludong University, Yantai, 264025, Shandong, P.R. China.

4. Department of Hepatology, the First Hospital, Jilin University, Changchun 130021, P.R. China.

5. Beijing Vitalstar Biotechnology Co. Ltd., Beijing 100000, P.R. China.

6. Contributed equally to this work.

7. Current addresses: School of Integrative Medicine, Tianjin University of Traditional Chinese Medicine, Tianjin, 301617, China.

Cancer Institute and Hospital, Huan-Hu-Xi Road, Tianjin, 300060, P.R. China; E-mail: zhangxiaodong@tjmuch.com; Tel: +86-22-58606092, Fax: +86-22-58606093. Junqi Niu, the First junqiniu@aliyun.com; Tel./ Fax: +86-431-88785101. 


\section{$1 \quad$ Abstract}

2 Chronic infection of HBV is a serious global health issue. However, the HBV covalently closed

3 circular DNA (cccDNA) cannot be completely cleaned in liver. Here, we engineer a novel

4 polypeptide, termed D-TTK001, targeting HBV X protein (HBx) against HBV cccDNA. D-

5 TTK001 is a D-type polypeptide, which has a high binding affinity to HBx. Interestingly, it is able

6 to against HBV efficiently in primary human hepatocytes (PHHs) from three donors. D-TTK001

7 displays high activities against HBV, remarkably reducing the levels of cccDNA in the HBV-

8 infected human liver-chimeric mice. Mechanically, D-TTK001 depresses cccDNA transcription

9 by regulating the epigenetic modification of cccDNA minichromosome and disturbing the

10 interaction of HBx with DDB1 in the cells. D-TTK001 decreases the levels of cccDNA by downregulating MSL2, leading to the increase of APOBEC3B in liver. When combined with entecavir or interferon- $\alpha$, D-TTK001 shows additive antiviral effects. Clinically, D-TTK001 is a strong candidate to clear cccDNA against HBV. 


\section{Introduction}

Hepatitis B virus (HBV) is a prototypical hepadnavirus that specifically infects hepatocytes ${ }^{1,2}$. Persistent HBV infection stimulates the development of chronic hepatitis B (CHB), liver cirrhosis, and hepatocellular carcinoma (HCC), which is a leading cause of liver cancer worldwide ${ }^{2,3}$. However, the current therapy rarely leads to HBV cure, and lifelong therapy is often required, contributing to the poor uptake and ongoing morbidity.

HBV covalently closed circular DNA (cccDNA) is the genomic form of $\mathrm{HBV}$, playing crucial roles in the viral transcription and viral persistence. The level of HBV replication is determined by the number of cccDNA molecules and their transcriptional productivity ${ }^{4}$. HBV cccDNA transcription is regulated by epigenetic modifications, including DNA methylation, histone modification, nucleosome remodeling, and RNA-mediated targeting ${ }^{5-8}$, which are imposed by viral and cellular proteins as well as inflammatory cytokines ${ }^{9}$. HBV X protein $(\mathrm{HBx})$ as a multifunctional HBV protein is crucial for HBV replication, pathogenesis, and hepatocyte carcinogenesis ${ }^{10}$. HBx interacts with cccDNA and activates transcription ${ }^{11}$. Multiple evidence from our team and others demonstrate that HBx is a key antiviral target ${ }^{2,12-14}$. Considering that the potential clinical importance of chronic HBV infection and liver diseases, and the central role of HBx in HBV replication, it is urgent to develop novel anti-HBV drugs targeting HBx protein to cure HBV-infected diseases ${ }^{10}$.

Currently, the recommended therapeutic reagents for chronic HBV infection include nucleotide analogs (NAs) and interferon- $\alpha$ (IFN- $\alpha)$ /pegylated IFN- $\alpha$. NAs inhibit the replication late in the viral life cycle with limited or no effect on viral protein production or on the persistence of cccDNA resulting in high rates of relapse once NAs are discontinued ${ }^{15,16}$. Research shows that IFN- $\alpha$ induces the decay of established HBV cccDNA, but it is limited by its adverse effects and 
1 low response rate around $20-40 \%$ of the whole IFN- $\alpha$ therapy ${ }^{17}$. Because the current anti-HBV

2 therapy is unsatisfactory, the new antiviral strategies and drugs are urgently needed.

3 Proteins carry out the majority of the biological processes, and it is generally accepted that protein-protein interactions (PPIs) are responsible for the cellular physiological and pathological

5 processes ${ }^{18-20}$. Consequently, some existing polypeptide drugs are developed according to the

6 therapeutic strategy of PPI inhibition ${ }^{21-23}$. PPIs are critical for understanding virus-host

7 interactions, and the biological functions of HBx are dependent on the pleiotropic PPIs ${ }^{10}$.

8 However, the anti-HBV drugs have not been reported according to the therapeutic strategy of PPI inhibition.

In this study, we engineered a novel polypeptide targeting $\mathrm{HBx}$ and evaluated its preclinical anti-HBV efficacy in vitro and in vivo. Surprisingly, our data demonstrated that the engineered Dtype polypeptide derived from hepatitis B X-interacting protein (HBXIP) sequence remarkably reduced the levels of cccDNA in primary human hepatocytes (PHHs) and $\mathrm{HBV}$-infected human liver-chimeric mice. Our finding provides a new strategy for controlling cccDNA against HBV.

\section{Results}

\section{A novel engineered D-type polypeptide}

According to the drug deployment strategy through PPIs, we tried to identify the polypeptides targeting HBx, leading to alter its biologic properties, from the candidate proteins binding to HBx. Interestingly, HBXIP, which negatively regulated HBx activity and controlled the replication life cycle of $\mathrm{HBV}^{24}$, stood out from the candidates. Moreover, we designed and screened several fragments from HBXIP, and finally, a fragment containing 12 amino acids (aa) termed TTK001 (25-36 aa in HBXIP) was selected (Fig.1a). We changed all L-type amino acids of TTK001 (or 
1 TK) into D-type amino acids, termed D-TTK001 (or D-TK). Then, we viewed the interaction

2 between TTK001/D-TTK001 and HBx using an in silico model, which was performed by using BIOVIA Discovery Studio 2016 (DS2016). Both TTK001 and D-TTK001 were compatible with the orthostatic amino acid binding pocket of $\mathrm{HBx}$, and the mutants of both significantly changed the interaction of polypeptide with HBx (Fig.S1a,b). Furthermore, surface plasmon resonance (SPR) showed that the dissociation constant (KD) value of TTK001/D-TTK001 was $15.06 \mathrm{nM}$ and $14.09 \mathrm{nM}$ (Fig. 1b, c). GST pull-down and co-immunoprecipitation (Co-IP) assays verified that HBx was able to interact with TTK001 (Fig.1d, e). As expected, D-TTK001 could block the interaction of endogenous or exogenous HBx with HBXIP (Fig.1f, g, Fig.S1c-e). To increase the

\section{half-life of the polypeptide, we selected D-type TTK001 (D-TTK001) for subsequent}

development. We further evaluated the ability of D-TTK001 to enter the host cells. Surprisingly, we observed the red fluorescence during the time point of $5 \mathrm{~min}$ to $90 \mathrm{~min}$ after incubated with red luciferin cy3-labeled D-TTK001 $(100 \mu \mathrm{M})$ in HepG2.2.15 and HepAD38 (Tet off) cells by immunofluorescence assays (Fig.1h, i), suggesting that D-TTK001 is able to enter the cells with high membrane permeability. Taken together, we conclude that D-TTK001 is a new D-type polypeptide derived from the HBXIP sequence with a high binding affinity to HBx.

To evaluate the stability of D-TTK001 in animals, the preclinical metabolism and pharmacokinetic studies of D-TTK001 were conducted (Fig.S1f). Our data showed that DTTK001 had a half-life of approximately $0.33-0.67 \mathrm{~h}$ in rats and $0.840-1.61 \mathrm{~h}$ in the monkeys (Fig. S1g-j). After subcutaneous injection of D-TTK001, the main parameters of the D-TTK001 plasma exposure, Cmax and AUC, increased proportionally with the increasing dose, and D-TTK001 had no obvious accumulation trend (Table S1-S4).

\section{Efficacy of D-TTK001 against HBV in vitro}


We evaluated the anti-HBV efficacy of D-TTK001 in vitro. The cell lines used for studying HBV included HepAD38 cell line which replicated HBV under the regulation of tetracycline (Tet) that supporting steps in replication, dHepaRG and HepG2-NTCP cell lines that supporting HBV infection, and primary human hepatocytes (PHHs) that supporting complete HBV life cycle ${ }^{25}$.

Firstly, in HepAD38 (Tet off) cell lines, we confirmed the anti-HBV efficacy of D-TTK001 with high concentration $(100 \mu \mathrm{M})$. Compared with the control group, D-TTK001 reduced the levels of HBV DNA, HBsAg, HBeAg, and HBcAg, and MTS assays showed that D-TTK001 had no chemical toxicity in this concentration (Fig.S2a). Then, we determined the appropriate drug action concentration used for further research. The results showed that D-TTK001 had anti-HBV efficacy in a dose-dependent manner, and D-TTK001 concentration had no cytotoxicity below $200 \mu \mathrm{M}$ (Fig.S2b). Then, we further evaluated the anti-HBV efficacy of D-TTK001 in different cells. DTTK001 decreased the levels of HBV, HBsAg, HBeAg, and HBcAg without affecting the viability of cells (Fig.2a-j). D-TTK001 displayed the antiviral effect, with around EC50 of 7.2113.8 $\mu \mathrm{M}$ in PHHs, HepG2-NTCP, HepAD38 (Tet off), and dHepaRG cell lines (Fig.2a, f, Fig.S2cf). ETV and IFN- $\alpha$ were selected as positive control drugs (Fig.2e, j). Hence, we conclude that DTTK001 is able to against HBV in vitro.

\section{Efficacy of D-TTK001 against HBV in vivo}

We next evaluated the anti-HBV efficacy of D-TTK001 in vivo. The HBV-infected human liverchimeric mouse (HBV-Huhep-URG mice) was used to evaluate the anti-HBV efficacy of DTTK001 (Fig.3a). The qPCR assays showed that the levels of HBV DNA were above $1.00 \times 10^{5}$ $\mathrm{IU} / \mathrm{mL}$ in the serum (Table S5), and IHC staining displayed that human albumin (hALB), HBsAg and $\mathrm{HBcAg}$ were positive in the liver tissue samples (Fig.S3a), suggesting that HBV-infected human liver-chimeric mouse model was successfully established. Statistical analysis showed no 
1 significant difference in body weight change among mice of different groups (Fig.S3b). Our data

2 showed that the levels of HBV DNA were decreased in serum from the D-TTK001 treated mice

3 one week later after the treatment, with a final decrease of $2.2(2.5 \mathrm{mg} / \mathrm{kg}$ group $), 2.5$ (5 mg/kg

4 group) and $2.8(10 \mathrm{mg} / \mathrm{kg}$ group) $\log$ value (HBV IU/mL) in four weeks (Fig.3b, c). The levels of

$\mathrm{HBeAg}$ and HBsAg were significantly reduced in the serum from experiment groups compared with control group (Fig.S3c, d). IHC staining revealed that the levels of HBsAg and HBcAg were markedly reduced in the liver tissues from the mice treated with D-TTK001 in comparison with control group (Fig.3d). RT-qPCR showed that the levels of HBV mRNA fragments, such as $\mathrm{HBx} /$ pgRNA, HBs mRNA, and HBc/HBe mRNA, were obviously decreased in the liver tissues treated by the D-TTK001, relative to 5\% Glu group (Fig.S3e-g). Moreover, we observed that the morphological character was improved in the liver tissues from the mice in the system (Fig.3d). Interestingly, the levels of alanine aminotransferase (ALT) and aspartate aminotransferase (AST) were significantly decreased in the serum from D-TTK001-treated mice (Fig.3e, f). ETV was used as a positive control in the system (Fig.3b-f, Fig.S3c-g). We also assessed the efficacy of DTTK001 against HBV using hydrodynamic transfection mouse model (Fig.S3h). The weight of the experiment mice was showed in Fig.S3i. As expected, the levels of HBV DNA on day 21 and Day 28 were significantly dropped compared with Day 0 in the serum from the mice treated with DTTK001 (Fig.S3j). Taken together, we conclude that D-TTK001 is able to against HBV in animal models.

We characterized the in vivo toxicity of D-TTK001 that may be useful for its further clinical trial. A straightforward approach to test the acute toxicity would be to challenge the animal with high doses of the drug. Therefore, we tested the acute toxicity in mice by challenging with DTTK001 via tail vein at $1000 \mathrm{mg} / \mathrm{kg}$ (Fig.S4a). The gross appearance, body weight, the hemogram 
1 index, and histopathology of major organs showed no toxic changes after the treatment with D-

TTK001 (Fig.S4b, c, Table S6), suggesting that D-TTK001 with $1000 \mathrm{mg} / \mathrm{kg}$ high doses displays no toxicity in mice. We also performed long-term toxicity experiment to test the in vivo toxicity of D-TTK001. The rats were given subcutaneous injection of D-TTK001 at $40 \mathrm{mg} / \mathrm{kg}$ once a day for 22 days (Fig.S4d). There was no significant influence of D-TTK001 on the gross appearance, body weight, and pathological observation (Fig.S4e, f). Although some hematology index and serum biochemical index were changed, the extent was moderate (Table S7-8). However, the blood electrolyte, organ weight and organ coefficients of the rats in different groups showed no obvious difference (Table S9-11). Thus, we conclude that D-TTK001 is safety in mice and rats.

\section{D-TTK001 hijacks HBV cccDNA in liver}

Given that HBV cccDNA was notoriously refractory to the NAs commonly used in clinical practice $^{26}$, we were interested in whether D-TTK001 was available to depress HBV cccDNA. Strikingly, qPCR showed that D-TTK001 remarkably decreased the levels of cccDNA in a dosedependent manner in PHHs, HepAD38, dHepaRG and HepG2-NTCP cell lines (Fig.4a, Fig.S5ad). Moreover, Southern blot analysis demonstrated that D-TTK001 dramatically reduced the levels of cccDNA in the system (Fig.4b, c), suggesting that D-TTK001 is able to reduce the cccDNA levels in hepatocytes. ETV and IFN- $\alpha$ were served as positive controls (Fig.4a, b, Fig.S5a-d). As expected, qPCR and Southern blot analysis displayed that D-TTK001 decreased the levels of cccDNA in a dose-dependent manner $(2.5,5$ and $10 \mathrm{mg} / \mathrm{kg})$ in the liver from HBV-infected human liver-chimeric mice (Fig.4d, e). HBV cccDNA samples of D-TTK001 $2.5 \mathrm{mg} / \mathrm{kg}$ group and control group were digested with EcoRI (Fig.4e, right lane). However, ETV failed to work in the system (Fig.4e), only reducing the levels of relaxed circular DNA (rcDNA) and double-stranded 
1 linear DNA (dsIDNA). Thus, we conclude that D-TTK001 efficiently controls the levels of HBV

cccDNA in vitro and in vivo.

\section{The mechanisms of D-TTK001 against HBV}

Next, we sought to explore the underlying mechanisms by which D-TTK001 controlled HBV cccDNA and inhibited HBV replication. To provide the evidence that D-TTK001 worked in the cells, we demonstrated the localization of D-TTK001 and HBx by immunofluorescence (IF) confocal microscopy. Interestingly, we observed that most of HBx (green) were limited in the cytoplasm of HepAD38 (Tet off) cells from the situation of diffuse distribution after D-TTK001 (red) treatment (Fig.5a). Moreover, Western blot analysis verified that the expression levels of HBx were decreased in a dose-dependent manner in the nucleus after D-TTK001 treatment (Fig.5b, c, Fig.S6a), suggesting that D-TTK001 blocks the nucleus entry of HBx.

Considering that nuclear HBx bound to the HBV minichromosome and modified the epigenetic regulation of $\operatorname{cccDNA}^{7}$, we further investigated the effect of D-TTK001 on the epigenetic modification of HBV cccDNA. Co-IP assay showed that D-TTK001 treatment attenuated the binding of HBx to p300 (Fig.S6b, S6c). ChIP assays revealed that D-TTK001 treatment significantly decreased the levels of AcH3, H3K4me3, EP300, and CBP, and promoted the deposition of H3K9me3, H3K27me3, HDAC1, SIRT1, and EZH2 on the cccDNA minichromosome (Fig.5d, e). Thereby, we summarize that D-TTK001 affects epigenetic modification of cccDNA minichromosome due to blocking the nuclear entry of HBx (Fig.S6d), leading to the repression of transcription of HBV DNA. Given that HBx was able to enhance the HBV transcription by hijacking DDB1-containing E3 ubiquitin ligase to target the Smc5/6 for proteasomal degradation ${ }^{27}$, we performed Co-IP assays to identify whether D-TTK001 disturbed the interaction of HBx with DDB1 in the cells. As expected, D-TTK001 prevented the binding of 
1 endogenous and exogenous HBx with DDB1 in HEK293T, HepG2, and HepG2-NTCP cell lines

2 (Fig.5f, g, Fig.S6e). Next, we tested whether D-TTK001 may prevent Smc5/6 degradation induced

by HBV. Consistently, D-TTK001 strongly increased the levels of Smc5/6 in HepAD38 (Tet off) and HepG2-NTCP cell lines (Fig.5h, Fig.S6f). Thus, we summarize that D-TTK001 blocks the interaction of HBx with DDB1, leading to the prevention of Smc5/6 degradation (Fig.S6g). It had been reported that the cytosine deaminization activity of APOBEC3A or APOBEC3B is essential for inducing cccDNA degradation ${ }^{17}$, and MSL2 mediated by HBx contributes to the degradation of APOBEC3B through ubiquitylation ${ }^{12}$. Accordingly, our data showed that DTTK001 down-regulated the levels of MSL2 and increased the levels of APOBEC3B in HepAD38 (Tet off) and HepG2-NTCP cell lines (Fig.5g, f).

Interestingly, we further observed that D-TTK001-mut failed to work in repressing HBV biomarkers, and the over-expression of HBx could remarkably neutralize the efficacy of DTTK001 in PHH, HepAD38 (Tet off) and HepG2-NTCP cell lines (Fig.5i, j, Fig.S6h), supporting that D-TTK001 works through targeting HBx. Thus, we conclude that the mechanisms of DTTK001 against HBV include: depressing cccDNA transcription by regulating the epigenetic modification of cccDNA minichromosome and disturbing the interaction of HBx with DDB1; decreasing the levels of cccDNA by down-regulating MSL2 which leads to the increase of APOBEC3B in liver.

\section{Combination of D-TTK001 with ETV or IFN-a}

Currently, the treatment guidelines recommend combination therapy for treating multidrugresistant $\mathrm{CHB}^{28}$. Accordingly, we were interested in whether D-TTK001 had synergistic antiHBV effects when combined with ETV or IFN- $\alpha$. Compared with the single-drug group, DTTK001 and ETV coadministration reduced the levels of HBV DNA, HBsAg, and HBeAg in 
1 HepAD38 cell line (Fig.6a-c, Fig.S7a-c). D-TTK001 and IFN- $\alpha$ coadministration displayed the

consistent effects (Fig.6E-G, Fig.S7D-F), suggesting that D-TTK001 has synergistic anti-HBV effects with ETV or IFN- $\alpha$. MTS assays showed that the combined treatment of D-TTK001 with ETV or IFN- $\alpha$ had no additional toxicity (Fig.6d, 6h). Collectively, we conclude that the combination of D-TTK001 with ETV or IFN- $\alpha$ displays synergistic anti-HBV effects in vitro.

\section{Discussion}

Chronic hepatitis B, caused by HBV infection, is a challenging prevalent infectious disease ${ }^{29}$. Importantly, HBV cccDNA is an obstacle in the treatment of chronic HBV infection ${ }^{4}$. However, the current therapy rarely leads to cccDNA elimination. Thus, a new generation of anti-HBV drugs that successfully block cccDNA is urgently needed. Here, we try to engineer a novel polypeptide targeting HBx to clear cccDNA.

$\mathrm{HBx}$, as a multifunctional exogenous virus protein, is an important therapeutic target for the interruption of chronic HBV replication ${ }^{10,30}$. However, the anti-HBV drugs targeting HBx protein have not been reported yet. The biological functions of HBx are mainly dependent on pleiotropic PPIs ${ }^{27,31-33}$. According to the drug deployment strategy through PPIs, we screened a series of interacting proteins, and finally identified a fragment from HBXIP sequence, termed TTK001. As expected, TTK001 could block the interaction of endogenous or exogenous HBx with HBXIP. We changed all L-type amino acids of TTK001 into D-type amino acids, termed D-TTK001. Interestingly, we demonstrated the phenotype of the interaction of $\mathrm{HBx}$ with the polypeptide in 3D structure using in silico model, but not the crystal model due to the crystal full structure of HBx was unavailable. Moreover, our data validated that D-TTK001 KD value was $14.09 \mathrm{nM}$. It suggested that D-TTK001 strongly binds to HBx protein. Because the polypeptide in clinic is 
1 limited by their susceptibility to enzymatic degradation, to improve the half-life of the TTK001,

we selected D-type TTK001 (D-TTK001) for subsequent development. Strikingly, the red fluorescence that labeled D-TTK001 was observed in the cells. It implies that D-TTK001 can work in the cells. The pharmacokinetic studies showed that D-TTK001 had a half-life of approximately $0.33-0.67 \mathrm{~h}$ in rats and $0.840-1.61 \mathrm{~h}$ in monkeys. It strongly supports that DTTK001 is available against HBV in humans.

Next, we evaluated the efficacy of D-TTK001 against HBV in vitro and in vivo. The human liver-chimeric mouse model was developed by partially repopulating the mouse liver with primary human hepatocytes, and HBV was able to infect and replicate ${ }^{34}$, it is an ideal model that offers a unique opportunity to evaluate the in vivo efficacy of antiviral compounds targeting different steps of the HBV life-cycle ${ }^{35,36}$, and especially it allows to test cccDNA in the liver ${ }^{37}$. As expected, our data demonstrated that D-TTK001 was able to significantly depress the viral biomarkers in the cell lines and animal models. Ideally, a cure for HBV infection needs to eliminate cccDNA, thereby preventing future reactivation. Accordingly, we focused on the investigation of cccDNA in this study. Notably, qPCR and Southern blot analysis revealed that D-TTK001 remarkably decreased the levels of cccDNA. In this study, ETV and IFN- $\alpha$ worked well as positive controls. However, ETV failed to control cccDNA. Our D-TTK001 is better than ETV in controlling cccDNA. Besides, we demonstrated that D-TTK001 was safe in mice and rats by using acute toxicity and long-term toxicity experiments. We concerned whether D-TTK001 generated the antibody in serum for long time treatment. However, the antibody against D-TTK001 could not be detected in monkeys with exposure of D-TTK001 (data not shown). It strongly suggests that D-TTK001 is available in clinic controls cccDNA against HBV. 
1 Mechanically, we investigated the details of D-TTK001 against HBV. We validated that D-

TTK001 worked through interacting with HBx in the cells. Interestingly, D-TTK001 inhibited the nuclear translocation of $\mathrm{HBx}$ in the cells. Nuclear $\mathrm{HBx}$ protein stimulates virus replication via histone modifications on cccDNA ${ }^{38}$. Interestingly, we found that D-TTK001 modulated the epigenetic regulation of cccDNA. Importantly, it has been reported that Smc5/6 binds to cccDNA minichromosome to block its transcription, and HBx binds to the DDB1 to target Smc5/6 complex for ubiquitin-mediated degradation ${ }^{27}$. As expected, our finding showed that D-TTK001 repressed the interaction of $\mathrm{HBx}$ with DDB1, increasing Smc5/6 protein levels. It had been reported that APOBEC3A and APOBEC3B are responsible for the deamination of HBV cccDNA ${ }^{17}$. Our previous study showed that MSL2 could mediate the ubiquitylation of APOBEC3B and HBx upregulated MSL2 to activate HBV cccDNA, forming a positive feedback loop of HBx/MSL2/ cccDNA/HBV ${ }^{12}$. Consistently, in this study we demonstrated that D-TTK001 reduced the levels of MSL2 and elevated APOBEC3B expression in the cells. However, it is elusive for the targets of D-TTK001 besides HBx in the cells.

Next, we moved to the combination of drugs. Numerous studies demonstrated superior results with combination therapy than monotherapy alone, and HBV cure needs a combination of new targets drugs and antiviral strategies ${ }^{39,40}$. In this study, our finding revealed that the combination of D-TTK001 with ETV or IFN- $\alpha$ increased the efficacy against HBV in vitro. It suggests that the combination of drugs with different targets works well and will be significant in clinic.

Taken together, we summarize a model that D-TTK001 controls cccDNA against HBV (Fig.S8). TTK001 is identified from the fragment of HBXIP sequence by PPI strategy. All of the amino acids of TTK001 are reversed into D-type amino acids, termed D-TTK001. Mechanically, 
1 D-TTK001 depresses cccDNA transcription through regulating the epigenetic modification of

cccDNA minichromosome and disturbing the interaction of HBx with DDB1; and decreases the levels of cccDNA by down-regulating MSL2 which leads to the increase of APOBEC3B in liver.

\section{Methods}

\section{Animals}

The HBV-infected human liver-chimeric mice (HBV-Huhep-URG mice) were generated by Beijing Vitalstar Biotechnology Co. Ltd.. (Beijing, China). Serum HBV load in the mice was determined by quantitative PCR (Da An Gene, Guangzhou, China) before sacrifice. The information about HBV-infected human liver-chimeric mice was shown in Table S5. Stock solutions of ETV (Sigma-Aldrich, USA) in PBS was further diluted in 5\% Glucose before intragastric administration (i.g.). D-TTK001 was generated by Shanghai AmbioPharm, Inc and was diluted with 5\% Glucose before subcutaneous (s.c.) injection. The mice were divided into 6 groups, including D-TTK001-10 mg/kg, D-TTK001-5 mg/kg, D-TTK001-2.5 mg/kg groups, ETV $(0.076 \mathrm{mg} / \mathrm{kg})$ positive control group, and vehicle ( $5 \%$ glucose injection) negative control group, 6 mice each group. The serum samples were collected from all groups of mice at the time point of pre-dose (Day 0), 1 week (Day 7), 2 weeks (Day 14), 3 weeks (Day 21), and 4 weeks (Day 28) after treatment. After daily administration for 28 days, mice were sacrificed and livers of mice were collected for quantitative polymerase chain reaction (qPCR) analysis, pathological observation, and immunostaining. The pathological observation was assessed by two independent pathologists with no prior knowledge of the sample characteristics, which was completed by Beijing Dian Diagnostics Laboratory Co., Ltd.. Discrepancies were resolved by consensus. All the analyses were performed blindly. 
previously described by using pAAV-HBV1.2 plasmid. The mice were divided into 3 groups, including D-TTK001-10 mg/kg group, ETV $(0.076 \mathrm{mg} / \mathrm{kg})$ positive control group and vehicle (5\% glucose injection) negative control group, 6 mice each group. The serum samples were collected from all groups of mice at the time point of pre-dose (Day 0), 1 week (Day 7), 2 weeks (Day 14), 3 weeks (Day 21), and 4 weeks (Day 28) after treatment. After daily administration for 28 days, mice were sacrificed.

Sprague-Dawley rats (3 months, weighting 200-250 g for female, 300-360 g for male) and cynomolgus monkeys (5 years old, weighting 2.6-3.8 kg) with half males and half females were used to test the pharmacokinetic study of D-TTK001 (as shown in Fig.S1F). Pharmacokinetic studies of D-TTK001 were completed by Tianjin Taincheng New Drug Evaluation Co. Ltd.. For single subcutaneous (SC) injection tests, rats and monkeys were separated into 3 groups $(1,2,4$ $\mathrm{mg} / \mathrm{kg}$ D-TTK001 for rats, and 0.5, 1, $2 \mathrm{mg} / \mathrm{kg}$ D-TTK001 for monkeys), 6 animals in each group, a single dose only. For multiple subcutaneous injection tests, rats and monkeys were exposed to continuous subcutaneous administration of D-TTK001 once daily for 7 days $(2 \mathrm{mg} / \mathrm{kg}$ for rats, and $1 \mathrm{mg} / \mathrm{kg}$ for monkeys), 6 animals in each group. After SC administration, $200 \mu \mathrm{L}$ of blood was collected at different specific time points $(0.0833,0.167,0.25,0.5,0.75,1.5,2,3,4,5$, and $6 \mathrm{~h}$ for rats, and $0,0.25,0.5,1,2,3,4,6,8,10,12$ and $24 \mathrm{~h}$ for monkeys) and frozen for pharmacokinetics studies. D-TTK001 concentration and pharmacokinetic parameters were then determined by liquid chromatography and mass spectroscopy (API5000, Applied Biosystems). Sprague-Dawley rats ( 2 months, weighting $190 \pm 5 \mathrm{~g}$ for female, $220 \pm 10 \mathrm{~g}$ for male) and Swiss albino mice (6 weeks of age, weighting $25 \pm 1 \mathrm{~g}$ for female, $29 \pm 1 \mathrm{~g}$ for male) with half males and half females were used for drug toxicity assays (as shown in Fig.S4A, S4D). The toxicity 
1 studies of D-TTK001 were completed by Tianjin Taincheng New Drug Evaluation Co. Ltd.. For

2 acute toxicity testing, the mice were given a single dose of $1000 \mathrm{mg} / \mathrm{kg}$ of D-TTK001. The mice

3 were observed once daily and weighed every 2 days for 14 days. The blood sample of $100 \mu \mathrm{L}$ was

4 collected at day 7 and day 14 for hemogram determined. Mice were euthanized at the endpoint,

5 and haematoxylin and eosin (H\&E) staining in different organs/tissues was performed. For long-

6 term toxicity experiment, rats were continuous subcutaneous administration of D-TTK001 once

7 daily for 7 days (40 mg/kg). Rats were observed once daily and weighed at day 1,4,13 and 21 . At

8 the endpoint of the experiment, the rats were euthanized. The blood samples were collected for

9 blood routine, coagulation function, biochemical and electrolyte test, and the organs were harvested for organ ratios and pathology determining.

The experiments were conducted following the Guide for the Care and Use of Laboratory Animals. The Institute Research Ethics Committee at Nankai University approved the study protocol.

\section{Cell lines}

HEK293T, HepG2, HepG2-NTCP, and HepG2.2.15 cells were cultured in DMEM medium (Invitrogen, Carlsbad, California, USA) supplemented with 10\% (vol/vol) fetal bovine serum (FBS), $2 \mathrm{mM}$ glutamine, $100 \mathrm{U} / \mathrm{mL}$ penicillin and $100 \mu \mathrm{g} / \mathrm{mL}$ streptomycin. dHepaRG cell lines were cultured in RPMI Medium 1640 (Invitrogen, Carlsbad, California, USA) supplemented with $10 \%$ (vol/vol) fetal bovine serum (FBS), penicillin $(100 \mathrm{U} / \mathrm{mL})$ and streptomycin $(100 \mathrm{mg} / \mathrm{mL})$.

The HepAD38 cell line regulates HBV replication through the presence or absence of tetracycline in the culture medium. HepAD38 cell was cultured in DMEM/F12 medium (Life Technologies, Carlsbad, CA) supplemented with 10\% (vol/vol) FBS, $100 \mathrm{U} / \mathrm{mL}$ penicillin, $100 \mu \mathrm{g} / \mathrm{mL}$ streptomycin, $100 \mu \mathrm{g} / \mathrm{mL}$ kanamycin, $400 \mu \mathrm{g} / \mathrm{mL}$ G418, and with $1 \mu \mathrm{g} / \mathrm{mL}$ tetracycline (for 
1 inhibition of HBV replication) or without any tetracycline (for induction of HBV replication). The

2 primary human hepatocytes $(\mathrm{PHH})$ of three donors were purchased from Shanghai RILD Inc.

3 (Shanghai, China). The cells were cultured similarly using the same plating and incubation medium as described above ${ }^{30}$. All the cell lines were cultured in $5 \% \mathrm{CO}_{2}$ at $37^{\circ} \mathrm{C}$.

HEK293T, HepG2, HepAD38, HepG2.2.15, HepG2-NTCP, and dHepaRG cells were transfected using VigoFect (Vigorous Biotechnology) or Lipofectamine 2000 (Invitrogen, USA) following the manufacturer's instructions. For the treatment of D-TTK001, ETV or IFN- $\alpha$ stock solution was diluted to the final concentrations in the DMEM medium. HepG2-NTCP, dHepaRG cells, and PHHs were cultured and infected with HBV as described ${ }^{41,42}$. The cells were washed with PBS three times and then cultured with D-TTK001, ETV or IFN- $\alpha$ for 7 days. The cytotoxicity was analyzed by CellTiter 96_AQueous One Solution Cell Proliferation Assay (G3580, Promega, USA) according to the manufacture's instruction.

\section{Viruses}

HBV particles were collected and purified from the supernatant of HepAD38 cells (Tet-off) as described ${ }^{30}$. Media were recovered every 3 days from HepAD38 cells at day's 7-15 postinduction of HBV by depletion of tetracycline. The media were cleared through a $0.45 \mu \mathrm{m}$ filter and precipitated with $10 \%$ PEG8000 and $2.3 \% \mathrm{NaCl}$. The precipitates were washed and resuspended with the medium at 200 -fold concentration. HBV DNA was quantified by qPCR.

Only HBV particles reaching a titer between $3 \times 10^{9}$ and $3 \times 10^{10} \mathrm{vp} / \mathrm{mL}$ were used. Immediately after collection, the virus stock was aliquoted and stored at $-80{ }^{\circ} \mathrm{C}$ until used for infection. HepG2NTCP, dHepaRG cells and PHH were infected with HBV particles at 500-1000 genome equivalents (GEq)/cell in the presence of $4 \%$ PEG8000 at $37^{\circ} \mathrm{C}$ for $16 \mathrm{~h}$ as previously described $^{43,44}$. 
1 RNA extraction, reverse-transcription polymerase chain reaction (RT-PCR), and

\section{quantitative real-time PCR (RT-qPCR)}

Total RNA was extracted from cells (or liver tissues from mice and patient tissues) using Trizol reagent (Invitrogen, Carlsbad, CA, USA) according to the manufacturer's instructions. First-strand cDNA was synthesized as reported before ${ }^{45}$. RT-qPCR was performed by a 7900 HT qRT-PCR system (Applied Biosystems, Life Technologies Darmstadt, Germany) according to the manufacturer's instructions using double-stranded DNA-specific SYBR Green Mix (TaKaRa, Ohtsu, Japan). Experiments were conducted in three independent assays. Relative transcriptional folds were calculated as $2^{-\Delta \Delta \mathrm{Ct}}$. Relative mRNA levels of all target genes were normalized to at least two house-keeping genes (HPRT; RHOT2; TBP; GAPDH) levels. All the primers used are listed in Table S12.

\section{HBV cccDNA extraction, qPCR and Southern blot analysis}

Before lysis, cell number was counted by using Cell Counting Chamber Set (Qiujing, Shanghai, China). The procedure of the isolation and quantification of HBV cccDNA from HepAD38, HepG2.2.15 cells or HBV infected PHH, dHepaRG, HepG2-NTCP cells and mice liver tissues was performed according to previous research ${ }^{46-48}$. qPCR experiments were performed in a qPCR system (Eppendorf, Germany) using a $20 \mu \mathrm{L}$ reaction volume containing $2 \mu$ digested HBV DNA. The primers used to amplify the cccDNA were listed in Supplementary KEY RESOURCES TABLES. For Southern blot analysis, the extracted HBV cccDNA sample was separated through $1.0 \%$ agarose gel, blotted onto a nylon membrane, and hybridized with DIG-labeled probes of linear HBx DNA fragments. When indicated, isolated DNA was digested with EcoRI that linearizes the HBV cccDNA.

\section{Surface plasmon resonance (SPR)}


1 SPR experiments were carried out to characterize the binding of HBx protein to two peptides (D-

TTK001 and TTK001) using a Biacore T200 (GE Healthcare), which was completed by Shanghai Ruizhi Chemistry Co., Ltd.. All SPR-based materials were purchased from GE Healthcare. DTTK001/TTK001 were diluted in HBS-EP and immobilized on CM5 sensor surface using amine coupling chemistry. Biotin-polypeptides were diluted in HBS-EP and immobilized on an SA chip. Interaction analyses were tested using HBS-EP as a running buffer. Increasing concentrations of His-HBx $(3.125,6.25,12.5,25,50,100 \mathrm{nM})$ were injected using the 'Kinetics/Affinity' program. A flow cell without immobilized peptide served as a non-specific binding control. Ka, Kd, and KD were determined using the 'Kinetics' model in the Biacore T200 evaluation software version 2.0.

\section{Western blot analysis}

Total protein lysates were extracted from hepatoma cells with RIPA buffer. Cytoplasmic and nuclear fractions were prepared from $5 \times 10^{8}$ hepatoma cells by using Minute Cytoplasmic $\&$ Nuclear Extraction Kits (SC-003, Invent Biotechnologies, Inc, Plymouth, MN, USA) according to the manufacturer's instructions. Protein concentrations were measured using the BCA Protein Quantification Kit (YEASEN, China), and 20-50 $\mu$ g protein extracts were subjected to SDSPAGE. Then proteins were transferred to a PVDF membrane, blocked with 5\% non-fat milk and incubated with first antibodies for $16 \mathrm{~h}$ at $4{ }^{\circ} \mathrm{C}$. After incubation with secondary antibody against mouse $(1: 10,000)$ or rabbit $(1: 10,000)$ for $1 \mathrm{~h}$ at $37^{\circ} \mathrm{C}$, the membrane was visualized by ECL Western Blotting Detection Kit (GE Healthcare, Waukesha, WI, USA). The primary antibodies used for Western blot analysis were listed in Table S13.

\section{Hepatitis B surface antigen (HBsAg) and Hepatitis B e antigen (HBeAg) quantification}

The levels of HBsAg in the supernatants of cultured cells was measured by diagnostic kit for hepatitis B virus surface antigen according to the manufacturer's instructions (Kehua Bio- 
1 engineering, Shanghai, China). The cut-off value (COV) for HBsAg analysis was indicated as:

$2 \mathrm{COV}=\mathrm{OD}$ (negative control, $\mathrm{NC}$ ) $/ 0.100 . \mathrm{HBeAg}$ in the supernatants of cultured cells was

3 measured by a diagnostic kit for Hepatitis B e antigen according to the manufacturer's instructions

4 (Kehua Bio-engineering, Shanghai, China). The cut-off value for HBeAg analysis was indicated

$5 \quad$ as: $\mathrm{COV}=\mathrm{OD}_{\mathrm{NC}} \times 2.1\left(0<\mathrm{OD}_{\mathrm{NC}} \leq 0.050, \mathrm{COV}=0.050 \times 2.1=0.105 ; 0.050<\mathrm{OD}_{\mathrm{NC}} \leq 0.100\right.$;

$6 \mathrm{OD}_{\mathrm{NC}}>0.100$, invalidation). The levels of HBsAg and HBeAg in the serum of HBV-Huhep-URG

$7 \quad$ mice were completed by Beijing Dian Diagnostics Laboratory Co., Ltd. using

8 electrochemiluminescence immunoassay (ECLIA) according to the manufacturer's instructions

9 (Roche, Mannheim, Germany).

\section{HBV DNA analysis}

HBV DNA was extracted in the supernatants of HepAD38 cells, HepG2.2.15 cells, and PHH, HepG2-NTCP and dHepaRG cells infected with different doses of HBV particles using the Blood \& Cell Culture DNA kit (QIAGEN, Germany) following the manufacturer's instructions. The qPCR was used to quantify HBV DNA copies according to a diagnostic kit for the quantification of HBV DNA (Da An Gene, Guangzhou, China) in a Bio-Rad sequence detection system.

\section{Immunofluorescence analysis}

Cells were grown on acid-treated glass coverslips in 24-well plates. Treated cells were fixed with ice-cold $4 \%$ paraformaldehyde for $10 \mathrm{~min}$, washed three times with phosphate-buffered saline (PBS), and permeabilized with $0.1 \%$ Triton X-100 in PBS for 30 min. After washing three times with PBS, samples were blocked with 5\% BSA for $2 \mathrm{~h}$. Cells were incubated with primary antibodies overnight at $4{ }^{\circ} \mathrm{C}$. After being washed, the cells were incubated with fluorophoreconjugated secondary antibody (DAKO, Denmark) and DAPI. After washing with PBS, slides 
1 were mounted with glycerol and observed under an upright fluorescence microscope (Zeiss Axio Imager Z1).

\section{GST-Pull-down}

The complementary DNA fragments encoding the TTK001 polypeptide and HBx were cloned into pGEX-6p-1 and PET-28a vector, respectively. The products were transformed into Escherichia coli BL21 competent cells to produce a GST-tagged TTK001 and His-tagged HBx fusion protein. The GST-tagged TTK001 was purified using Glutathione Sepharose 4B beads (GE Healthcare) according to the manufacturer's instructions. His-tagged HBx was purified according to previously described ${ }^{49}$. GST-tagged TTK001 and His-tagged HBx were added to the resin and incubated overnight at $4{ }^{\circ} \mathrm{C}$. The resin was then washed five times with a wash solution, and the proteins were eluted with glutathione elution buffer. The eluted proteins were detected by Western blotting.

\section{Co-immunoprecipitation (Co-IP)}

The whole cellular extracts were prepared using IP lysis buffer (Beyotime) supplemented with a complete protease inhibitor cocktail according to the manufacturer's instructions. Cell lysates were then incubated with the IP antibody overnight at $4{ }^{\circ} \mathrm{C}$ on a rotating wheel. Then the cell lysates were incubated with Protein A/G Magnetic beads (Millipore) for $4 \mathrm{~h}$ at $4{ }^{\circ} \mathrm{C}$ on a rotating wheel. The protein-protein interaction was analyzed by immunoblotting.

\section{Chromatin immunoprecipitation (ChIP)}

ChIP assays were performed in HepAD38, HepG2-NTCP cells (treated with tet on and tet off) according to the manufacturer's protocol (Epigentek Group Inc, Brooklyn, NY, USA) as previously reported ${ }^{50}$. Immunoprecipitated DNA was quantified by qPCR using cccDNA specific primers (Table S12). Samples were normalized to input DNA using the $\triangle \mathrm{Ct}$ method and 
1 calculated as percentage of the input. Results are expressed as the average of at least three

2 independent experiments. Error bars represent means \pm SD (n=3). Statistical differences were

3 analyzed by Student's $t$ test.

4 Hematoxylin-eosin (H\&E) staining and Immunohistochemistry (IHC)

5 For IHC, animals were sacrificed and liver tissue samples was collected. Samples were fixed in

$6 \quad 10 \%$ formalin for $24 \mathrm{~h}$ then embedded with paraffin, sectioned at $5 \mu \mathrm{m}$ onto slides. H\&E staining

7 was carried out using an H\&E staining kit (Beyotime, China) according to the manufacturer's

8 instruction. Immunohistochemical staining of samples was performed as previously reported ${ }^{51}$

9 and the according to primary antibody were used (Table S13). The samples were monitored

10 microscopically.

11 Quantification and statistical analysis

Each experiment was repeated at least three times. All analyses and graphs were generated with

GraphPad Prism 6. Statistical significance was assessed by comparing mean values ( \pm SD) using a

Student's $t$ test and was assumed for ${ }^{*} p<0.05 ;{ }^{* *} p<0.01 ; * * * p<0.001$.

\section{REFERENCES}

1 Benhenda, S., Cougot, D., Buendia, M. A. \& Neuveut, C. Hepatitis B virus X protein

2 Kremsdorf, D., Soussan, P., Paterlini-Brechot, P. \& Brechot, C. Hepatitis B virus-related hepatocellular carcinoma: paradigms for viral-related human carcinogenesis. Oncogene 25, 3823-3833, doi:10.1038/sj.onc.1209559 (2006).

3 Dienstag, J. L. Hepatitis B virus infection. $N$ Engl $J$ Med 359, 1486-1500, 
doi:10.1056/NEJMra0801644 (2008).

24 Testoni, B., Levrero, M. \& Zoulim, F. Challenges to a Cure for HBV Infection. Semin Liver Dis 37, 231-242, doi:10.1055/s-0037-1606212 (2017).

Mazor, T. et al. DNA Methylation and Somatic Mutations Converge on the Cell Cycle and Define Similar Evolutionary Histories in Brain Tumors. Cancer Cell 28, 307-317, doi:10.1016/j.ccell.2015.07.012 (2015).

Yang, G. et al. HAT1 signaling confers to assembly and epigenetic regulation of HBV cccDNA minichromosome. Theranostics 9, 7345-7358, doi:10.7150/thno.37173 (2019).

Belloni, L. et al. Nuclear HBx binds the HBV minichromosome and modifies the epigenetic doi:10.1073/pnas.0908365106 (2009).

Hensel, K. O., Rendon, J. C., Navas, M. C., Rots, M. G. \& Postberg, J. Virus-host interplay in hepatitis B virus infection and epigenetic treatment strategies. FEBS J 284, 3550-3572, doi:10.1111/febs.14094 (2017).

9 Pollicino, T. et al. Hepatitis B virus replication is regulated by the acetylation status of hepatitis B virus cccDNA-bound H3 and H4 histones. Gastroenterology 130, 823-837, doi:10.1053/j.gastro.2006.01.001 (2006).

Slagle, B.

B. L. \& Bouchard, M therapeutic implications. Curr Opin Virol 30, 32-38, doi:10.1016/j.coviro.2018.01.007 (2018).

Hensel, K. O., Cantner, F., Bangert, F., Wirth, S. \& Postberg, J. Episomal HBV persistence within transcribed host nuclear chromatin compartments involves HBx. Epigenetics Chromatin 11, 34, doi:10.1186/s13072-018-0204-2 (2018). 
112 Gao, Y. et al. Hepatitis B virus X protein-elevated MSL2 modulates hepatitis B virus covalently closed circular DNA by inducing degradation of APOBEC3B to enhance hepatocarcinogenesis. Hepatology 66, 1413-1429, doi:10.1002/hep.29316 (2017).

13 Zhang, S. et al. Anti-HBV drugs suppress the growth of HBV-related hepatoma cells via down-regulation of hepatitis $\mathrm{B}$ virus $\mathrm{X}$ protein. Cancer Lett 392, 94-104, doi:10.1016/j.canlet.2017.02.003 (2017).

Gut 61 Suppl 1, i6-17, doi:10.1136/gutjnl-2012-302056 (2012).

signal transducer and activator of transcription 3. $J$ Hepatol 53, 57-66, doi:10.1016/j.jhep.2009.12.043 (2010).

15 Dandri, M. \& Locarnini, S. New insight in the pathobiology of hepatitis B virus infection. Durantel, D. \& Zoulim, F. New antiviral targets for innovative treatment concepts for hepatitis $\mathrm{B}$ virus and hepatitis delta virus. $J$ Hepatol 64, S117-S131, doi:10.1016/j.jhep.2016.02.016(2016).

17 Lucifora, J. et al. Specific and nonhepatotoxic degradation of nuclear hepatitis B virus cccDNA. Science 343, 1221-1228, doi:10.1126/science.1243462 (2014).

18 Zeke, A., Misheva, M., Remenyi, A. \& Bogoyevitch, M. A. JNK Signaling: Regulation and Functions Based on Complex Protein-Protein Partnerships. Microbiol Mol Biol Rev 80, 793835, doi:10.1128/MMBR.00043-14 (2016).

19 Liu, Q. et al. A proximity-tagging system to identify membrane protein-protein interactions. Nat Methods 15, 715-722, doi:10.1038/s41592-018-0100-5 (2018).

Ma, W. \& Mayr, C. A Membraneless Organelle Associated with the Endoplasmic Reticulum Enables 3'UTR-Mediated Protein-Protein Interactions. Cell 175, 1492-1506 e1419, 
doi:10.1016/j.cell.2018.10.007 (2018).

21 Burdelya, L. G. et al. An agonist of toll-like receptor 5 has radioprotective activity in mouse and primate models. Science 320, 226-230, doi:10.1126/science.1154986 (2008).

22 Llinas-Brunet, M. et al. Peptide-based inhibitors of the hepatitis C virus serine protease. Bioorg Med Chem Lett 8, 1713-1718, doi:10.1016/s0960-894x(98)00299-6 (1998).

23 Andrei, S. A. et al. Stabilization of protein-protein interactions in drug discovery. Expert Opin Drug Discov 12, 925-940, doi:10.1080/17460441.2017.1346608 (2017).

24 Melegari, M., Scaglioni, P. P. \& Wands, J. R. Cloning and characterization of a novel hepatitis B virus $\mathrm{x}$ binding protein that inhibits viral replication. J Virol 72, 1737-1743 (1998).

25 Hu, J., Lin, Y. Y., Chen, P. J., Watashi, K. \& Wakita, T. Cell and Animal Models for Studying Hepatitis B Virus Infection and Drug Development. Gastroenterology 156, 338-354, doi:10.1053/j.gastro.2018.06.093 (2019).

26 Werle-Lapostolle, B. et al. Persistence of cccDNA during the natural history of chronic hepatitis B and decline during adefovir dipivoxil therapy. Gastroenterology 126, 1750-1758, doi:10.1053/j.gastro.2004.03.018 (2004).

27 Decorsiere, A. et al. Hepatitis B virus X protein identifies the Smc5/6 complex as a host restriction factor. Nature 531, 386-389, doi:10.1038/nature17170 (2016).

28 Terrault, N. A. et al. AASLD guidelines for treatment of chronic hepatitis B. Hepatology 63, 261-283, doi:10.1002/hep.28156 (2016).

29 Kim, G. A. et al. High risk of hepatocellular carcinoma and death in patients with immunetolerant-phase chronic hepatitis B. Gut 67, 945-952, doi:10.1136/gutjnl-2017-314904 (2018).

30 Lucifora, J. et al. Hepatitis B virus X protein is essential to initiate and maintain virus replication after infection. $J$ Hepatol 55, 996-1003, doi:10.1016/j.jhep.2011.02.015 (2011). 
131 Leupin, O., Bontron, S., Schaeffer, C. \& Strubin, M. Hepatitis B virus X protein stimulates viral genome replication via a DDB1-dependent pathway distinct from that leading to cell death. J Virol 79, 4238-4245, doi:10.1128/JVI.79.7.4238-4245.2005 (2005).

32 Geng, X. et al. Hepatitis B virus X protein targets Bcl-2 proteins to increase intracellular calcium, required for virus replication and cell death induction. Proc Natl Acad Sci U S A 109, 18471-18476, doi:10.1073/pnas.1204668109 (2012).

33 Hodgson, A. J., Hyser, J. M., Keasler, V. V., Cang, Y. \& Slagle, B. L. Hepatitis B virus regulatory $\mathrm{HBx}$ protein binding to $\mathrm{DDB} 1$ is required but is not sufficient for maximal HBV replication. Virology 426, 73-82, doi:10.1016/j.virol.2012.01.021 (2012).

34 Dandri, M. et al. Repopulation of mouse liver with human hepatocytes and in vivo infection with hepatitis B virus. Hepatology 33, 981-988, doi:10.1053/jhep.2001.23314 (2001).

35 Dandri, M. \& Lutgehetmann, M. Mouse models of hepatitis B and delta virus infection. $J$ Immunol Methods 410, 39-49, doi:10.1016/j.jim.2014.03.002 (2014).

36 Ishida, Y. et al. Acute hepatitis B virus infection in humanized chimeric mice has multiphasic viral kinetics. Hepatology 68, 473-484, doi:10.1002/hep.29891 (2018).

37 Feng, J. et al. LncRNA PCNAP1 modulates hepatitis B virus replication and enhances tumor growth of liver cancer. Theranostics 9, 5227-5245, doi:10.7150/thno.34273 (2019).

38 Bock, C. T. et al. Structural organization of the hepatitis B virus minichromosome. J Mol Biol 307, 183-196, doi:10.1006/jmbi.2000.4481 (2001).

39 Emery, J. S. \& Feld, J. J. Treatment of hepatitis B virus with combination therapy now and in the future. Best Pract Res Clin Gastroenterol 31, 347-355, doi:10.1016/j.bpg.2017.04.007 (2017).

40 Node, K. Benefits and risks of combination therapy in hypertension. Hypertens Res 32, 727- 
728, doi:10.1038/hr.2009.103 (2009).

41 Schulze-Bergkamen, H. et al. Primary human hepatocytes--a valuable tool for investigation of apoptosis and hepatitis B virus infection. J Hepatol 38, 736-744, doi:10.1016/s01688278(03)00120-x (2003).

42 Lee, S. M., Schelcher, C., Demmel, M., Hauner, M. \& Thasler, W. E. Isolation of human hepatocytes by a two-step collagenase perfusion procedure. $J$ Vis Exp, 50615, doi:10.3791/50615 (2013).

43 Ni, Y. \& Urban, S. Hepatitis B Virus Infection of HepaRG Cells, HepaRG-hNTCP Cells, and Primary Human Hepatocytes. Methods Mol Biol 1540, 15-25, doi:10.1007/978-1-49396700-1_2(2017).

44 Watashi, K. et al. Cyclosporin A and its analogs inhibit hepatitis B virus entry into cultured hepatocytes through targeting a membrane transporter, sodium taurocholate cotransporting polypeptide (NTCP). Hepatology 59, 1726-1737, doi:10.1002/hep.26982 (2014).

45 Feng, G. X. et al. Hepatitis B virus X protein promotes the development of liver fibrosis and hepatoma through downregulation of miR-30e targeting P4HA2 mRNA. Oncogene 36, 6895-6905, doi:10.1038/onc.2017.291 (2017).

46 Xia, Y. et al. Interferon-gamma and Tumor Necrosis Factor-alpha Produced by T Cells Reduce the HBV Persistence Form, cccDNA, Without Cytolysis. Gastroenterology 150, 194-205, doi:10.1053/j.gastro.2015.09.026 (2016).

47 Riviere, L. et al. HBx relieves chromatin-mediated transcriptional repression of hepatitis B viral cccDNA involving SETDB1 histone methyltransferase. J Hepatol 63, 1093-1102, doi:10.1016/j.jhep.2015.06.023 (2015).

48 Pollicino, T. et al. Hepatitis B virus maintains its pro-oncogenic properties in the case of 
occult HBV infection. Gastroenterology 126, 102-110, doi:10.1053/j.gastro.2003.10.048 (2004)

49 Jo, B. B., Jeong, M. S., Park, S. Y., Cheong, J. \& Jang, S. B. The binding of hepatitis B virus $\mathrm{X}$ protein to glioma-associated oncogene homologue 1 and its biological characterization in vitro. Appl Biochem Biotechnol 165, 109-122, doi:10.1007/s12010-011-9237-8 (2011).

50 Shen, W. et al. Epigenetic modification of the leptin promoter in diet-induced obese mice and the effects of N-3 polyunsaturated fatty acids. Sci Rep 4, 5282, doi:10.1038/srep05282 (2014)

51 Shackelford, D. B. et al. LKB1 inactivation dictates therapeutic response of non-small cell lung cancer to the metabolism drug phenformin. Cancer Cell 23, 143-158, doi:10.1016/j.ccr.2012.12.008 (2013).

\section{Acknowledgments}

We thank Tianjin Pharmaceutical Research Institute New Drug Evaluation Co. Ltd. for safety pharmacology and pharmacokinetic/toxicokinetic studies. This work was supported by National Science and Technology Major Project, China (No. 2014ZX10002002-001-005), Major New Drug Innovation \& Made, China (No. 2012ZX09103-301-042), National Natural Science Foundation of China (No. 81970519), Program for JLU Science and Technology Innovative Research Team (2017TD-08), the Fundamental Research Funds for the Central Universities. TianQing Liver Disease Research Fund Subject (No. TQGB20200118), National Science and Technology Major Project of China (No. 2018ZX10732101), Natural Science Foundation of Shandong, China (No. ZR2019MC004) and the High-end Talent Team Construction Foundation (No. 108-10000318). 


\section{Author contributions}

2 Conceptualization, X.D.Z., H.F.Y.; Methodology, S.Q.Z., L.N.Z., H.W.G., X.Z.Z., G.Y., Y.X.L.,

3 C.L.S., X.Z.G., X.M.W., M.Z., M.Y., and Z.C.M.; Investigation, H.F.Y., X.D.Z., S.Z., S.Q.Z., and

4 L.N.Z.; Validation, H.L.Y., Y.F.W., J.P.W., W.Z., Y.G., and Y.Y.; Writing-Review \& Editing,

5 H.F.Y. and X.D.Z.; Funding Acquisition, X.D.Z., J.Q.N.; Resources, X.D.Z., J.Q.N.; Supervision, $6 \quad$ X.D.Z..

7

8 Competing interests

$9 \quad$ Authors declare no competing interests. 


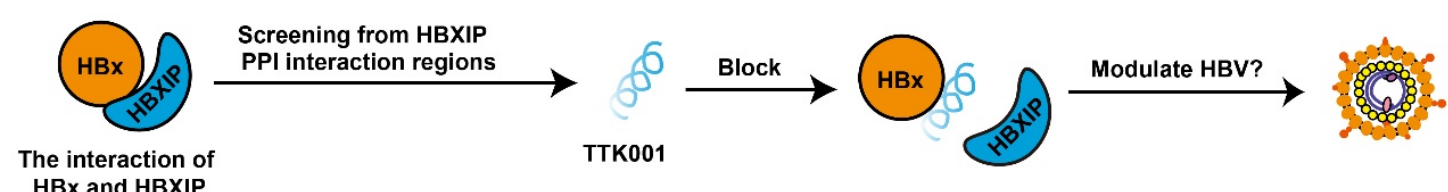

b

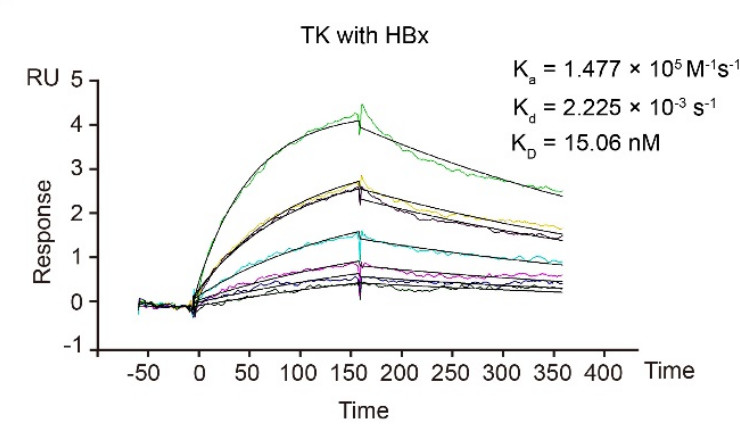

C

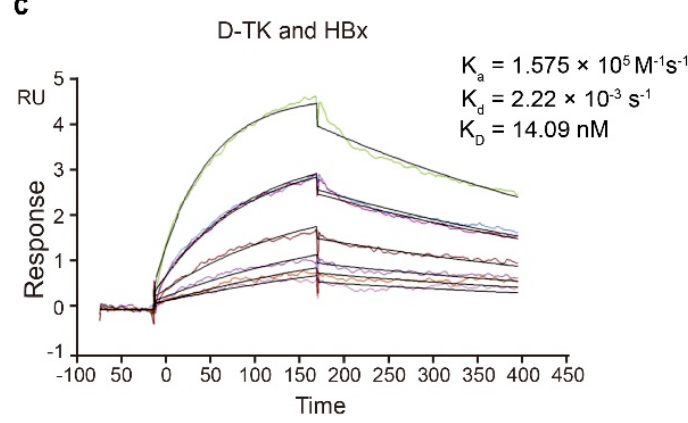

d

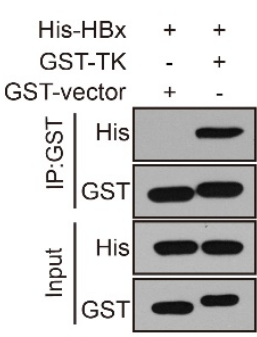

e

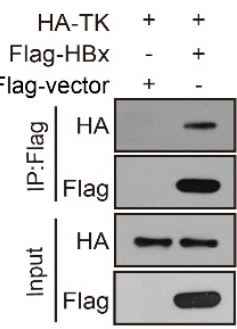

f HEK293T

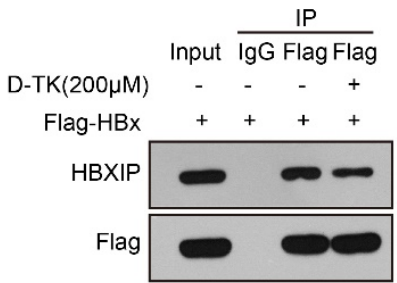

g HepG2-NTCP ( HBV de novo)

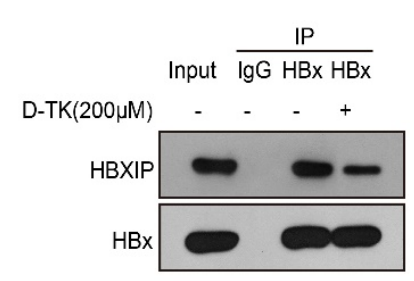

h
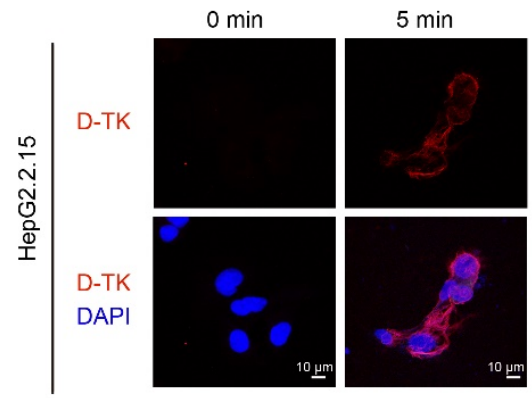

$15 \mathrm{~min}$
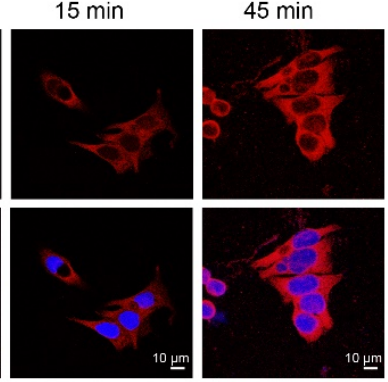

$90 \mathrm{~min}$

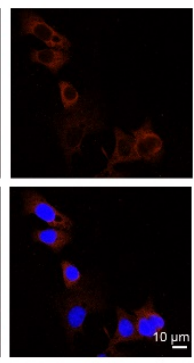

$180 \mathrm{~min}$

$240 \mathrm{~min}$
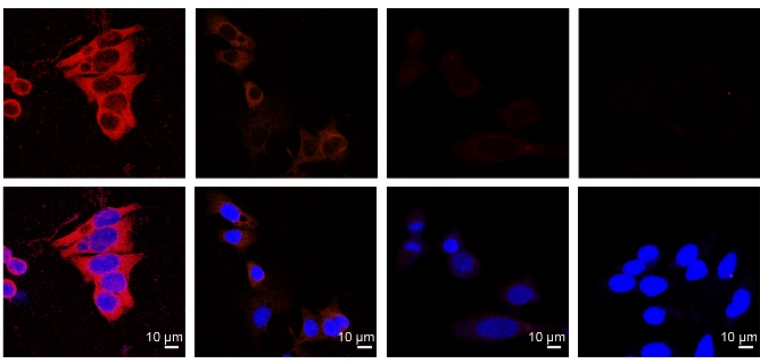

i

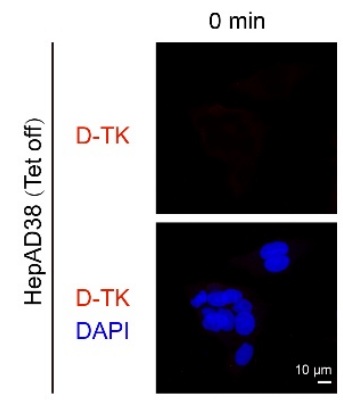

\begin{abstract}
$5 \mathrm{~min}$
\end{abstract}
15 min
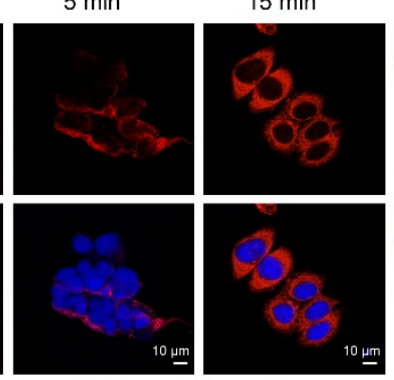

$90 \mathrm{~min}$

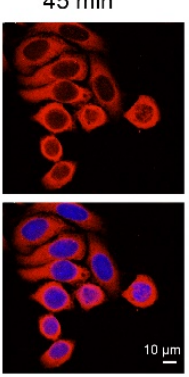

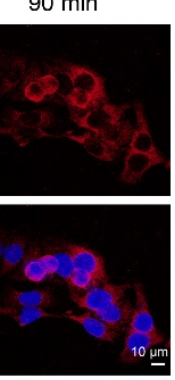

$180 \min$

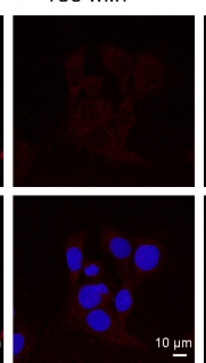

$240 \mathrm{~min}$

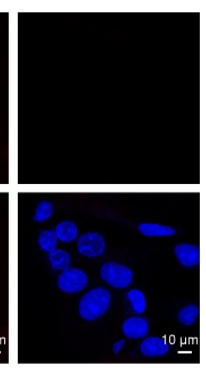
strategy against HBV for TTK001. b, Affinity analysis of HBx binding to TTK001 using SPR. c,

4 Affinity analysis of HBx binding to D-TTK001 using SPR. d, The interaction of HBx with D-

$5 \quad$ TTK001 was tested by GST-Pull-down assays. e, Co-IP assays to test the binding of HBx and D-

6 TTK001. HEK293T cells were transfected with plasmids Flag-HBx, and cells were incubated with 
1 HA-tagged TTK001 polypeptide. The interaction of HBx with TTK001 was examined by Co-IP

2 and immunoblotting. $\mathbf{f}$, The effect of D-TTK001 on the binding of HBXIP with exogenous HBx

3 was measured by Co-IP assays in HEK293T cells transfected with plasmids Flag-HBx and treated

4 with D-TTK001 $(200 \mu \mathrm{M})$ for 7 days. g, The effect of D-TTK001 on the binding of HBXIP with

5 endogenous HBx was measured by Co-IP assays in HBV de novo HepG2-NTCP cells treated with

6 D-TTK001 $(200 \mu \mathrm{M})$ for 7 days. h-i, Immunofluorescence analysis of D-TTK001 (red) in

7 HepG2.2.15 and HepAD38 (Tet off) cells. HepG2.2.15 (h) and HepAD38 (i) cells were treated

8 with red luciferin cy3-labeled D-TTK001 $(100 \mu \mathrm{M})$ and determined by immunofluorescence

9 assays at different time points. DAPI (blue) stained the nuclei. Scale bars, $10 \mu \mathrm{m}$. 
Yuan $\mathrm{HF}$, et al. Figure 2
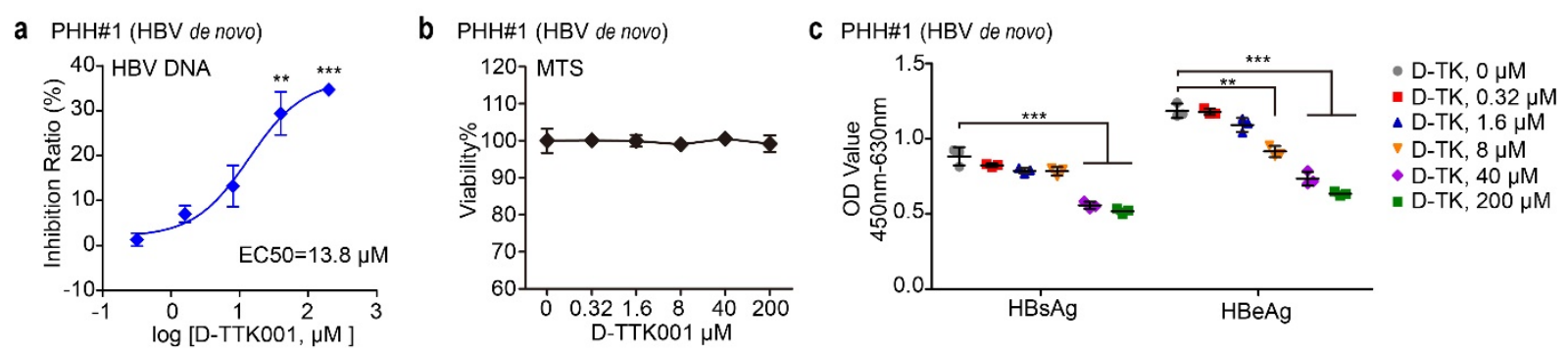

d PHH\#1 (HBV de novo)

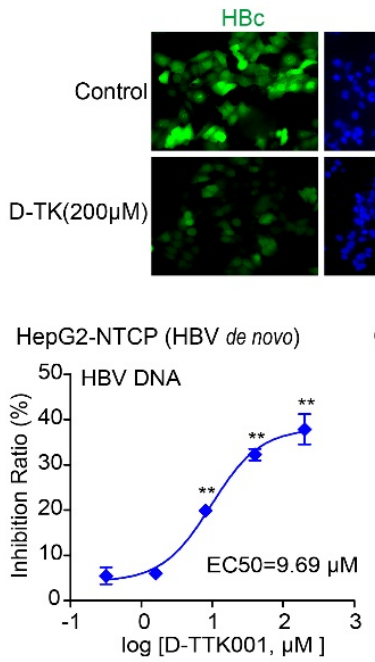

DAPI

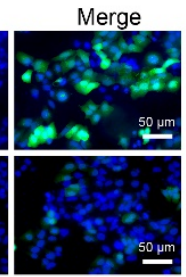

g HepG2-NTCP (HBV de novo)

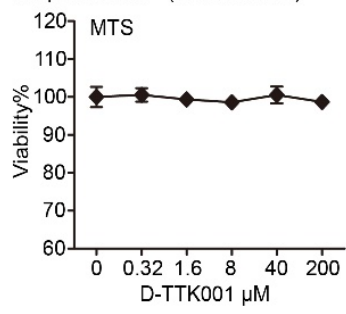

i HepG2-NTCP (HBV de novo)
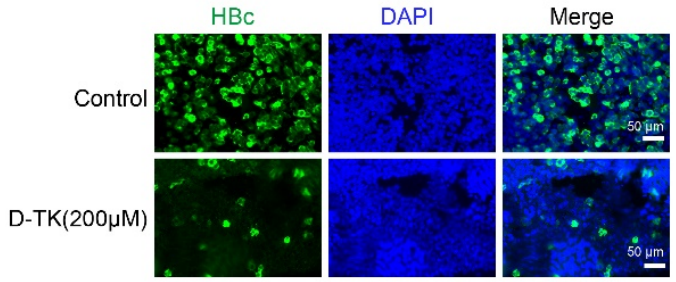

e $\mathrm{PHH \# 1}$ (HBV de novo)

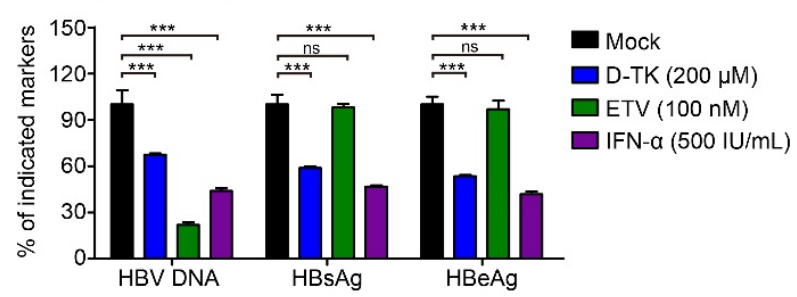

h HepG2-NTCP (HBV de novo)

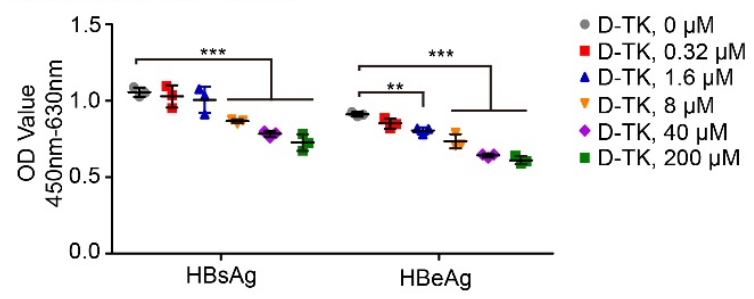

j HepG2-NTCP (HBV de novo)

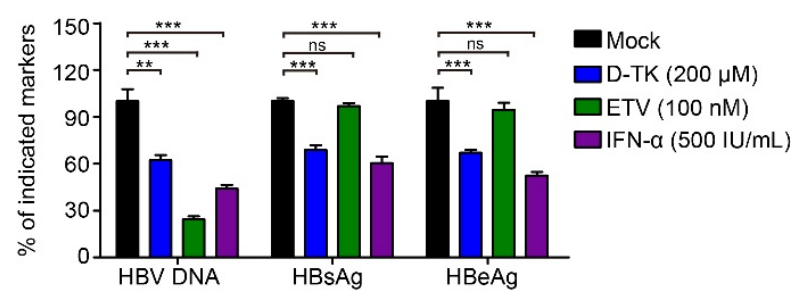

Fig. 2. Efficacy of D-TTK001 against HBV in vitro. a, The levels of HBV DNA were measured by qPCR in the supernatant of HBV de novo PHH cells. b, PHH cell viability was measured by MTS assay. c, The levels of HBsAg and HBeAg were examined by ELISA in the supernatant of HBV de novo PHH cells. d, The levels of $\mathrm{HBcAg}$ were determined by immunofluorescence staining in HBV de novo PHH cells. Scale bars, $50 \mu \mathrm{m}$. e, The levels of HBV DNA, HBsAg, and HBeAg were tested by qPCR and ELISA assays in the supernatant of HBV de novo PHH cells. f, The levels of HBV DNA were measured by qPCR in the supernatant of HBV de novo HepG2NTCP cells. g, HepG2-NTCP cell viability was evaluated by MTS assays. h, The levels of HBsAg and HBeAg were examined by ELISA in the supernatant of HBV de novo HepG2-NTCP cells. i, The level of HBcAg was measured by immunofluorescence staining in HBV de novo HepG2-

NTCP cells. Scale bars, $50 \mu \mathrm{m}$. j, The levels of HBV DNA, HBsAg, and HBeAg were determined 3 by qPCR and ELISA assays in the supernatant of HBV de novo HepG2-NTCP cells. Data are 
1 represented as means $\pm \mathrm{SD}(\mathrm{n}=3)$. ns, no significant; ${ }^{*} p<0.05 ;{ }^{* *} p<0.01 ;{ }^{* * *} p<0.001$ (Student's $t$ 2 test).

3 
a HBV-HuHep-URG mice model

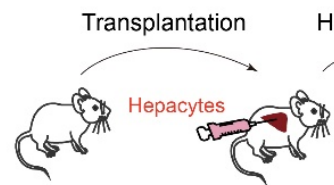

URG

Huhep-URG

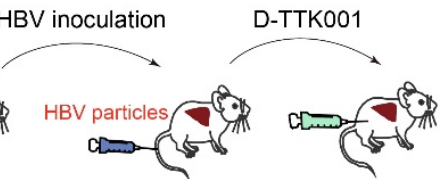

HBV-Huhep-URG b

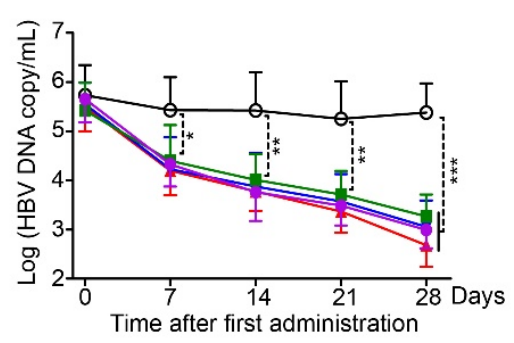

- $5 \%$ Glu

$\rightarrow-\mathrm{D}-\mathrm{TK}, 2.5 \mathrm{mg} / \mathrm{kg}$

$\rightarrow$ D-TK, $5 \mathrm{mg} / \mathrm{kg}$

$\rightarrow$ D-TK, $10 \mathrm{mg} / \mathrm{kg}$

- - ETV, $0.076 \mathrm{mg} / \mathrm{kg}$

c

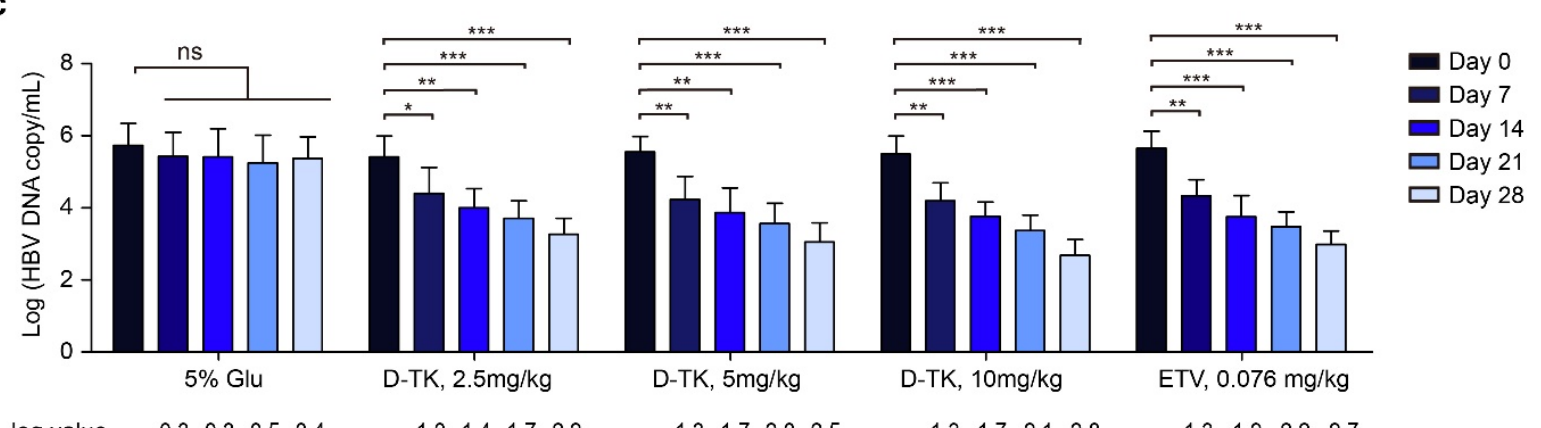

log value $\quad-0.3-0.3-0.5-0.4 \quad-1.0-1.4-1.7-2.2 \quad-1.3-1.7-2.0-2.5 \quad-1.3-1.7-2.1-2.8 \quad-1.3-1.9-2.2-2.7$

d

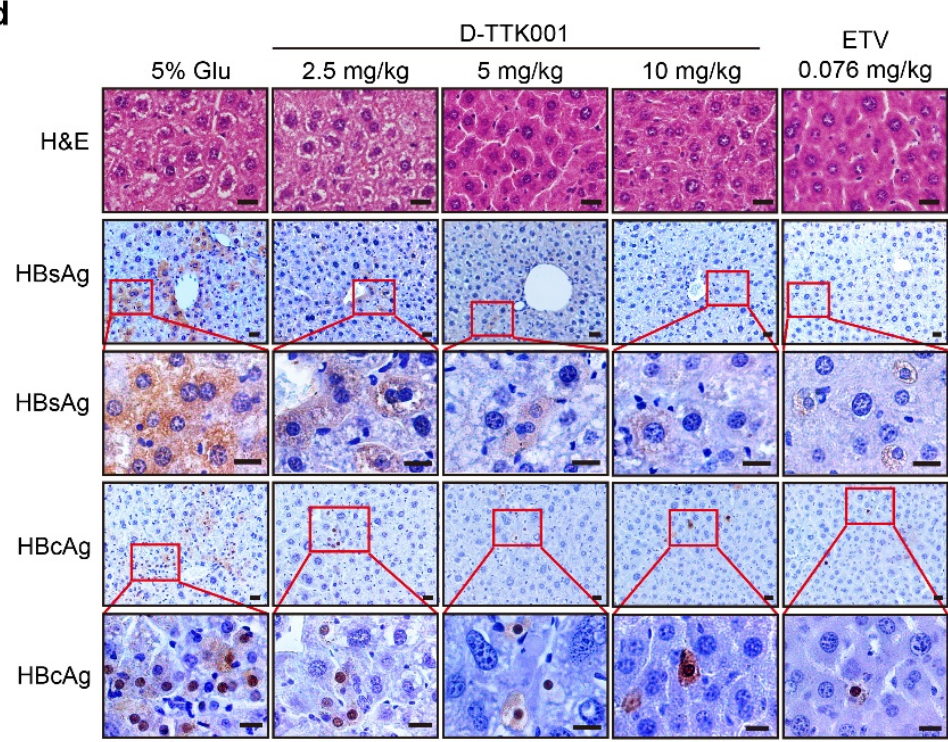

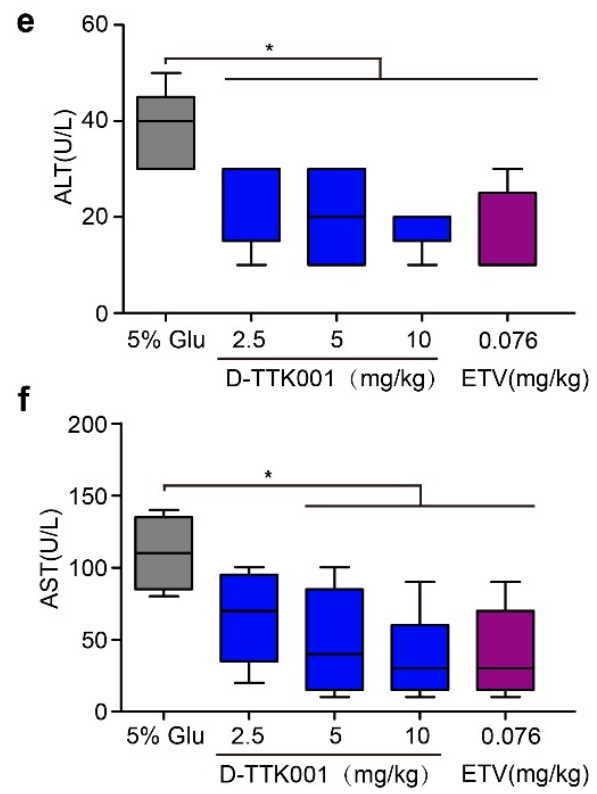

Fig. 3. Efficacy of D-TTK001 against $\mathrm{HBV}$ in $\mathrm{HBV}$-infected human liver-chimeric mice. a, A model of HBV-infected human liver-chimeric mice (HBV-Huhep-URG mice). b-c, The level of HBV DNA was tested by qPCR in the serum of human liver-chimeric mice. The HBV-HuhepURG mice were given dose-administration $(2.5,5,10 \mathrm{mg} / \mathrm{kg})$ once a day for 4 weeks. Serum samples were collected before exposure (Day 0) and 1, 2, 3, 4 weeks post-exposure (Day 7, Day 14, Day 21, Day 28), respectively. d, Pathological observation and immunohistochemistry staining for HBsAg and HBcAg were measured in the liver tissues from HBV-Huhep-URG mice with different treatments. Scale bars: $20 \mu \mathrm{m}$. e-f, The levels of ALT and AST were evaluated by ALT/AST detection kits in the serum of HBV-Huhep-URG mice. The HBV-Huhep-URG mice were given dose-administration once a day for 4 weeks. Serum samples were collected after 
1 exposure (Day 28). Data are represented as means $\pm \mathrm{SD}(\mathrm{n}=3) .{ }^{*} p<0.05 ; * * p<0.01 ; * * * p<0.001$ 2 (Student's $t$ test).

3 
a PHH\#1 (HBV de novo)

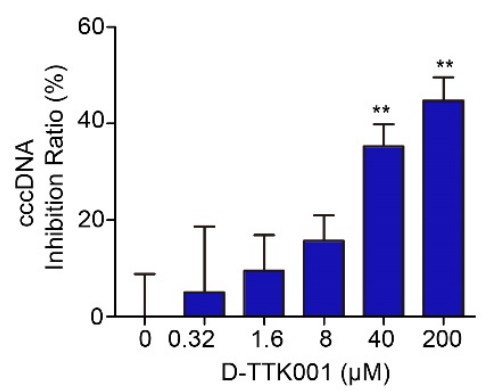

b

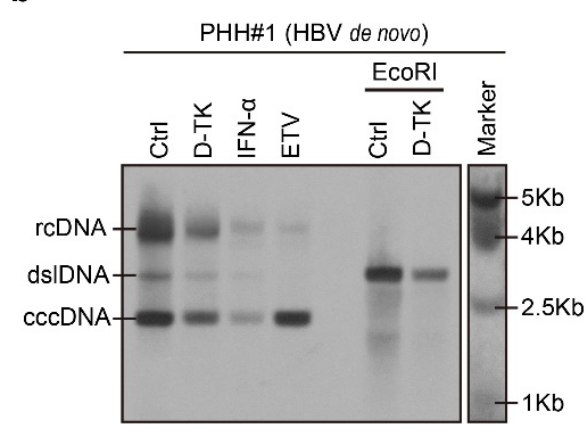

d

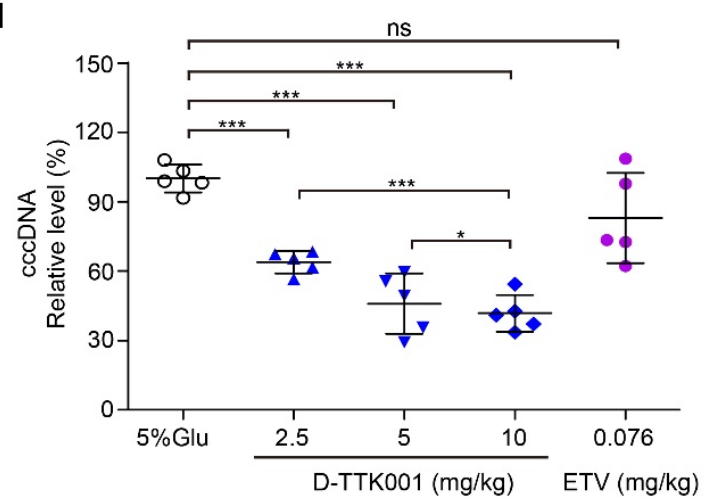

C
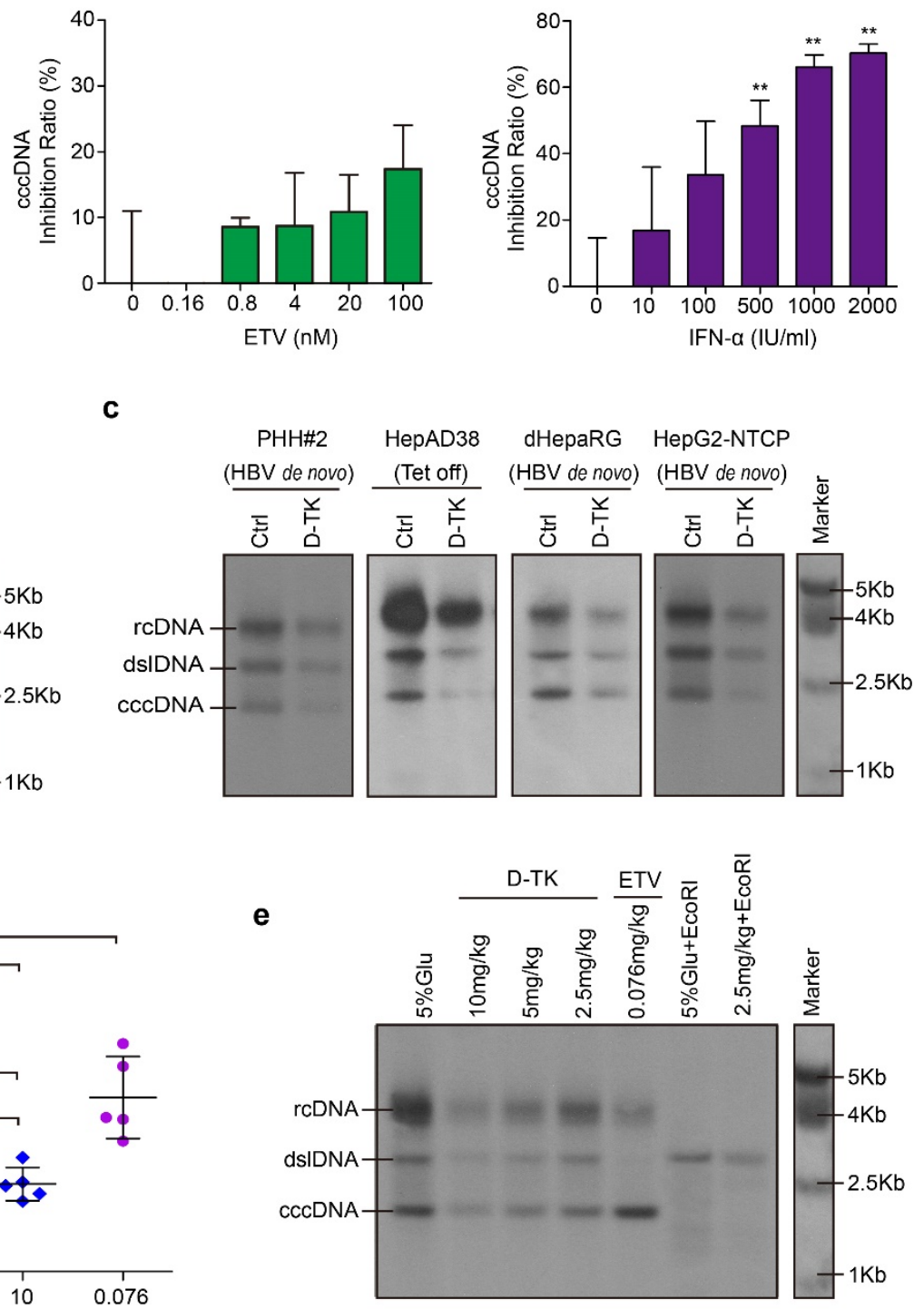

Fig. 4. D-TTK001 efficiently controls the levels of HBV cccDNA in vitro and in vivo. a, The cccDNA levels were measured by qPCR assays in the nucleus of HBV de novo PHH cells treated with D-TTK001, ETV or IFN- $\alpha$ for 7 days. b, The cccDNA levels were examined by Southern blot analysis in the nucleus of HBV de novo PHH cells treated with D-TTK001 (200 $\mu \mathrm{M})$, ETV (100 nM), and IFN- $\alpha(2000 \mathrm{IU} / \mathrm{mL})$ for 7 days. c, The cccDNA levels were measured by Southern blot analysis in the nucleus of cells of HepAD38 (Tet off), HBV de novo PHH, dHepaRG, and HepG2-NTCP treated with D-TTK001 $(200 \mu \mathrm{M})$ for 7 days. d, The cccDNA levels were determined by qPCR assays in the liver of HBV-Huhep-URG mice treated with D-TTK001 (10, 5, $2.5 \mathrm{mg} / \mathrm{kg})$ and ETV $(0.076 \mathrm{mg} / \mathrm{kg})$ for 28 days. e, The cccDNA levels were tested by Southern blot analysis in the liver of HBV-Huhep-URG mice. Data are represented as means $\pm \mathrm{SD}$. $*_{p}<0.05 ; * * p<0.01 ; * * * p<0.001$ (Student's $t$ test). 
a

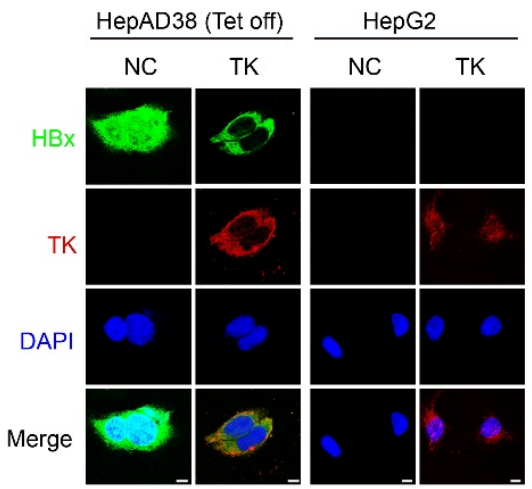

b HepAD38 (Tet off)

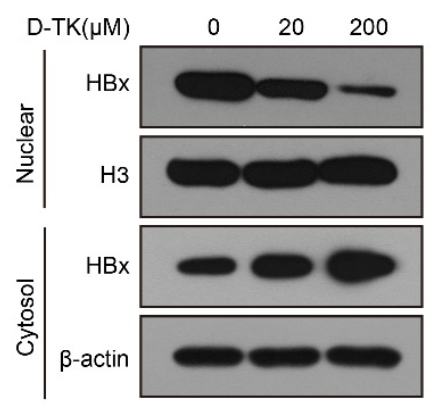

C $\mathrm{PHH}$ (HBV de novo)

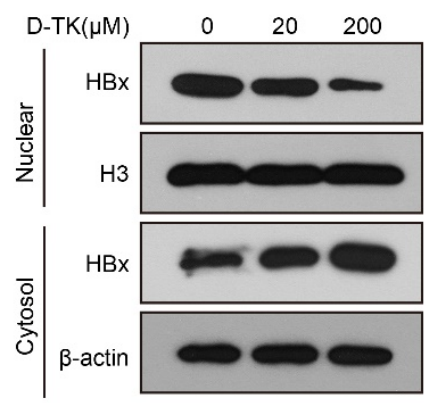

d HepAD38 (Tet off)

e HepG2-NTCP (HBV de novo)

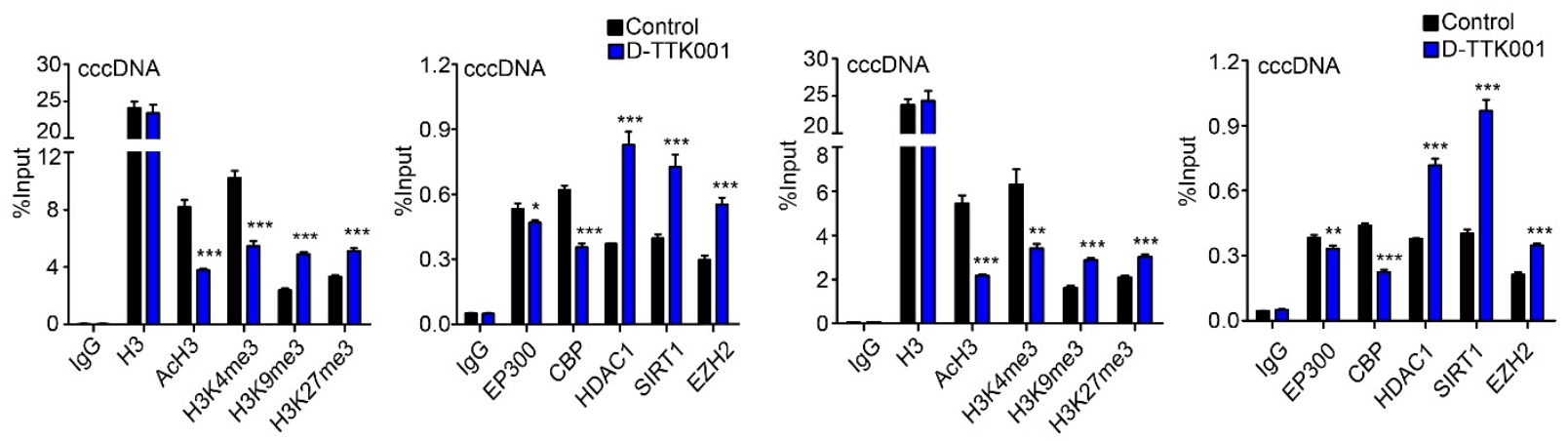

f HEK293T

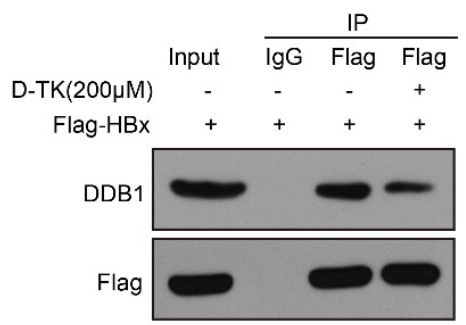

i $\mathrm{PHH \# 1}$ (HBV de novo)

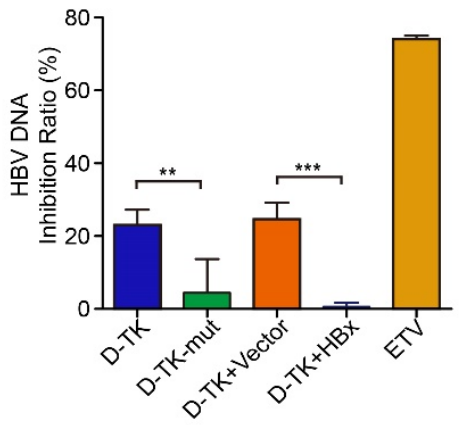

g HepG2-NTCP (HBV de novo)
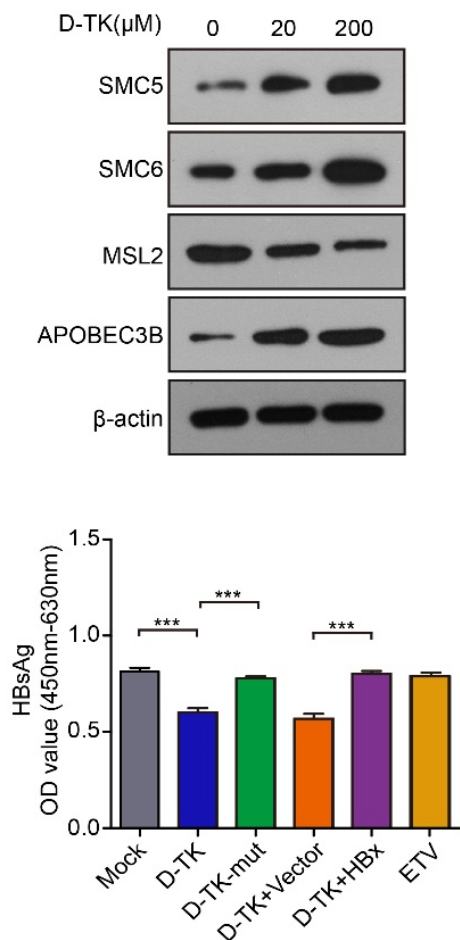

h HepAD38 (Tet off)
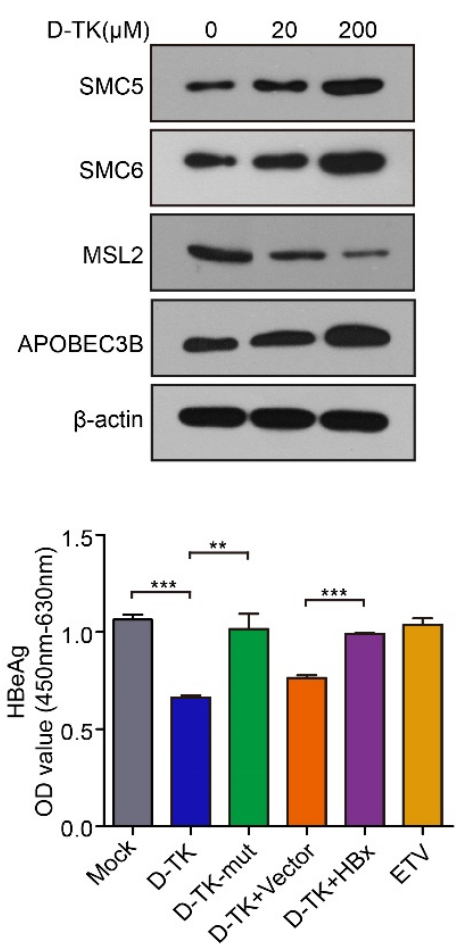

2 Fig. 5. The mechanisms of D-TTK001 against HBV. a, Immunofluorescence staining was used

3 to identify the location of D-TTK001 (red) and HBx (green) in HepAD38 (Tet off) and HepG2

4 cells treated with or without Red luciferin cy3-labeled D-TTK001 (100 $\mu \mathrm{M})$. DAPI (blue) stained 
1 the nuclei. Scale bars: $10 \mu \mathrm{m}$. b-c, The effect of D-TTK001 on the expression of HBx was tested

2 by Western blot analysis in HepAD38 (Tet off) and HBV de novo PHH cells treated with D-

3 TTK001 for 7 days. d-e, The assembly of histone H3, AcH3, H3K4me3, H3K9me3, H3K27me3,

4 EP300, CBP, HDAC1, SIRT1, and EZH2 onto cccDNA was determined by ChIP-qPCR in

5 HepaAD38 (Tet off) or HBV de novo HepG2-NTCP cells treated with D-TTK001 for 7 days,

6 respectively. $\mathbf{f}$, The interaction of DDB1 with exogenous HBx was examined by Co-IP assay in

7 HEK293T cells transfected with Flag-tagged HBx and treated with D-TTK001 for 7 days. g, The

8 effect of D-TTK001 on the expression of SMC5, SMC6, MSL2 and APOBEC3B was evaluated

9 by Western blot analysis in HBV de novo HepG2-NTCP cells treated with D-TTK001 for 7 days.

h, The effect of D-TTK001 on the expression of SMC5, SMC6, MSL2 and APOBEC3B was evaluated by Western blot analysis in HepAD38 cells treated with D-TTK001 for 7 days. i, The levels of HBV DNA, HBsAg, and HBeAg were measured by qPCR and ELISA assays in the supernatant of HBV de novo PHH cells treated with D-TTK001 (200 $\mu \mathrm{M})$, D-TTK001-mut (200 $\mu \mathrm{M})$, ETV (100 nM) for 7 days. The pcDNA3.1-HBx $(2 \mu \mathrm{g})$ and pcDNA3.1-Vector $(2 \mu \mathrm{g})$ were transfected at time points of day 0 , day 2 , and day 4 . Data are represented as means \pm SD $(n=3)$. 
a HepAD38 (Tet off)

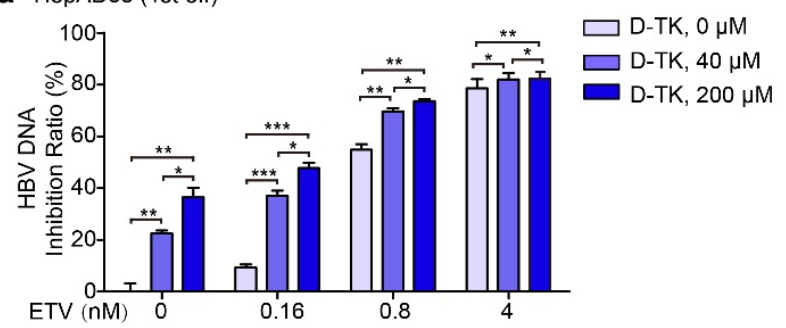

C HepAD38 (Tet off)

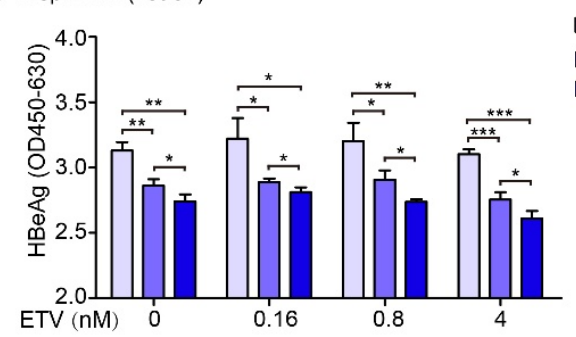

e HepAD38 (Tet off)

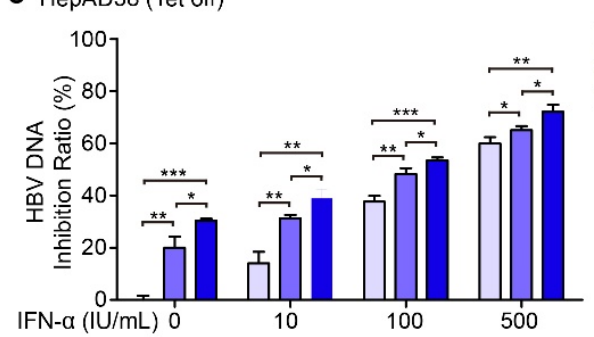

g HepAD38 (Tet off)
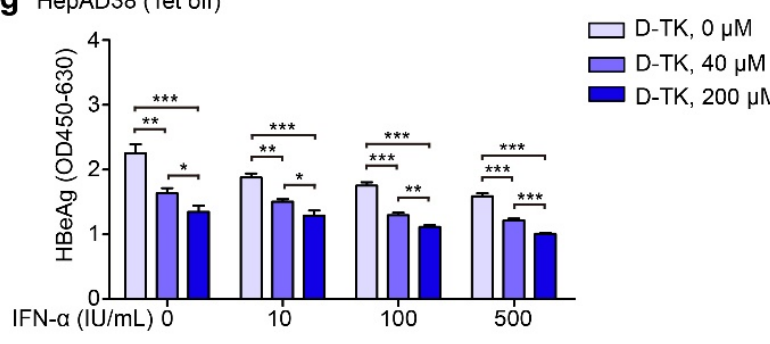
$\square$ D-TK, $40 \mu \mathrm{M}$ b HepAD38 (Tet off)

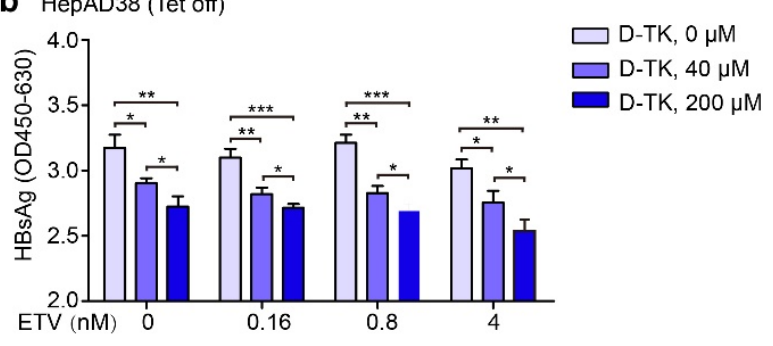

d HepAD38 (Tet off)

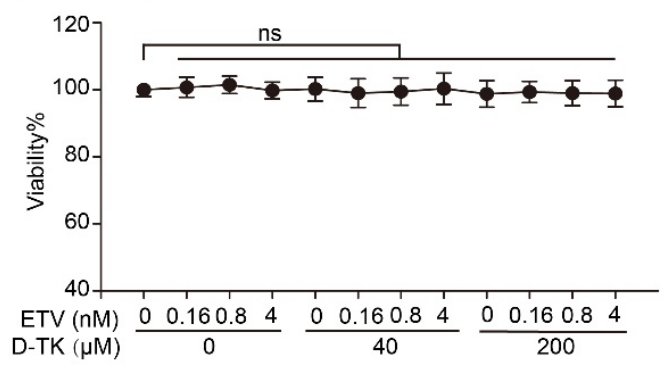

f HepAD38 (Tet off)

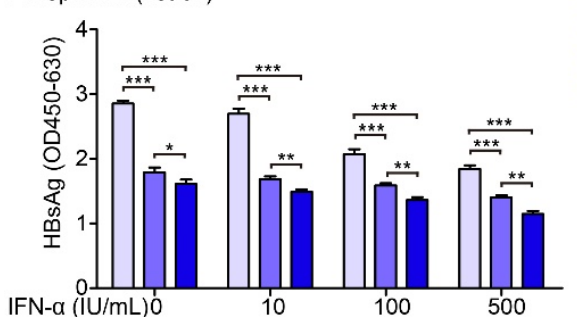

$\square \mathrm{D}-\mathrm{TK}, 0 \mu \mathrm{M}$ $\square$ D-TK, $40 \mu \mathrm{M}$ $\square$ D-TK, $200 \mu \mathrm{M}$

h HepAD38 (Tet off)

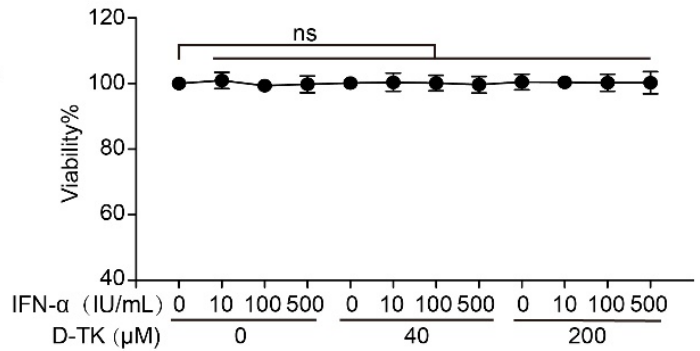
.

Fig. 6. Efficacy of the combination of D-TTK001 with ETV or IFN- $\alpha$ in vitro. a-c, The levels of HBV DNA, HBsAg, and HBeAg were measured by qPCR and ELISA assays in the supernatant of HepAD38 (Tet off) cells treated with both D-TTK001 and ETV for 7 days. d, HepAD38 cell viability was tested by MTS assays. e-g, The levels of HBV DNA, HBsAg, and HBeAg were evaluated by qPCR and ELISA assays in the supernatant of HepAD38 (Tet off) cells treated with both D-TTK001 and IFN- $\alpha$ for 7 days. (H) HepAD38 cell viability was tested by MTS assays. Data are represented as means $\pm \mathrm{SD}(\mathrm{n}=3) .{ }^{*} p<0.05 ; * * p<0.01 ; * * * p<0.001$ (Student's $t$ test). 
a

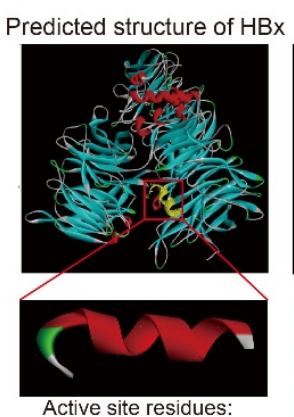

Active site residues: 88-ILPKVLHKRTLGLS-101 TK: L-GSAVMFSSKERG D-TK: D-GSAVMFSSKERG D-TK-mut: GSAGSPSSKERG
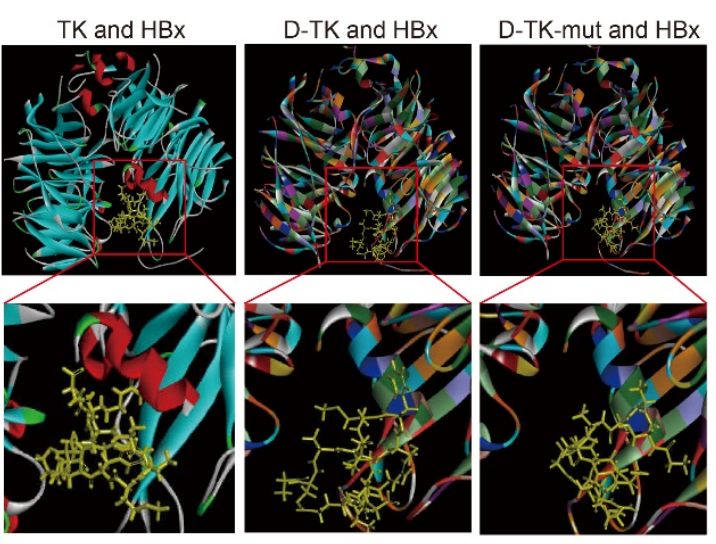

C HepG2:

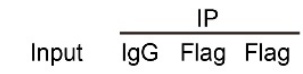

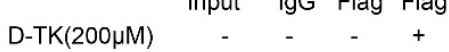

Flag-HBx

HBXIP

Flag

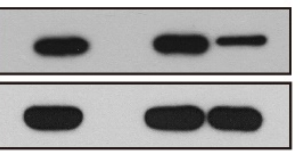

d dHepaRG (HBV de novo):
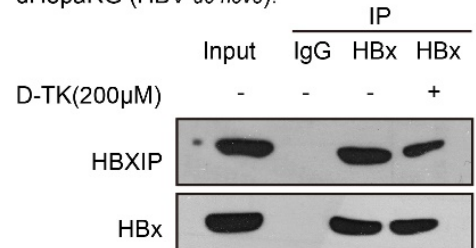

b

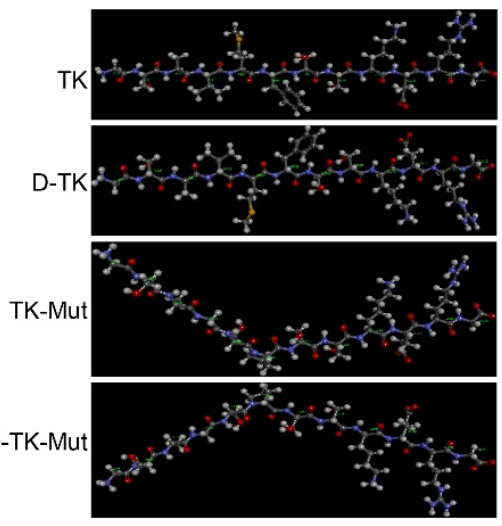

e HepAD38 (Tet off):

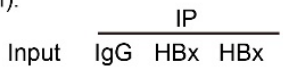

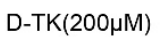

HBXIP

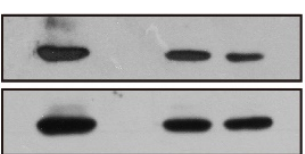

f Pharmacokinetic experiment

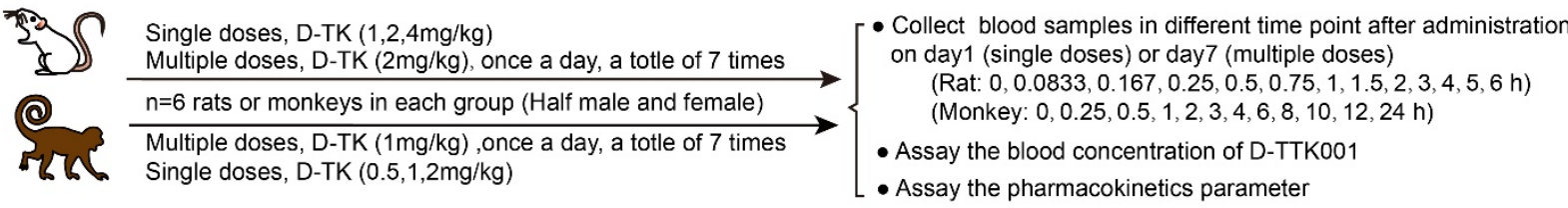

g

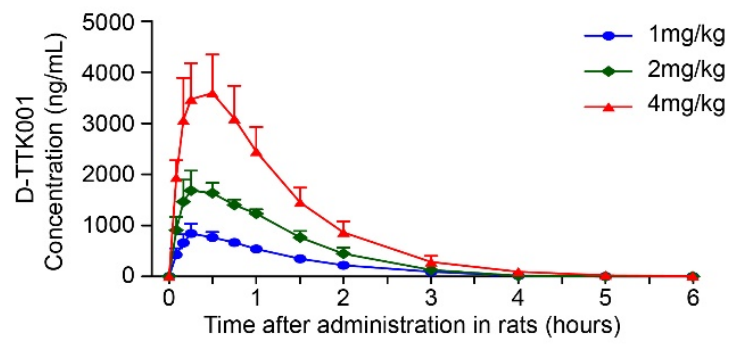

i

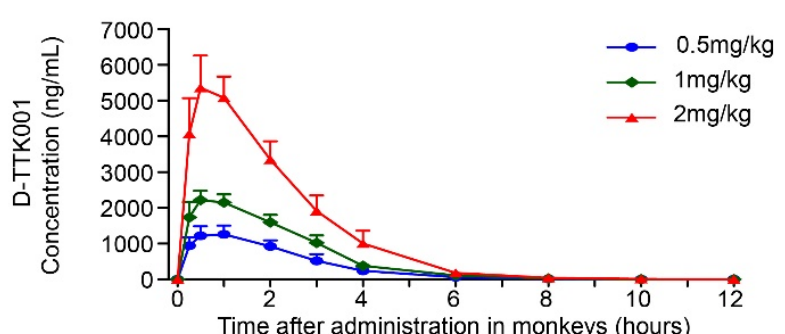

h

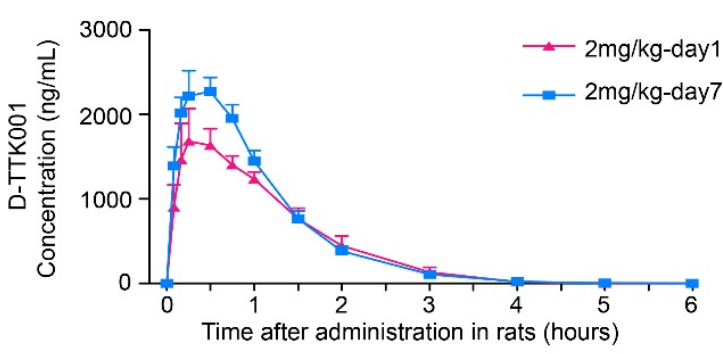

j

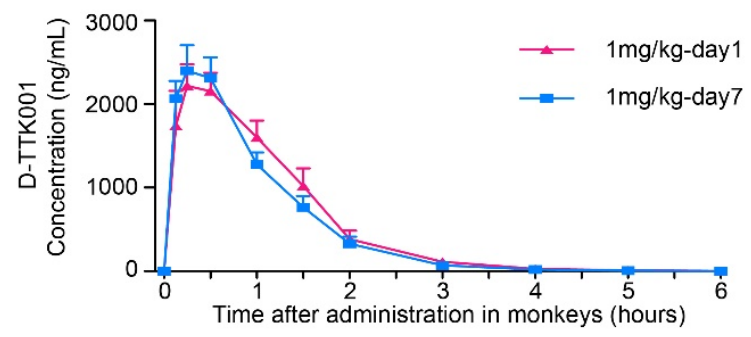

2 Fig. S1. A new D-type polypeptide derived from HBXIP sequence is engineered. a, A model

3 of the interaction of TTK001/D-TTK001 (TK/D-TK) with HBx using in silico model. b, The

4 structures of TTK001, D-TTK001, TTK001-mut and D-TTK001-mut were demonstrated by using

5 in silico model. c, The effect of D-TTK001 on the binding of HBXIP with exogenous HBx was

6 examined by Co-IP assays in HepG2 cells transfected with Flag-HBx and incubated with D-

7 TTK001. d-e, The effect of D-TTK001 on the binding of HBXIP with endogenous HBx was 
1 tested by Co-IP assays in HBV de novo HepG2-NTCP and HepAD38 (Tet off) cells treated with

2 D-TTK001 for 7 days. f, A model showed the protocol of the pharmacokinetic experiment. $\mathbf{g}-\mathbf{j}$,

3 Pharmacokinetics of indicated D-TTK001 doses in plasma after single or multiple subcutaneous

4 administration in rats and monkeys.

5

6 
Yuan HF, et al. Figure S2

a HepAD38 (Tet off)
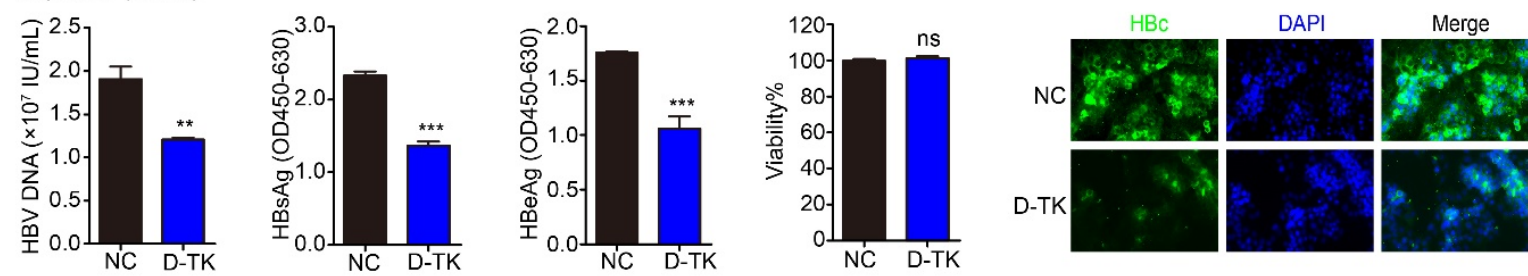

b HepAD38 (Tet off)
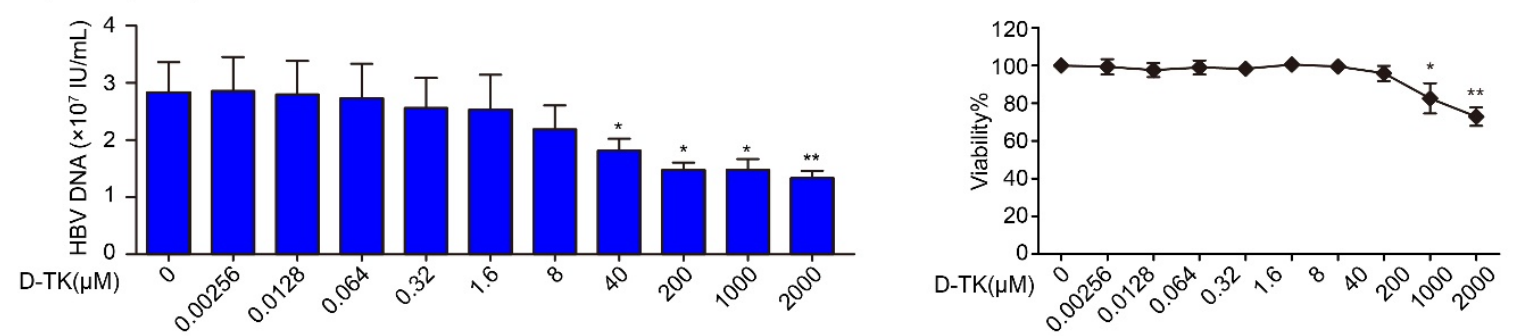

C HepAD38 (Tet off)
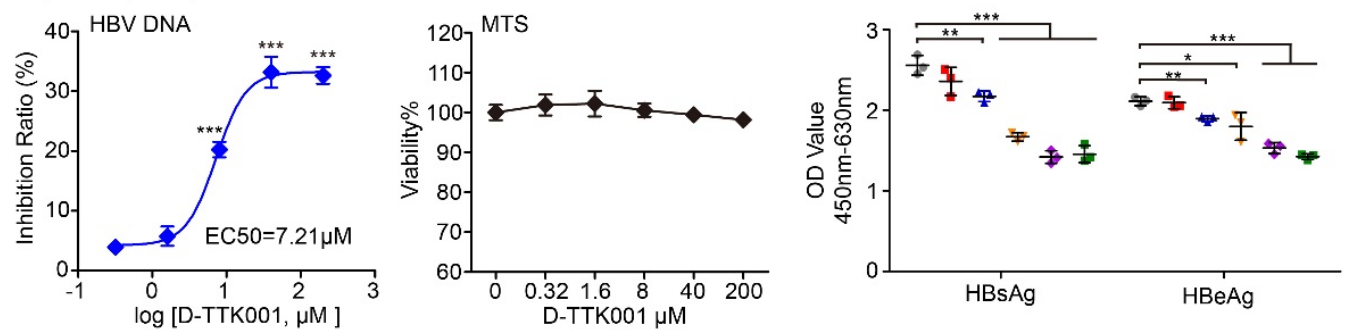

- D-TK, $0 \mu \mathrm{M}$ - D-TK, $0.32 \mu \mathrm{M}$ $\Delta \mathrm{D}-\mathrm{TK}, 1.6 \mu \mathrm{M}$ D-TK, $8 \mu \mathrm{M}$ D-TK, $40 \mu \mathrm{M}$ - D-TK, $200 \mu \mathrm{M}$

d PHH\#2 (HBV de novo)
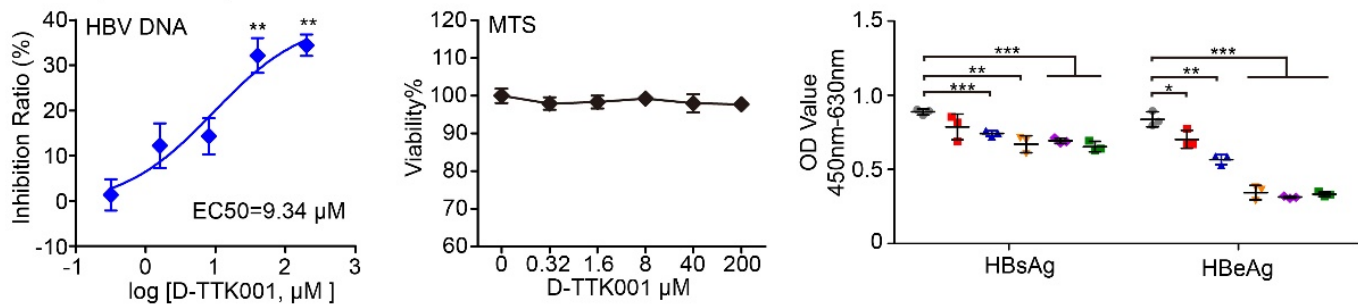

- D-TK, $0 \mu \mathrm{M}$ - D-TK, $0.32 \mu \mathrm{M}$ D-TK, $1.6 \mu \mathrm{M}$ $\checkmark$ D-TK, $8 \mu \mathrm{M}$ - D-TK, $40 \mu \mathrm{M}$ - D-TK, $200 \mu \mathrm{M}$

e $\mathrm{PHH} 3$ ( $\mathrm{HBV}$ de novo)
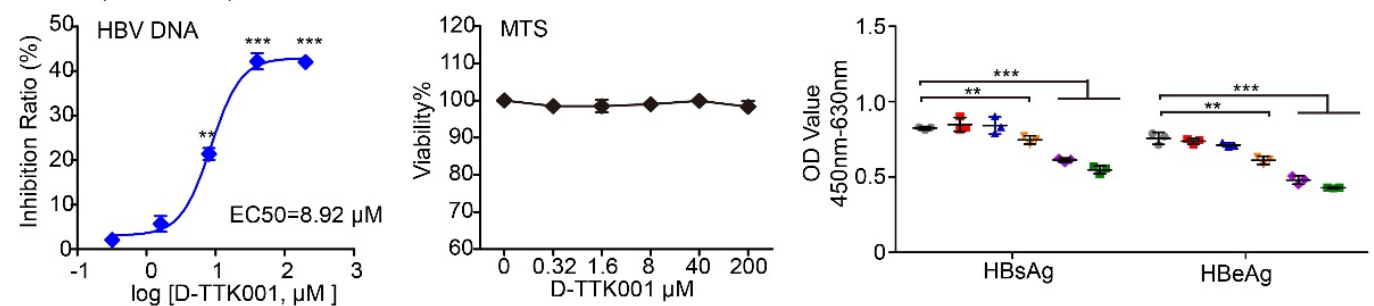

- D-TK, $0 \mu \mathrm{M}$ - D-TK, $0.32 \mu \mathrm{M}$ $\Delta \mathrm{D}-\mathrm{TK}, 1.6 \mu \mathrm{M}$ v D-TK, $8 \mu \mathrm{M}$ - D-TK, $40 \mu \mathrm{M}$ - D-TK, $200 \mu \mathrm{M}$

f dHepaRG (HBV de novo)
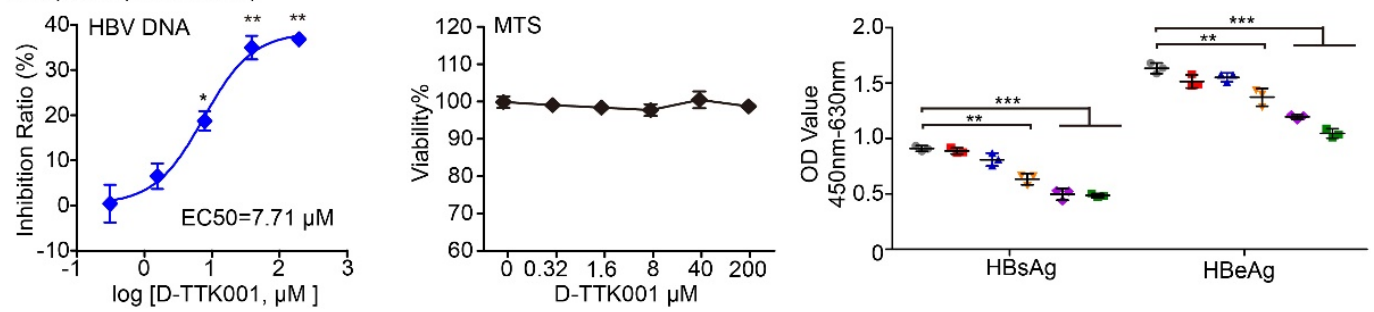

- D-TK, $0 \mu \mathrm{M}$

- D-TK, $0.32 \mu \mathrm{M}$ $\Delta \mathrm{D}-\mathrm{TK}, 1.6 \mu \mathrm{M}$ $\checkmark \mathrm{D}-\mathrm{TK}, 8 \mu \mathrm{M}$

- D-TK, $40 \mu \mathrm{M}$

- D-TK, $200 \mu \mathrm{M}$

Fig. S2. Efficacy of D-TTK001 against HBV in vitro. a, The levels of HBV DNA, HBsAg,

$3 \mathrm{HBeAg}, \mathrm{HBcAg}$, and cell viability were respectively examined by RT-qPCR, ELISA,

4 immunofluorescence and MTS assays in HepAD38 (Tet off) cells treated with D-TTK001 (100

$5 \quad \mu \mathrm{M}$ ) for 7 days. b, The levels of HBV DNA and the cell viability were determined by RT-qPCR 
1 and MTS assays in HepAD38 (Tet off) cells treated with D-TTK001 for 7 days. c-f, The levels of

2 HBV DNA, HBsAg, and HBeAg were evaluated by qPCR and ELISA assays in the supernatant of 3 HepAD38 (Tet off), dHepaRG and PHH cells. The cell viability was measured by MTS assay.

4 HepAD38 (Tet off) cells were infected with HBV and were continuously treated with D-TTK001,

$5 \quad$ ETV or IFN- $\alpha$ for 7 days. Data are represented as means $\pm \operatorname{SD}(\mathrm{n}=3) .{ }^{*} p<0.05 ;{ }^{*} p<0.01$;

$6 \quad * * * p<0.001$ (Student's $t$ test). 


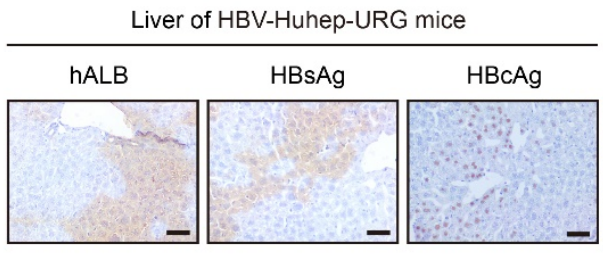

c

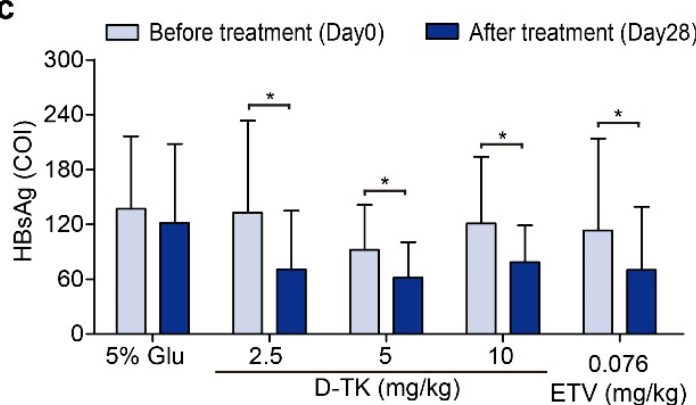

b

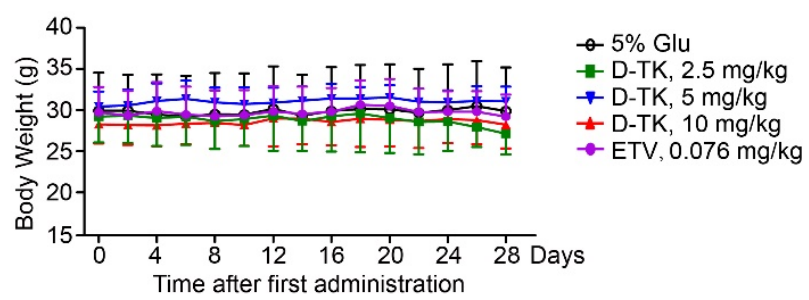

d

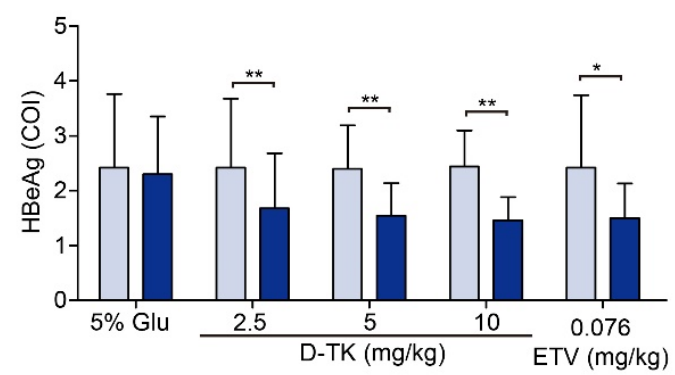

e

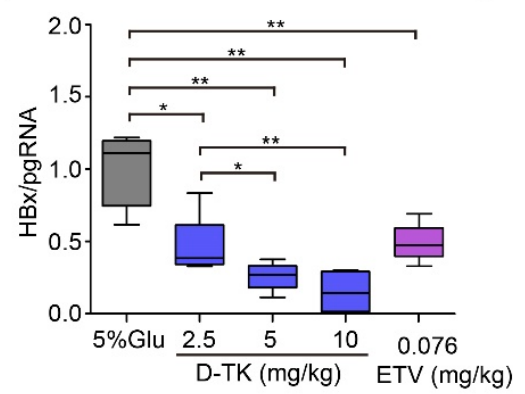

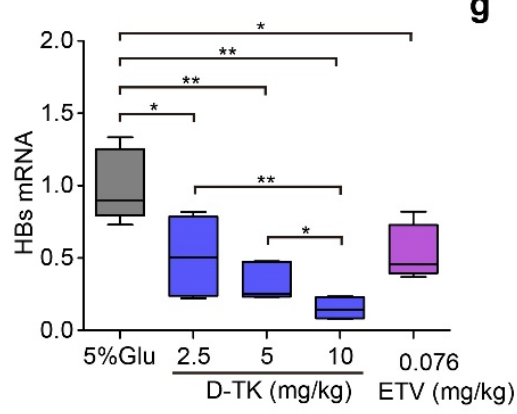

g

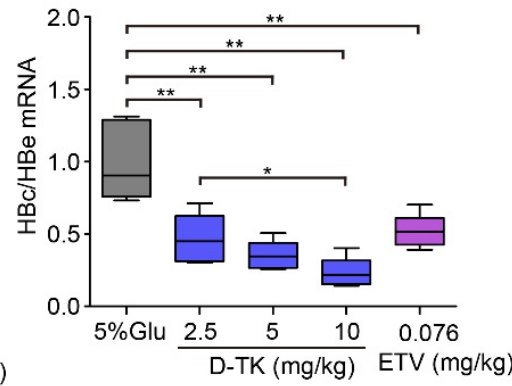

h

Transfected mice with hydrodynamic injection

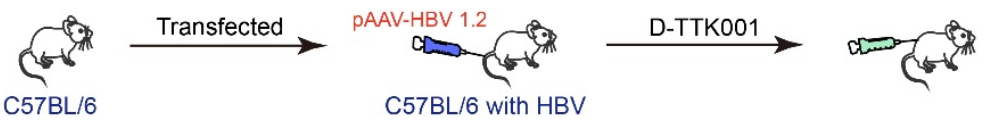

i

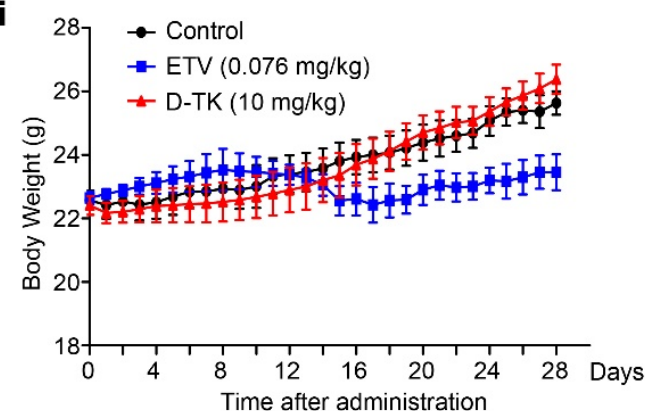

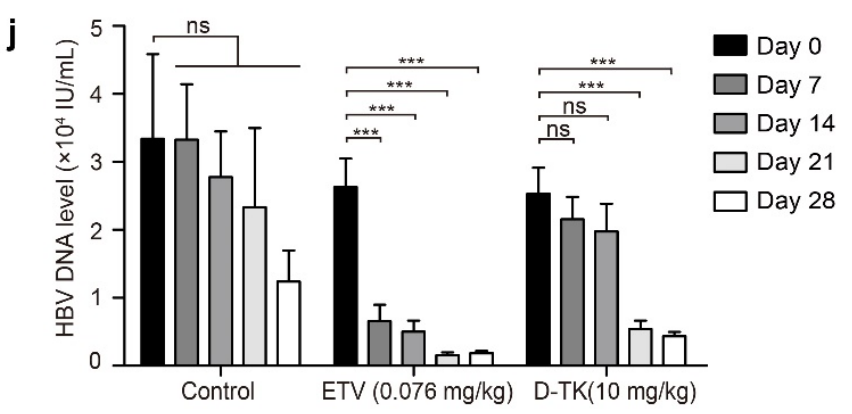

Fig. S3. Efficacy of D-TTK001 against HBV in vivo. a, Immunohistochemistry staining for hALB, HBsAg and $\mathrm{HBcAg}$ were measured in the liver tissues from HBV-Huhep-URG mice.

Scare bars: $50 \mu \mathrm{m}$. b, A comparative evaluation of changes in weight of HBV-Huhep-URG mice treated with drugs. c, The levels of HBsAg were tested by ECLIA assays in the serum of HBVHuhep-URG mice before and after drug treatment. d, The levels of HBeAg were determined by ECLIA assays in the serum of HBV-Huhep-URG mice before and after treatment. e-g, The levels 
1 of HBV mRNA fragments, such as pgRNA, S, C-E were measured in the liver tissues from HBV-

2 infected human liver-chimeric mice by RT-qPCR assays. GAPDH gene was served as the internal

3 reference. $\mathbf{h}$, A model of hydrodynamic injection (HDI)-based HBV-carrier mice. i, A

4 comparative evaluation of changes in weight of HDI-based HBV carrier mice treated with drug. $\mathbf{j}$,

5 HBV DNA (IU/mL) levels were tested by qPCR in the serum of HDI-based HBV carrier mice.

6 The HDI-based HBV carrier mice were given dose-administration once a day for 4 weeks. Serum

7 samples were collected before exposure (Day 0) and 1, 2, 3, 4 weeks post-exposure (Day7, Day 14,

8 Day21, Day28), respectively. Data are represented as means $\pm \mathrm{SD}(\mathrm{n}=3) .{ }^{*} p<0.05 ; * * p<0.01$;

$9 \quad * * * p<0.001$ (Student's $t$ test). 
a Acute toxicity experiment

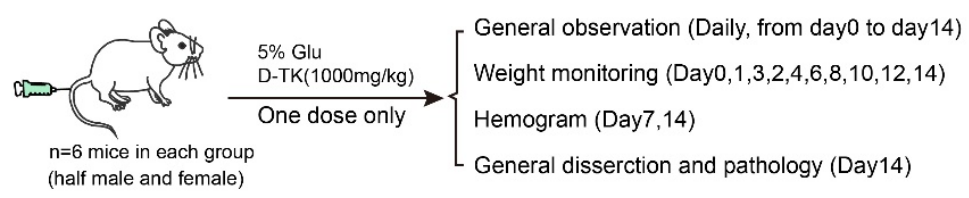

b

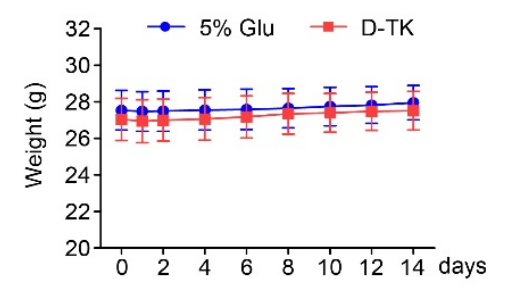

c

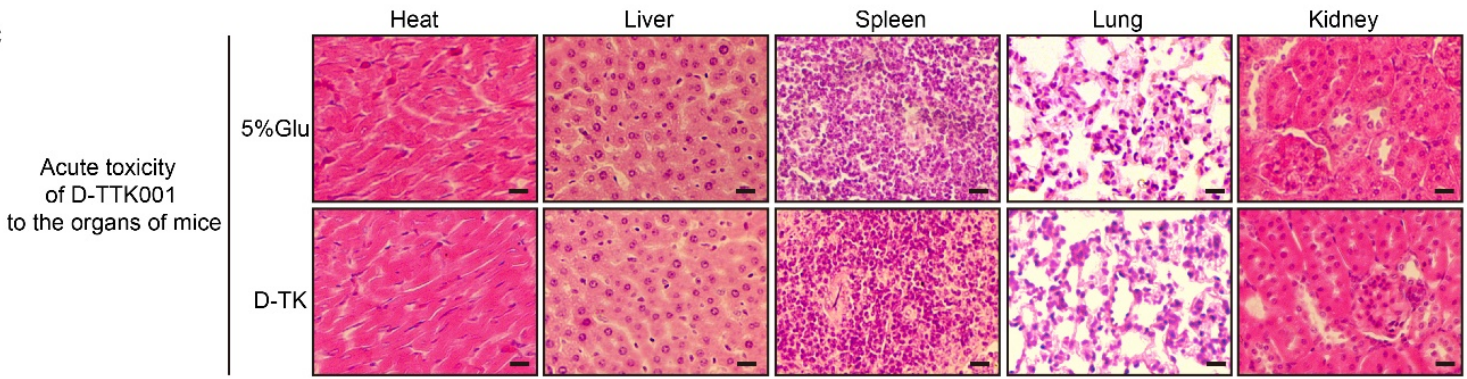

d Long-term toxicity experiment

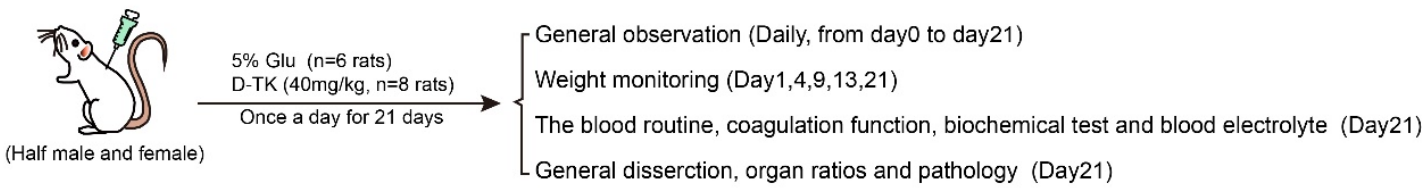

e
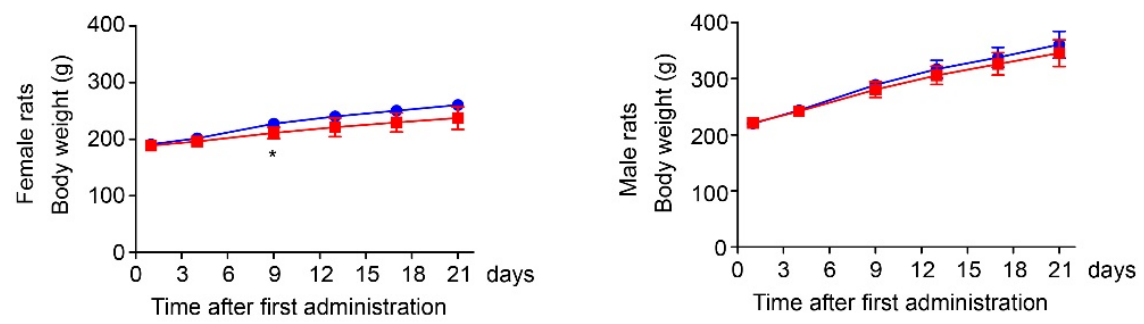

$-5 \%$ Glu $(n=3)$

$=-\mathrm{D}-\mathrm{TK}(\mathrm{n}=4)$

f

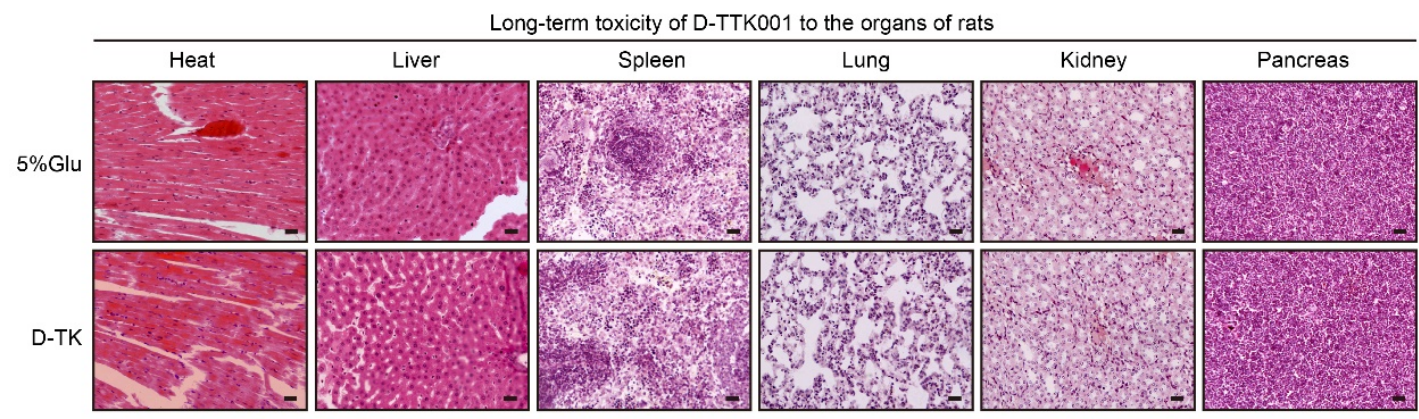

Fig. S4. The toxicity evaluation of D-TTK001 in vivo. a, A model showed the protocol of acute toxicity experiment. $\mathbf{b}$, A comparative evaluation of changes in the weight of mice after the drug

4 treatment. c, Pathological characteristics of the organs of mice with acute toxicity treatment were

5 observed by H\&E staining. d, A model showed the protocol of long-term toxicity experiment. e, A

6 comparative evaluation of changes in the weight of rats after drug treatment. $\mathbf{f}$, Pathological

7 characteristics of the organs of rats with long-term toxicity treatment were observed by H\&E 
1 staining. Data are represented as means $\pm \mathrm{SD}(\mathrm{n}=3) .{ }^{*} p<0.05 ; * * p<0.01 ; * * * p<0.001$ (Student's $t$ 2 test).

3 
Yuan HF, et al. Figure S5

a $\mathrm{PHH} 2(\mathrm{HBV}$ de novo)

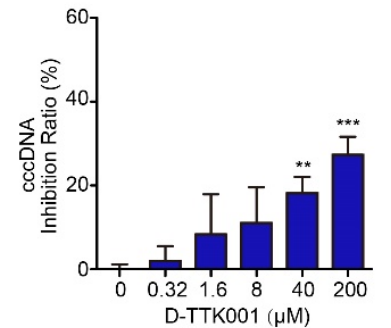

b HepAD38 (Tet off)

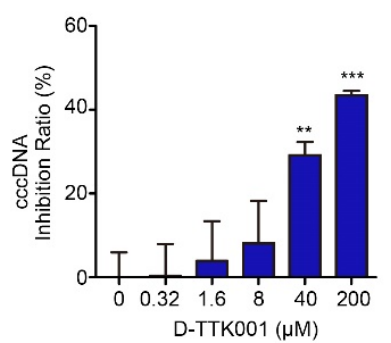

C dHepaRg (HBV de novo)

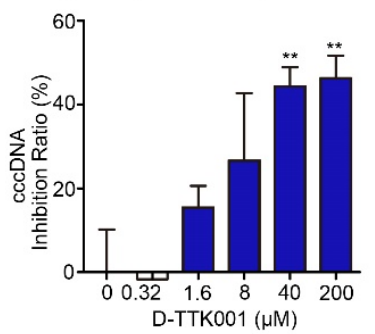

d HepG2-NTCP (HBV de novo)

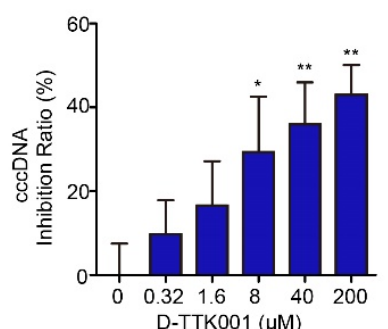

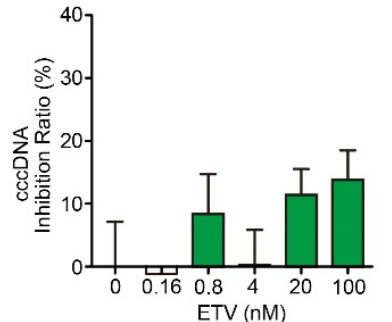
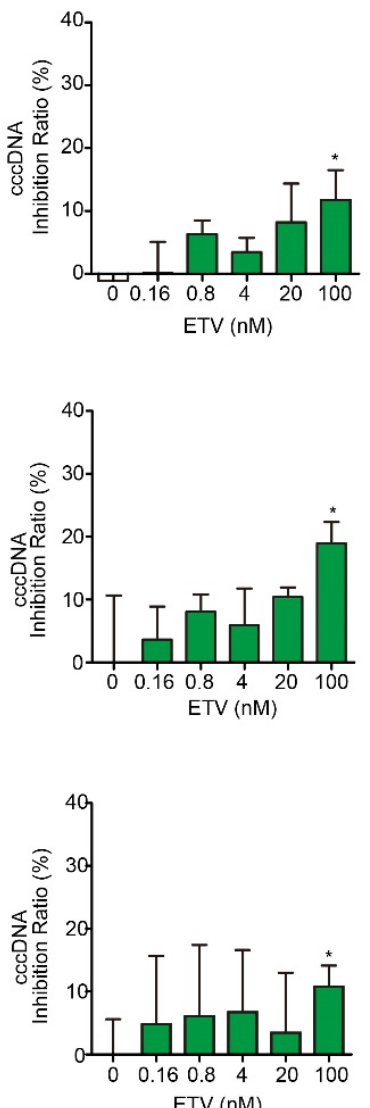
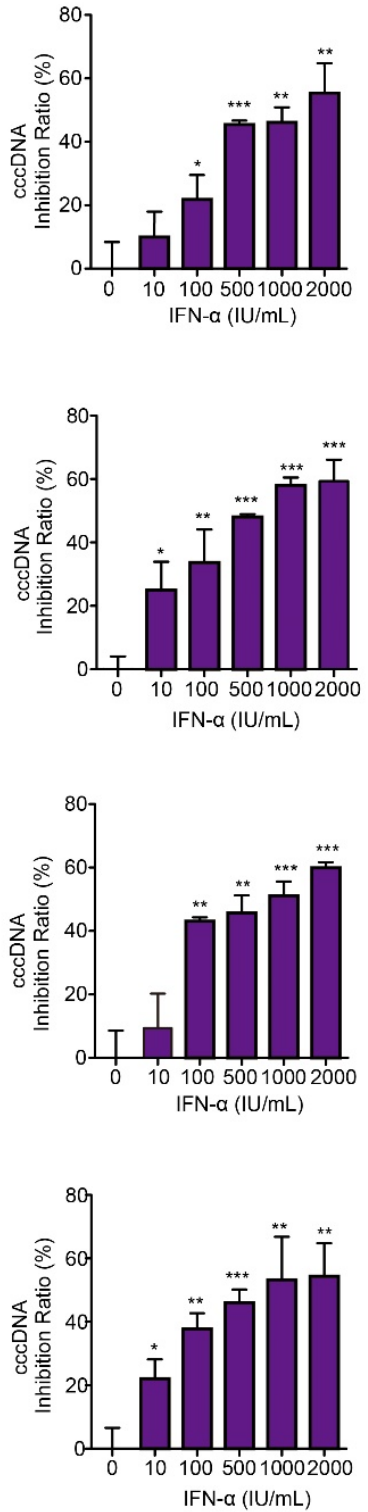

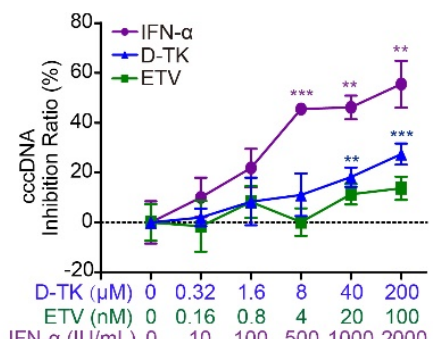

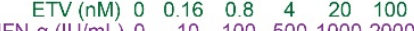
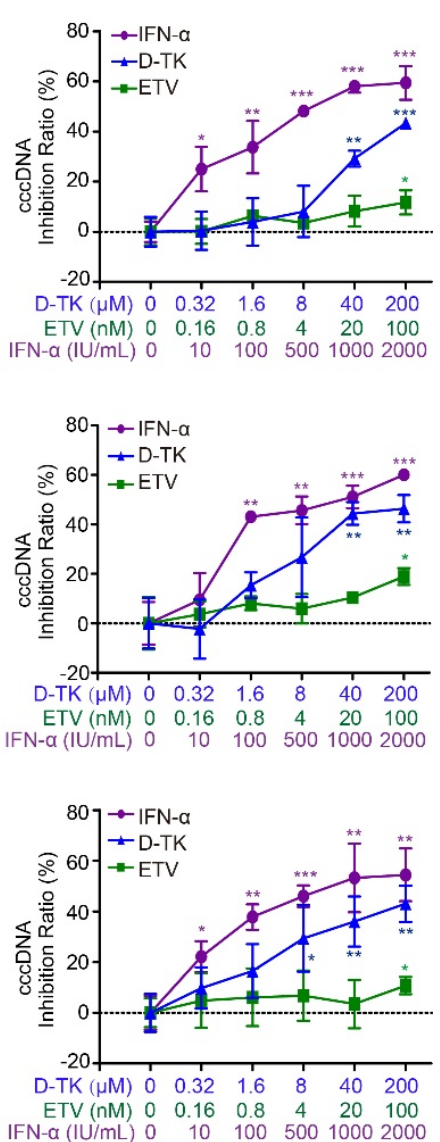

Fig. S5. D-TTK001 efficiently controls the levels of HBV cccDNA in vitro and in vivo. a-d,

HBV cccDNA levels were measured by qPCR assays in the nucleus of HepAD38 (Tet off) and

4 HBV de novo PHH\#2, dHepaRG, and HepG2-NTCP cells treated with D-TTK001, ETV or IFN- $\alpha$

5 for 7 days. Data are represented as means $\pm \mathrm{SD}(\mathrm{n}=3)$. ${ }^{*} p<0.05 ; * * p<0.01 ; * * * p<0.001$ (Student's

$6 \quad t$ test). 
Yuan HF, et al. Figure S6

a HepG2-NTCP (HBV de novo)

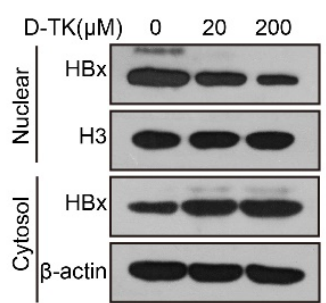

d HepG2

$$
\text { Input IgG Flag Flag }
$$

$\mathrm{D}-\mathrm{TK}(200 \mu \mathrm{M}) \quad-\quad-\quad+\quad+$

Flag-HBx

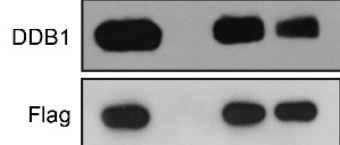

b HEK293T:

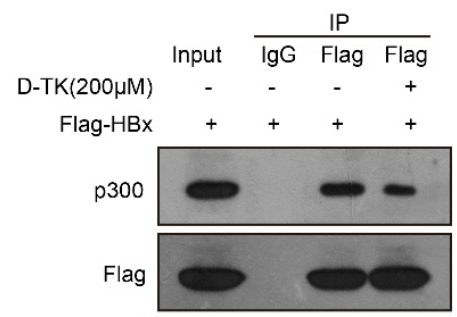

c

HepG2-NTCP (HBV de novo)

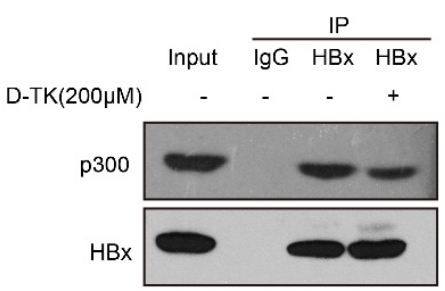

e HepG2-NTCP (HBV de novo)

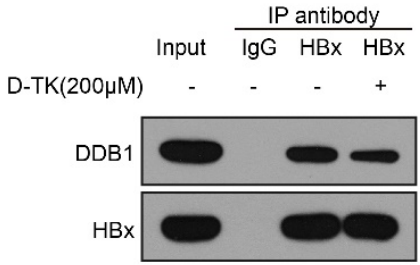

f D-TTK001 controls HBV cccDNA

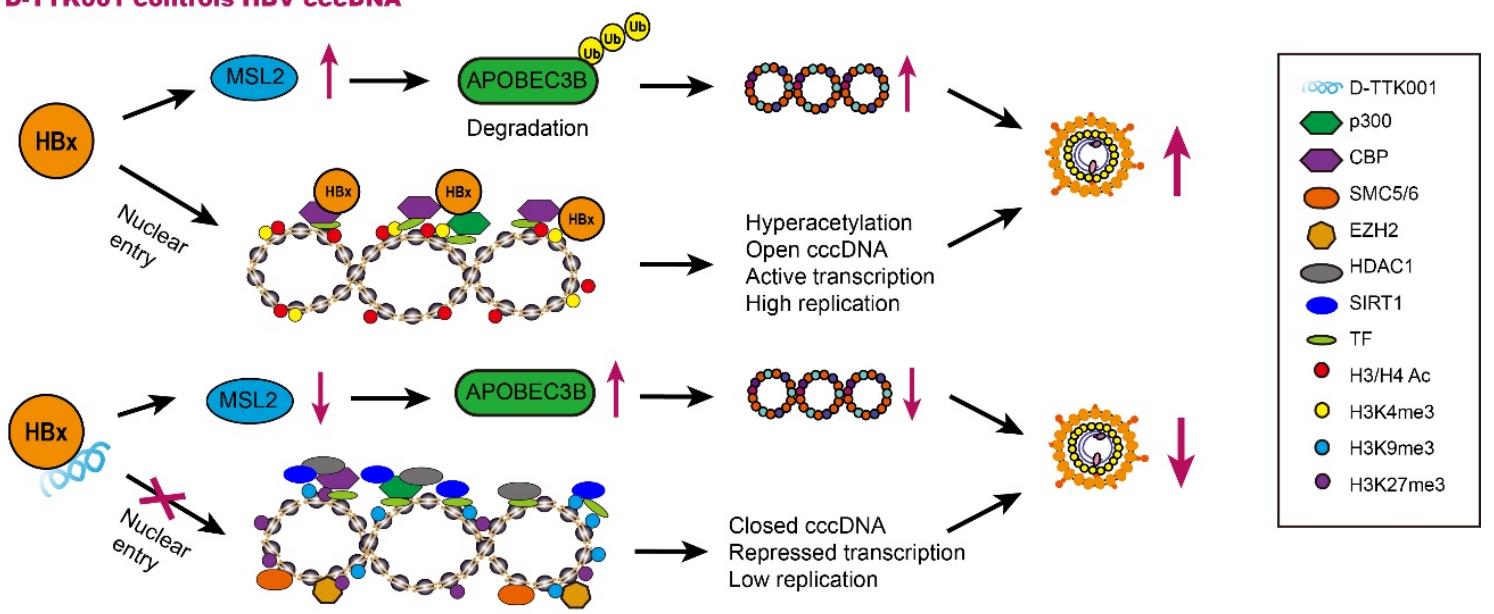

g HepAD38(Tet off)
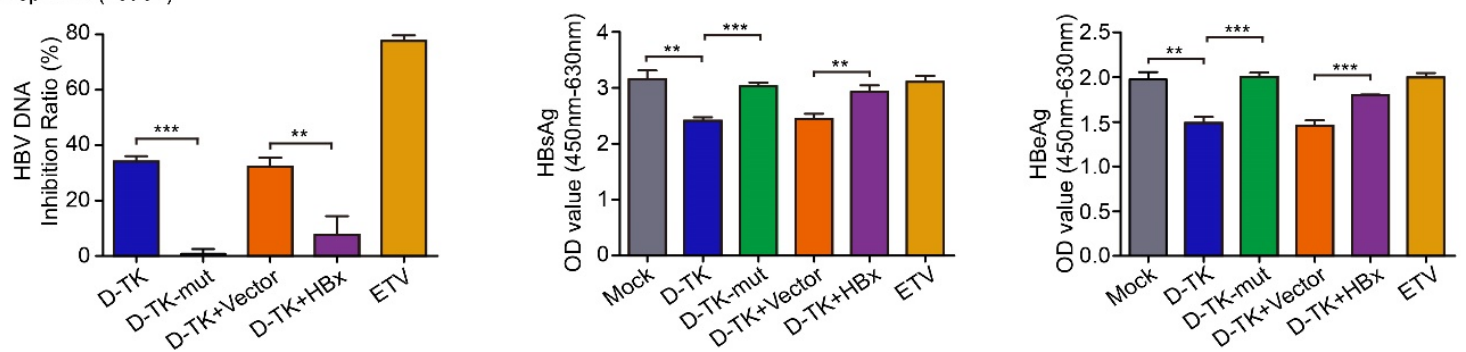

h HepG2-NTCP (HBV de novo)
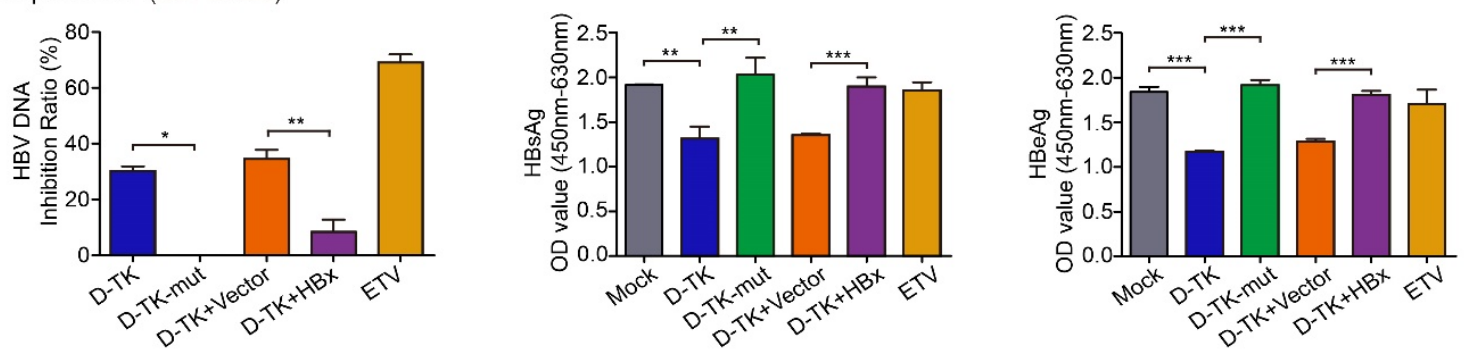

2 Fig. S6. The mechanisms of D-TTK001 against HBV. a, The effect of D-TTK001 on the expression of

3 HBx was measured by Western blot analysis in HBV de novo HepG2-NTCP cells treated with D-

4 TTK001 for 7 days. b, The interaction of p300 with exogenous HBx was examined by Co-IP 
1 assays in HEK293T cells transfected with Flag-tagged HBx and treated with D-TTK001 for 7

2 days. c, The interaction of p300 with endogenous HBx was examined by Co-IP assays in HBV de

3 novo HepG2-NTCP cells treated with D-TTK001 for 7 days. d, The interaction of DDB1 with

4 exogenous HBx was tested by Co-IP assay in HepG2 cells transfected with Flag-tagged HBx and

5 treated with D-TTK001 for 7 days. e, The interaction of DDB1 with exogenous HBx was tested by

6 Co-IP assay in HBV de novo HepG2-NTCP cells treated with D-TTK001 for 7 days. f, A model

7 of D-TTK001 against HBV. D-TTK001 depresses cccDNA transcription through regulating the

8 epigenetic modification of cccDNA minichromosome and disturbing the interaction of HBx with

9 DDB1; and decreases the levels of cccDNA by down-regulating MSL2 which leads to the increase

10 of APOBEC3B in liver. $\mathbf{g}-\mathbf{h}$, The levels of HBV DNA, HBsAg and HBeAg were evaluated by

11 qPCR and ELISA assays in the supernatant of HepAD38 (tet off) and HBV de novo HepG2-

12 NTCP cells. The cells were continuously treated with D-TTK001 (200 $\mu \mathrm{M})$, D-TTK001-mut (200

$13 \mu \mathrm{M})$, ETV $(100 \mathrm{nM})$ for 7 days. The pcDNA3.1-HBx and pcDNA3.1-Vector were transfected at

14 time points of day 0 , day 2 , and day 4 . Data are represented as means $\pm \operatorname{SD}(\mathrm{n}=3) .{ }^{*} p<0.05$;

${ }^{* *} p<0.01 ; * * * p<0.001$ (Student's $t$ test). 


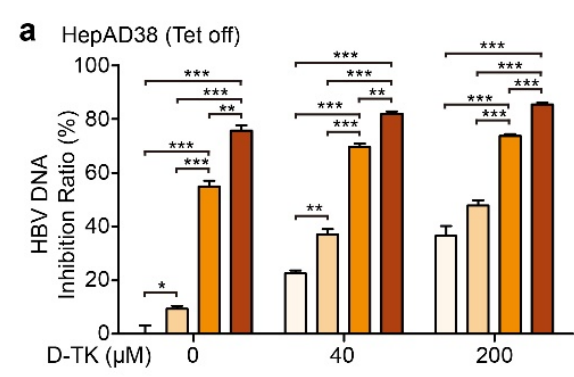

C HepAD38 (Tet off)

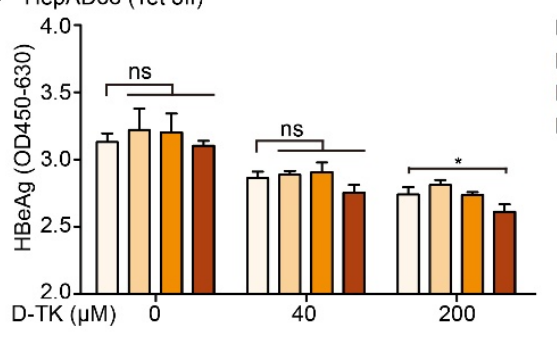

e HepAD38 (Tet off)

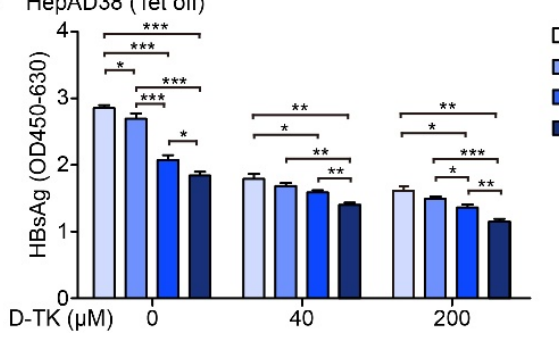

b HepAD38 (Tet off)

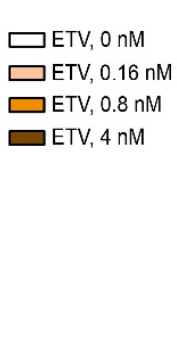

$\square$ ETV, 0 nM

$\square$ ETV, $0.16 \mathrm{nM}$ $\square$ ETV, $0.8 \mathrm{nM}$

$\square$ ETV, 4 nM

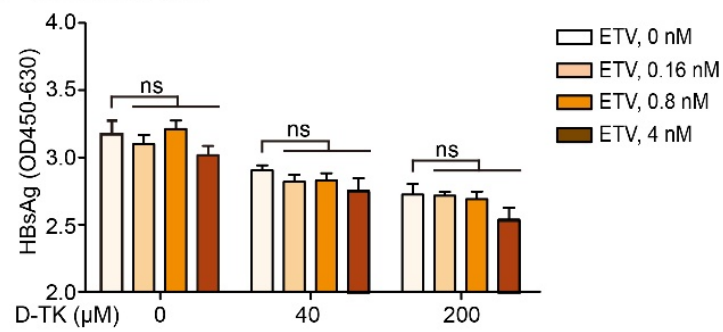

d HepAD38 (Tet off)

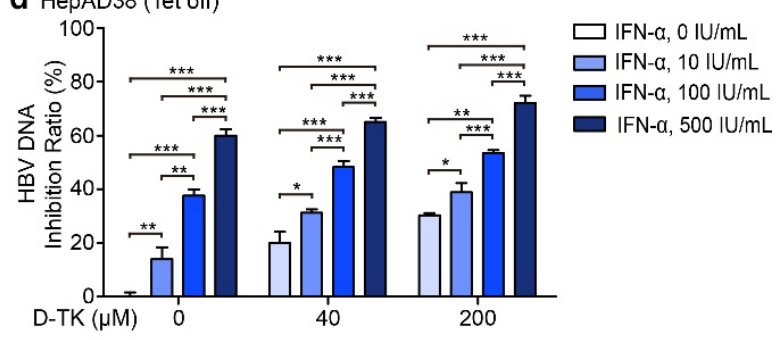

f HepAD38 (Tet off)

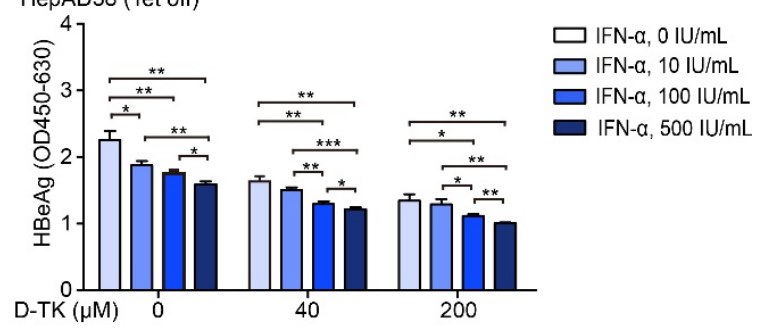

2 Fig. S7. Efficacy of the combination of D-TTK001 with ETV or IFN- $\alpha$ in vitro. a-c, The levels

3 of HBV DNA, HBsAg, and HBeAg were measured by qPCR and ELISA assays in the supernatant

4 of HepAD38 (Tet off) cells treated with both D-TTK001 and ETV for 7 days. d-f, The levels of

5 HBV DNA, HBsAg, and HBeAg were evaluated by qPCR and ELISA assays in the supernatant of

6 HepAD38 (Tet off) cells treated with both D-TTK001 and IFN- $\alpha$ for 7 days. Data are represented

$7 \quad$ as means $\pm \mathrm{SD}(\mathrm{n}=3) .{ }^{*} p<0.05 ; * * p<0.01 ; * * * p<0.001$ (Student's t test). 


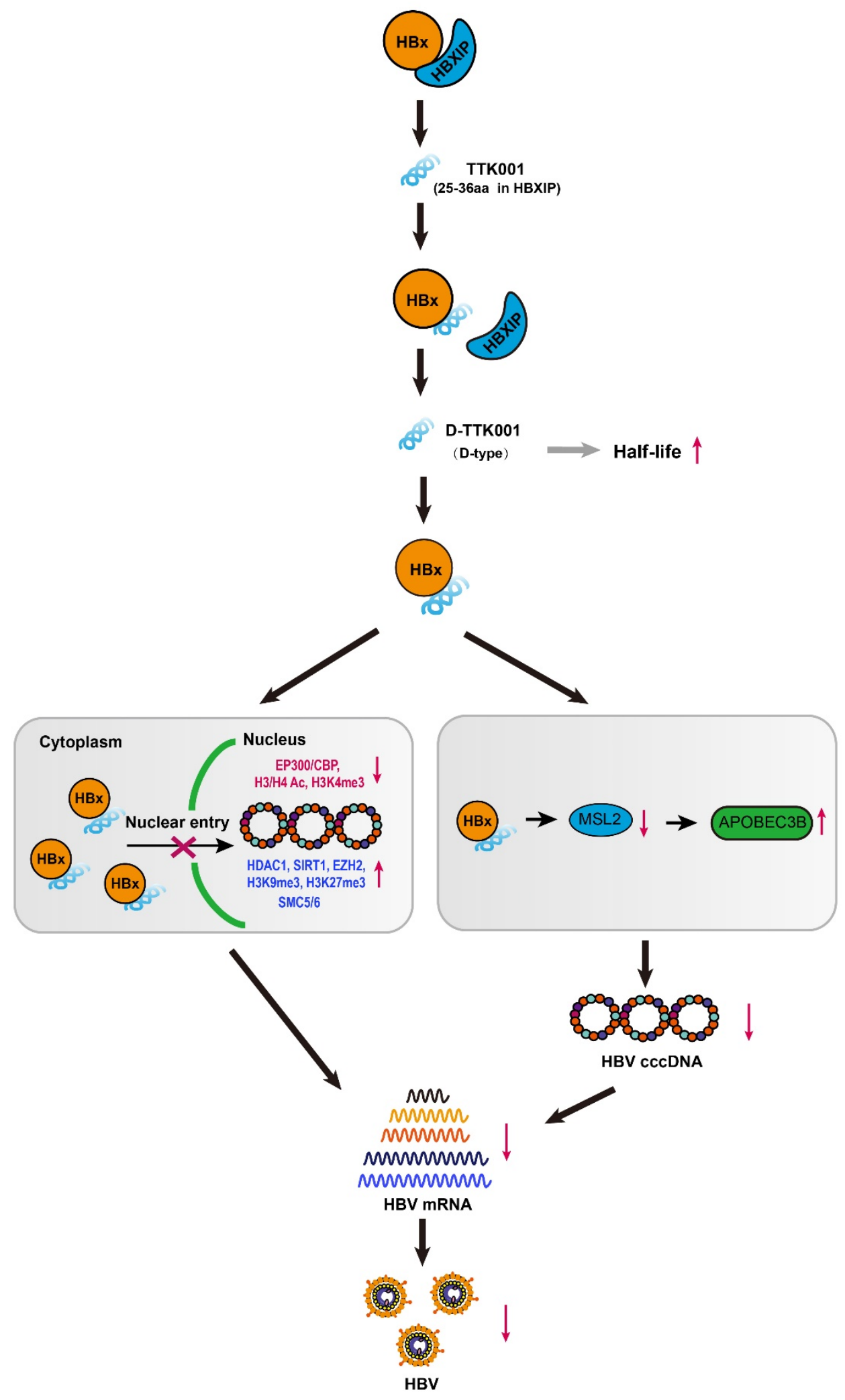

3 HBXIP sequence by PPI strategy. All of the amino acids of TTK001 are reversed into the D-type

4 amino acids, termed D-TTK001. Mechanically, D-TTK001 depresses cccDNA transcription 
1 through regulating the epigenetic modification of cccDNA minichromosome and disturbing the

2 interaction of HBx with DDB1; and decreases the levels of cccDNA by down-regulating MSL2

3 which leads to the increase of APOBEC3B in liver, contributing to the inhibition of HBV.

4 
1 Table S1. Pharmacokinetics of D-TTK001 in rats with subcutaneous injection

\begin{tabular}{|c|c|c|c|c|c|c|c|c|}
\hline \multicolumn{2}{|c|}{ Parameters } & \multicolumn{7}{|c|}{ Single subcutaneous administration } \\
\hline Name & Units & \multicolumn{2}{|c|}{$1 \mathrm{mg} / \mathrm{kg}$} & \multicolumn{2}{|c|}{$2 \mathrm{mg} / \mathrm{kg}$} & \multicolumn{3}{|c|}{$4 \mathrm{mg} / \mathrm{kg}$} \\
\hline$C_{\max }$ & $\mathrm{ng} / \mathrm{mL}$ & 857 & \pm 178 & 1790 & \pm 298 & 3610 & \pm & 734 \\
\hline$T_{\max }$ & $\mathrm{h}$ & 0.333 & \pm 0.204 & 0.417 & \pm 0.204 & 0.417 & \pm & 0.129 \\
\hline $\mathrm{AUC}_{0-6 \mathrm{~h}}$ & $\mathrm{~h} \cdot \mathrm{ng} / \mathrm{mL}$ & 1250 & \pm 63.9 & 2570 & \pm 194 & 5360 & \pm & 651 \\
\hline $\mathrm{AUC}_{0-\infty}$ & $\mathrm{h} \cdot \mathrm{ng} / \mathrm{mL}$ & 1250 & $\pm \quad 63.7$ & 2570 & \pm 193 & 5370 & \pm & 648 \\
\hline $\mathrm{MRT}_{0-6 \mathrm{~h}}$ & $\mathrm{~h}$ & 1.14 & \pm 0.154 & 1.06 & \pm 0.146 & 1.11 & \pm & 0.176 \\
\hline $\mathrm{MRT}_{0-\infty}$ & $\mathrm{h}$ & 1.15 & \pm 0.152 & 1.07 & \pm 0.145 & 1.12 & \pm & 0.182 \\
\hline $\mathrm{V}_{\mathrm{d}}$ & $\mathrm{L} / \mathrm{kg}$ & 0.555 & \pm 0.116 & 0.45 & $\pm \quad 0.0714$ & 0.565 & \pm & 0.162 \\
\hline CL & $\mathrm{L} / \mathrm{h} / \mathrm{kg}$ & 0.801 & $\pm \quad 0.0398$ & 0.781 & \pm 0.0631 & 0.755 & \pm & 0.102 \\
\hline$t_{1 / 2}$ & $\mathrm{~h}$ & 0.481 & $\pm \quad 0.102$ & 0.398 & $\pm \quad 0.0474$ & 0.515 & \pm & 0.113 \\
\hline
\end{tabular}


1 Table S2. Pharmacokinetic parameters for D-TTK001 after single and multiple doses in rats

\begin{tabular}{|c|c|c|c|c|c|c|}
\hline \multicolumn{2}{|c|}{ Parameters } & \multicolumn{5}{|c|}{$2 \mathrm{mg} / \mathrm{kg}$} \\
\hline \multirow{2}{*}{$\frac{\text { Name }}{C_{\max }}$} & \multirow{2}{*}{$\frac{\text { Units }}{\mathrm{ng} / \mathrm{mL}}$} & \multicolumn{2}{|c|}{ Single injection Day1 } & \multicolumn{3}{|c|}{ Continuous injection Day7 } \\
\hline & & 1790 & 298 & 2360 & \pm & 123 \\
\hline$T_{\max }$ & $\mathrm{h}$ & 0.417 & 0.204 & 0.375 & \pm & 0.137 \\
\hline $\mathrm{AUC}_{0-6 \mathrm{~h}}$ & $\mathrm{~h} \cdot \mathrm{ng} / \mathrm{mL}$ & 2570 & 194 & 3060 & \pm & 169 \\
\hline $\mathrm{AUC}_{0-\infty}$ & $\mathrm{h} \cdot \mathrm{ng} / \mathrm{mL}$ & 2570 & 193 & 3060 & \pm & 170 \\
\hline $\mathrm{MRT}_{0-\infty}$ & $\mathrm{h}$ & 1.07 & 0.145 & 0.955 & \pm & 0.0663 \\
\hline $\mathrm{V}_{\mathrm{d}}$ & $\mathrm{L} / \mathrm{kg}$ & 0.45 & 0.0714 & 0.655 & \pm & 0.0373 \\
\hline $\mathrm{CL}$ & $\mathrm{L} / \mathrm{h} / \mathrm{kg}$ & 0.781 & 0.0631 & 0.449 & \pm & 0.06 \\
\hline$t_{1 / 2}$ & $\mathrm{~h}$ & 0.398 & 0.0474 & 0.476 & \pm & 0.0604 \\
\hline
\end{tabular}

2 
1 Table S3. Pharmacokinetics of D-TTK001 in monkey with subcutaneous injection

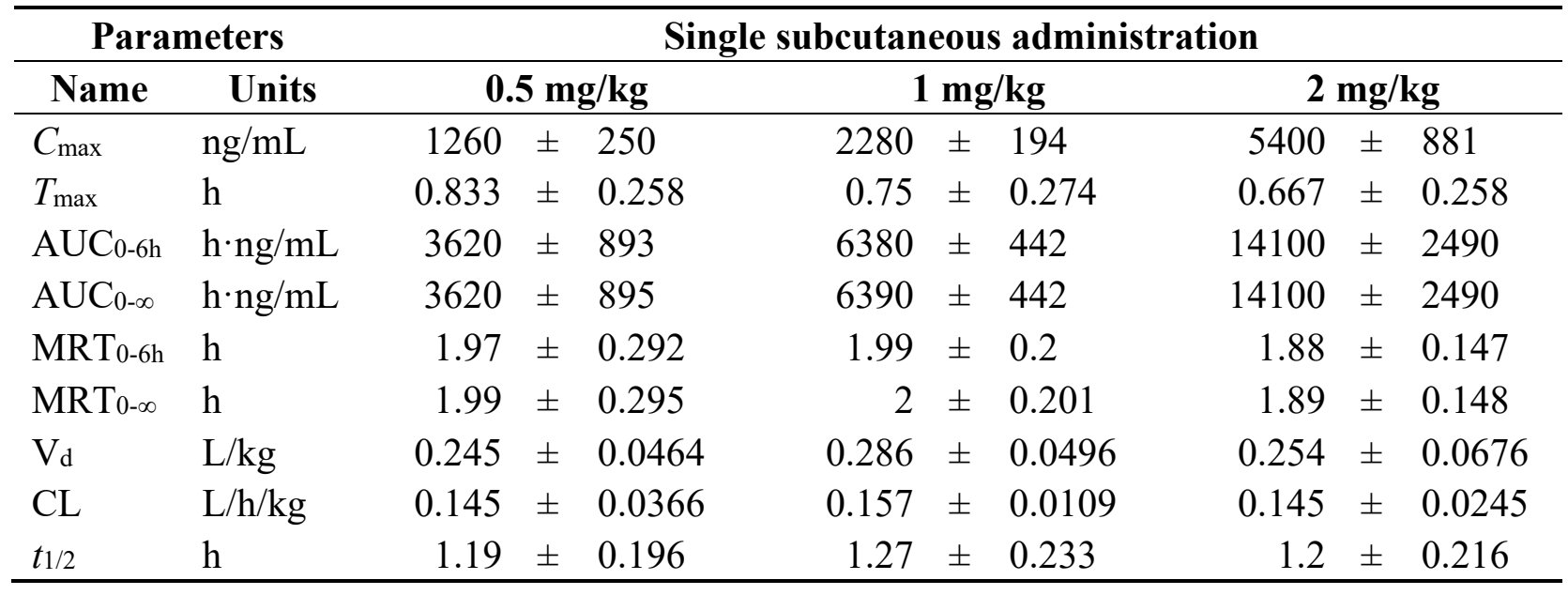


1 Table S4. Pharmacokinetic parameters for D-TTK001 after single and multiple doses in monkeys

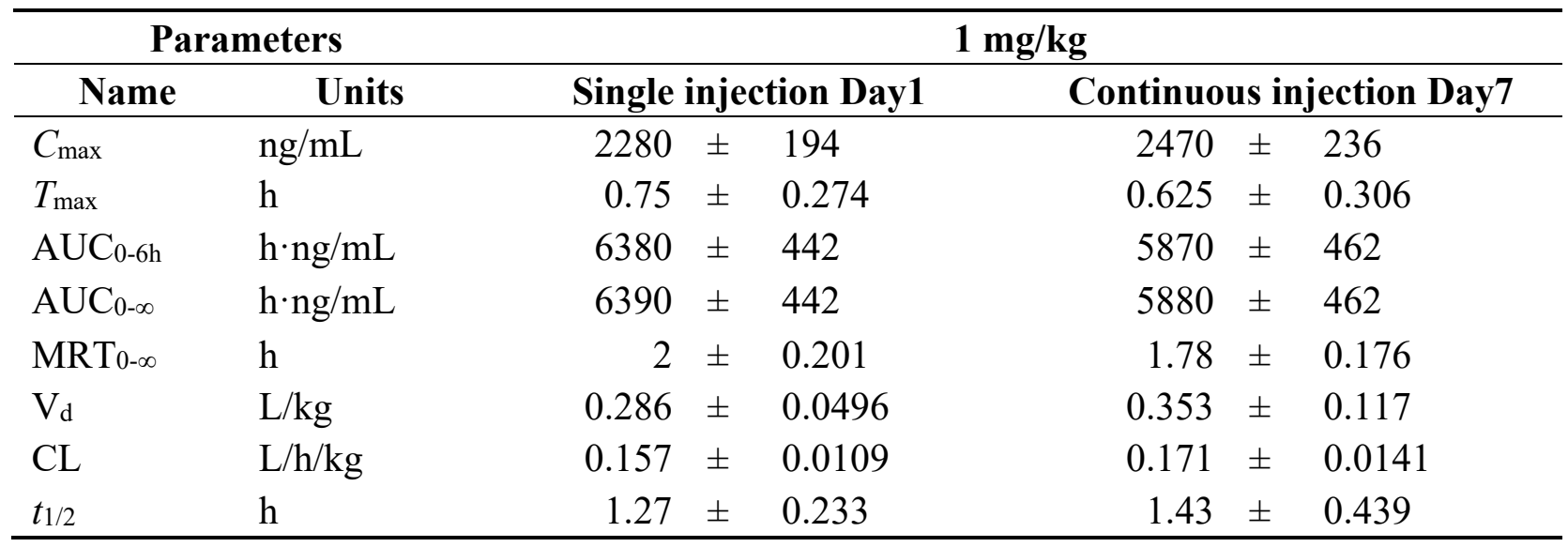

2 
1 Table S5. Information of HBV-infected human liver-chimeric mice

\begin{tabular}{|c|c|c|c|c|c|}
\hline \multirow{2}{*}{ Groups } & \multirow{2}{*}{ Number } & \multirow{2}{*}{$\begin{array}{c}\text { HSA } \\
\text { (ng/ml) }\end{array}$} & \multicolumn{3}{|c|}{ HBV DNA (copy/ml) after HBV particles injection } \\
\hline & & & 4 week & 5 week & 6 week \\
\hline \multirow{5}{*}{$\begin{array}{c}\text { D-TTK001 } \\
10 \mathrm{mg} / \mathrm{kg}\end{array}$} & 1 & $2,654,191.50$ & $2.00 \mathrm{E}+06$ & $2.42 \mathrm{E}+06$ & $1.58 \mathrm{E}+06$ \\
\hline & 2 & $816,344.45$ & $4.30 \mathrm{E}+05$ & $7.11 \mathrm{E}+05$ & $9.11 \mathrm{E}+05$ \\
\hline & 3 & $2,047,426.25$ & $8.29 \mathrm{E}+03$ & $5.77 \mathrm{E}+05$ & $5.69 \mathrm{E}+05$ \\
\hline & 4 & $1,118,151.25$ & $3.07 \mathrm{E}+05$ & $4.38 \mathrm{E}+05$ & $2.79 \mathrm{E}+05$ \\
\hline & 5 & $1,135,842.05$ & $2.34 \mathrm{E}+05$ & $2.57 \mathrm{E}+05$ & $1.40 \mathrm{E}+05$ \\
\hline \multirow{5}{*}{$\begin{array}{c}\text { D-TTK001 } \\
5 \mathrm{mg} / \mathrm{kg}\end{array}$} & 6 & $4,350,590.85$ & $8.57 \mathrm{E}+06$ & $2.18 \mathrm{E}+07$ & $1.32 \mathrm{E}+07$ \\
\hline & 7 & $2,341,671.35$ & $1.25 \mathrm{E}+05$ & $5.71 \mathrm{E}+05$ & $5.81 \mathrm{E}+05$ \\
\hline & 8 & $1,488,376.40$ & $1.42 \mathrm{E}+05$ & $6.22 \mathrm{E}+05$ & $4.33 \mathrm{E}+05$ \\
\hline & 9 & $1,445,497.30$ & $2.87 \mathrm{E}+05$ & $2.93 \mathrm{E}+05$ & $2.56 \mathrm{E}+05$ \\
\hline & 10 & $1,286,685.25$ & $4.86 \mathrm{E}+05$ & $1.63 \mathrm{E}+05$ & $1.44 \mathrm{E}+05$ \\
\hline \multirow{5}{*}{$\begin{array}{c}\text { D-TTK001 } \\
2.5 \mathrm{mg} / \mathrm{kg}\end{array}$} & 11 & $1,850,263.55$ & $1.37 \mathrm{E}+06$ & $3.91 \mathrm{E}+06$ & $1.83 \mathrm{E}+06$ \\
\hline & 12 & $1,232,876.30$ & $9.02 \mathrm{E}+05$ & $8.51 \mathrm{E}+05$ & $7.37 \mathrm{E}+05$ \\
\hline & 13 & $1,981,115.80$ & $2.95 \mathrm{E}+05$ & $4.80 \mathrm{E}+05$ & $5.11 \mathrm{E}+05$ \\
\hline & 14 & $1,879,166.35$ & $2.26 \mathrm{E}+05$ & $1.37 \mathrm{E}+05$ & $1.55 \mathrm{E}+05$ \\
\hline & 15 & $1,102,910.35$ & $4.24 \mathrm{E}+05$ & $3.89 \mathrm{E}+05$ & $1.34 \mathrm{E}+05$ \\
\hline \multirow{5}{*}{ ETV } & 16 & $4,330,688.85$ & $2.92 \mathrm{E}+06$ & $2.25 \mathrm{E}+06$ & $1.86 \mathrm{E}+06$ \\
\hline & 17 & $3,180,305.40$ & $6.27 \mathrm{E}+06$ & $2.02 \mathrm{E}+06$ & $9.24 \mathrm{E}+05$ \\
\hline & 18 & $1,927,548.95$ & $6.89 \mathrm{E}+05$ & $6.10 \mathrm{E}+05$ & $4.34 \mathrm{E}+05$ \\
\hline & 19 & $1,245,156.35$ & $4.76 \mathrm{E}+04$ & $1.93 \mathrm{E}+05$ & $1.89 \mathrm{E}+05$ \\
\hline & 20 & $1,291,550.10$ & $8.23 \mathrm{E}+04$ & $1.11 \mathrm{E}+05$ & $1.32 \mathrm{E}+05$ \\
\hline \multirow{5}{*}{$5 \%$ Glu } & 21 & $1,128,271.85$ & $1.22 \mathrm{E}+06$ & $6.38 \mathrm{E}+06$ & $4.49 \mathrm{E}+06$ \\
\hline & 22 & $3,288,609.55$ & $1.88 \mathrm{E}+06$ & $1.06 \mathrm{E}+06$ & $9.26 \mathrm{E}+05$ \\
\hline & 23 & $3,662,839.75$ & $2.49 \mathrm{E}+05$ & $6.94 \mathrm{E}+05$ & $3.43 \mathrm{E}+05$ \\
\hline & 24 & $1,028,102.75$ & $5.07 \mathrm{E}+05$ & $9.41 \mathrm{E}+05$ & $3.19 \mathrm{E}+05$ \\
\hline & 25 & $1,163,458.80$ & $6.55 \mathrm{E}+04$ & $1.37 \mathrm{E}+05$ & $1.39 \mathrm{E}+05$ \\
\hline
\end{tabular}

2 Note: HAS is short for Human Serum Albumin. 
Table S6. The influence of D-TTK001 on the hemogram index of mice

\begin{tabular}{|c|c|c|c|c|c|c|c|c|c|c|c|}
\hline \multirow{2}{*}{\multicolumn{2}{|c|}{ Index }} & \multirow{3}{*}{$\begin{array}{c}\text { Group } \\
\text { No. } \\
\lambda\end{array}$} & \multicolumn{3}{|c|}{$5 \%$ Glu } & \multirow{3}{*}{$\begin{array}{c}\text { Mean } \\
8.26\end{array}$} & \multicolumn{3}{|c|}{ D-TK } & \multirow{3}{*}{$\begin{array}{l}\text { Mean } \\
8.70\end{array}$} & \multirow{3}{*}{$\begin{array}{l}\text { P value } \\
0.0821\end{array}$} \\
\hline & & & \multirow{2}{*}{$\begin{array}{c}\mathbf{1} \\
8.08\end{array}$} & \multirow{2}{*}{$\frac{2}{8.63}$} & \multirow{2}{*}{$\begin{array}{c}\mathbf{3} \\
8.06\end{array}$} & & \multirow{2}{*}{$\frac{1}{8.63}$} & \multirow{2}{*}{$\begin{array}{c}\mathbf{2} \\
8.68\end{array}$} & \multirow{2}{*}{$\begin{array}{c}\mathbf{3} \\
8.8\end{array}$} & & \\
\hline WRC & $\left(\times 10^{9} / \mathrm{I}\right)$ & & & & & & & & & & \\
\hline$W B C$ & & q & 8.89 & 8.26 & 8.16 & 8.44 & 8.11 & 8.41 & 8.13 & 8.22 & 0.4254 \\
\hline \multirow{2}{*}{ RBC } & \multirow{2}{*}{$\left(\times 10^{9} / \mathrm{L}\right)$} & $\sigma^{\lambda}$ & 7.76 & 7.27 & 7.62 & 7.55 & 7.63 & 7.65 & 7.49 & 7.59 & 0.8081 \\
\hline & & q & 7.36 & 7.56 & 7.5 & 7.47 & 7.96 & 7.29 & 7.69 & 7.65 & 0.4422 \\
\hline \multirow{2}{*}{ HGB } & \multirow{2}{*}{$\left(\times 10^{2} \mathrm{~g} / \mathrm{L}\right)$} & $\widehat{0}$ & 1.37 & 1.3 & 1.4 & 1.36 & 1.33 & 1.4 & 1.35 & 1.36 & 0.9311 \\
\hline & & 우 & 1.4 & 1.4 & 1.43 & 1.41 & 1.33 & 1.4 & 1.38 & 1.37 & 0.1583 \\
\hline \multirow{2}{*}{ HCT } & \multirow{2}{*}{$(\%)$} & $0^{\lambda}$ & 26.48 & 28.86 & 27.66 & 27.67 & 26.1 & 27.44 & 26.4 & 26.65 & 0.2703 \\
\hline & & q & 28.98 & 27.31 & 26.42 & 27.57 & 28.58 & 26.69 & 28.55 & 27.94 & 0.7240 \\
\hline \multirow{2}{*}{ PLT } & \multirow{2}{*}{$\left(\times 10^{8} / \mathrm{L}\right)$} & $\sigma^{\lambda}$ & 6.22 & 6.26 & 6.1 & 6.19 & 6.21 & 6.2 & 6.3 & 6.24 & 0.4940 \\
\hline & & o & 6.21 & 6.12 & 6.24 & 6.19 & 6.23 & 6.1 & 6.27 & 6.20 & 0.8810 \\
\hline \multirow{2}{*}{ PCT } & \multirow{2}{*}{$(\%)$} & $0^{\lambda}$ & 0.29 & 0.29 & 0.27 & 0.28 & 0.3 & 0.29 & 0.27 & 0.29 & 0.7780 \\
\hline & & o & 0.3 & 0.27 & 0.28 & 0.28 & 0.28 & 0.28 & 0.3 & 0.29 & 0.7780 \\
\hline \multirow{2}{*}{ PDW } & \multirow{2}{*}{$(\%)$} & $0^{\lambda}$ & 17.97 & 17.37 & 17.97 & 17.77 & 17.07 & 17.57 & 17.48 & 17.37 & 0.1911 \\
\hline & & q & 17.83 & 17.79 & 17.56 & 17.73 & 17.13 & 17 & 17.97 & 17.37 & 0.3174 \\
\hline \multirow{2}{*}{ MPV } & \multirow{2}{*}{ (fL) } & o & 4.55 & 4.59 & 4.56 & 4.57 & 4.51 & 4.56 & 4.51 & 4.53 & 0.1234 \\
\hline & & o & 4.52 & 4.63 & 4.62 & 4.59 & 4.54 & 4.55 & 4.65 & 4.58 & 0.8503 \\
\hline \multirow{2}{*}{ MCV } & \multirow{2}{*}{ (fL) } & $\widehat{0}$ & 37.88 & 37.58 & 37.73 & 37.73 & 36.2 & 37.6 & 36.9 & 36.90 & 0.1150 \\
\hline & & 우 & 36.97 & 36.02 & 36.89 & 36.63 & 36.6 & 36.97 & 36.47 & 36.68 & 0.8826 \\
\hline
\end{tabular}

2 Abbreviation: WBC, White Blood Cell Count; RBC, Red Blood Count; HGB, Hemoglobin; HCT,

3 Hematocrit; PLT, Platelet; PCT, Thrombolytic; PDW, Platelet Distribution Width; MPV, Mean

4 Platelet Volume; MCV, Mean Corpuscular Volume. 
Table S7. The influence of D-TTK001 on the hematology and coagulation of rats

\begin{tabular}{|c|c|c|c|c|c|c|c|c|c|c|c|c|}
\hline \multirow{2}{*}{\multicolumn{2}{|c|}{ Index }} & \multirow{3}{*}{$\begin{array}{c}\text { Group } \\
\text { No. } \\
\hat{\sigma}\end{array}$} & \multicolumn{3}{|c|}{$5 \%$ Glu } & \multirow{3}{*}{$\begin{array}{c}\text { Mean } \\
6.55\end{array}$} & \multicolumn{4}{|c|}{ D-TK } & \multirow{3}{*}{$\begin{array}{c}\text { Mean } \\
19.56\end{array}$} & \multirow{3}{*}{$\begin{array}{l}\text { P value } \\
0.7869\end{array}$} \\
\hline & & & \multirow{2}{*}{$\begin{array}{c}\mathbf{1} \\
31.44\end{array}$} & \multirow{2}{*}{$\begin{array}{c}\mathbf{2} \\
17.36\end{array}$} & \multirow{2}{*}{$\begin{array}{c}\mathbf{3} \\
3.51\end{array}$} & & \multirow{2}{*}{$\begin{array}{c}\mathbf{1} \\
26.91\end{array}$} & \multirow{2}{*}{$\begin{array}{c}2 \\
19.96\end{array}$} & \multirow{2}{*}{$\begin{array}{c}\mathbf{3} \\
16.3\end{array}$} & \multirow{2}{*}{$\begin{array}{c}4 \\
15.07\end{array}$} & & \\
\hline WBC & $\left(\times 10^{9} / \mathrm{I}\right)$ & & & & & & & & & & & \\
\hline WDC & $($ A $10 \%)$ & q & 26.71 & 39.27 & 20.92 & 28.97 & 14.74 & 18.76 & 15.78 & 19.37 & 17.16 & 0.0545 \\
\hline \multirow{2}{*}{ RBC } & \multirow{2}{*}{$\left(\times 10^{12} / \mathrm{L}\right)$} & 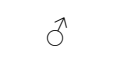 & 7.46 & 8.33 & 7.06 & 7.62 & 8.16 & 7.9 & 7.62 & 8.76 & 8.11 & 0.2987 \\
\hline & & q & 7.63 & 7.49 & 7.78 & 7.63 & 7.91 & 8.23 & 8.53 & 8.29 & $8.24^{\mathrm{a}}$ & 0.0149 \\
\hline \multirow{2}{*}{ HGB } & \multirow{2}{*}{$(g / L)$} & $\widehat{\partial}$ & 147 & 161 & 141 & 150 & 154 & 159 & 159 & 171 & 161 & 0.1513 \\
\hline & & o & 150 & 142 & 147 & 146 & 145 & 150 & 158 & 150 & 151 & 0.2899 \\
\hline \multirow{2}{*}{ HCT } & \multirow{2}{*}{ (\%) } & 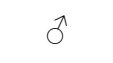 & 45.1 & 49.7 & 43.8 & 46.2 & 48.7 & 47.3 & 48.3 & 52 & 49.1 & 0.195 \\
\hline & & o & 45 & 43.8 & 44.5 & 44.4 & 44.5 & 46.8 & 47.7 & 46.3 & 46.3 & 0.0763 \\
\hline \multirow{2}{*}{ MCV } & \multirow{2}{*}{ (fL) } & $\hat{\sigma}$ & 60.5 & 59.7 & 62.1 & 60.8 & 59.7 & 59.8 & 63.4 & 59.3 & 60.6 & 0.8718 \\
\hline & & q & 58.9 & 58.5 & 57.3 & 58.2 & 56.2 & 56.9 & 55.9 & 55.9 & $56.2^{\mathrm{b}}$ & 0.0093 \\
\hline \multirow{2}{*}{ МСH } & \multirow{2}{*}{ (pg) } & $\hat{\sigma}$ & 19.7 & 19.4 & 20 & 19.7 & 18.9 & 20.1 & 20.8 & 19.5 & 19.8 & 0.8136 \\
\hline & & q & 19.6 & 19 & 18.9 & 19.2 & 18.4 & 18.2 & 18.5 & 18.1 & $18.3^{b}$ & 0.0095 \\
\hline \multirow{2}{*}{ МСНС } & \multirow{2}{*}{$(g / L)$} & $\delta$ & 326 & 325 & 322 & 324 & 316 & 336 & 329 & 330 & 328 & 0.5312 \\
\hline & & 우 & 333 & 325 & 330 & 329 & 327 & 320 & 330 & 324 & 325 & 0.2572 \\
\hline \multirow{2}{*}{ PLT } & $\left(\times 10^{9} / \mathbf{I}\right)$ & $\hat{0}$ & 1473 & 1037 & 1626 & 1379 & 1135 & 996 & 943 & 1116 & 1047 & 0.0895 \\
\hline & $(\times 107 \mathbf{L})$ & q & 1552 & 1359 & 1875 & 1595 & 968 & 695 & 1160 & 1121 & $986^{\mathrm{a}}$ & 0.0185 \\
\hline $\mathbf{N}$ & & $\hat{\sigma}$ & 26.7 & 8.2 & 8.5 & 14.5 & 7.2 & 5.6 & 10.6 & 9.8 & 8.3 & 0.2969 \\
\hline $\mathbf{N}$ & (\%) & 우 & 11.5 & 9.9 & 3.4 & 8.3 & 7.3 & 6 & 8.6 & 8.4 & 7.6 & 0.7648 \\
\hline $\mathbf{I}$ & & 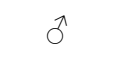 & 69 & 84.7 & 87.2 & 80.3 & 87.8 & 87.8 & 74.4 & 83.8 & 83.5 & 0.6253 \\
\hline $\mathbf{L}$ & (\%) & 우 & 83.6 & 85.7 & 92.9 & 87.4 & 78 & 88 & 85 & 85.1 & 84 & 0.3724 \\
\hline & & $\hat{\sigma}$ & 2.5 & 2.8 & 1.3 & 2.2 & 1.8 & 2 & 3 & 2.9 & 2.4 & 0.6876 \\
\hline М & $(\%)$ & q & 2.4 & 1.5 & 1.4 & 1.8 & 2.9 & 2.9 & 2.4 & 2.7 & $2.7^{\mathrm{a}}$ & 0.0243 \\
\hline $\mathbf{F}$ & $(0 / 0)$ & $\hat{\sigma}$ & 0.3 & 0.3 & 1.5 & 0.7 & 0.2 & 0.3 & 0.5 & 0.2 & 0.3 & 0.2986 \\
\hline $\mathbf{E}$ & (1/o) & q & 0.6 & 0.2 & 0.7 & 0.5 & 0.5 & 0.7 & 0.7 & 0.9 & 0.7 & 0.2672 \\
\hline & & $\delta$ & 6.06 & 3.82 & 8.16 & 6.01 & 5.27 & 4.84 & 4.13 & 3.23 & 4.37 & 0.2198 \\
\hline Ret & (\%) & q & 7.9 & 7.29 & 5.3 & 6.83 & 4.77 & 4.33 & 5 & 6.18 & 5.07 & 0.0808 \\
\hline PT & & $\widehat{0}$ & 18.3 & 32 & 14.3 & 21.5 & 19.6 & 21.5 & 18.8 & 16.7 & 19.2 & 0.6291 \\
\hline P1 & (S) & q & 17.3 & 14.1 & 14.7 & 15.4 & 13.7 & 15.4 & 15.6 & 14.9 & 14.9 & 0.6488 \\
\hline APTT & (s) & $\partial$ & 25.2 & 30.8 & 21.9 & 26 & 25.1 & 25.9 & 25.6 & 26.2 & 25.7 & 0.9079 \\
\hline & & q & 27 & 23.9 & 23.7 & 24.9 & 22.1 & 21.3 & 22.7 & 22.8 & $22.2^{\mathrm{a}}$ & 0.0434 \\
\hline
\end{tabular}

2 NOTE: $\mathrm{a}, \mathrm{p}<0.05 ; \mathrm{b}, \mathrm{p}<0.01$, vs $5 \%$ Glu group.

3 Abbreviation: WBC, White Blood Cell Count; RBC, Red Blood Count; HGB, Hemoglobin; HCT,

4 Hematocrit; MCV, Mean Corpuscular Volume; MCH, Mean Corpuscular Hemoglobin; MCHC,

5 Mean Corpuscular Hemoglobin Concentration; PLT, Platelet; N, Neutrophil; L, Lymphocyte; M,

6 Monocytes; E, Eosinophil; Ret, Reticulocyte; PT, Prothrombin Time; APTT, The Activated

$7 \quad$ Partial Thromboplastin Time. 
Table S8. The influence of D-TTK001 on serum biochemical index of rats

\begin{tabular}{|c|c|c|c|c|c|c|c|c|c|c|c|}
\hline \multirow{2}{*}{ Index } & \multirow{2}{*}{ Group } & \multicolumn{3}{|c|}{$5 \%$ Glu } & \multirow{2}{*}{ Mean } & \multicolumn{4}{|c|}{ D-TK } & \multirow{2}{*}{ Mean } & \multirow{2}{*}{$\begin{array}{c}P \\
\text { value }\end{array}$} \\
\hline & & 1 & 2 & 3 & & 1 & 2 & 3 & 4 & & \\
\hline ALT & o & 31.1 & 38.5 & 30.6 & 33.4 & 39.1 & 46.2 & 57.4 & 58.5 & $50.3^{*}$ & 0.0354 \\
\hline$(\mathrm{U} / \mathrm{L})$ & q & 29.1 & 27.2 & 27.3 & 27.9 & 31.3 & 31.8 & 25.4 & 26 & 28.6 & 0.7294 \\
\hline AST & $\widehat{0}$ & 172.4 & 229.4 & 173.7 & 191.8 & 193.4 & 199.2 & 207.2 & 207.4 & 201.8 & 0.5658 \\
\hline$(\mathrm{U} / \mathrm{L})$ & q & 177.9 & 149.7 & 223.6 & 183.7 & 187.3 & 125.9 & 174.7 & 192.9 & 170.2 & 0.6183 \\
\hline ALP & $\hat{\sigma}$ & 190.9 & 187.7 & 164.5 & 181 & 267.8 & 319.5 & 169.9 & 243.9 & 250.3 & 0.1236 \\
\hline$(\mathrm{U} / \mathrm{L})$ & q & 67.7 & 100.4 & 86.2 & 84.8 & 66.8 & 81.3 & 91.2 & 101.3 & 85.2 & 0.9753 \\
\hline BUN & $\hat{\sigma}$ & 5.83 & 8.56 & 7.35 & 7.25 & 7.81 & 7.22 & 6.9 & 8.24 & 7.54 & 0.7094 \\
\hline$(\mathrm{mmol} / \mathrm{L})$ & q & 6.66 & 6.87 & 6.13 & 6.55 & 8.32 & 11.47 & 8.16 & 9.06 & $9.25^{*}$ & 0.0329 \\
\hline Crea & $\widehat{\sigma}$ & 50.4 & 61.4 & 67.1 & 59.6 & 66.7 & 56.5 & 58.4 & 59.1 & 60.2 & 0.916 \\
\hline$(\mu \mathrm{mol} / \mathrm{L})$ & q & 61.8 & 75.4 & 64.4 & 67.2 & 58.4 & 72.4 & 62.9 & 64 & 64.4 & 0.5964 \\
\hline $\mathrm{TP}$ & 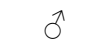 & 55.4 & 52 & 58.3 & 55.2 & 58.1 & 56.1 & 52.7 & 56.2 & 55.8 & 0.7995 \\
\hline$(\mathrm{g} / \mathrm{L})$ & q & 60.8 & 55.8 & 61.5 & 59.4 & 58.7 & 51.6 & 58.3 & 58.2 & 56.7 & 0.3372 \\
\hline ALB & $\hat{0}$ & 19.2 & 18.5 & 20.5 & 19.4 & 21.5 & 22.7 & 19.1 & 20.1 & 20.9 & 0.2275 \\
\hline$(\mathrm{g} / \mathrm{L})$ & q & 22.3 & 20.8 & 24.4 & 22.5 & 22.6 & 18.9 & 22 & 24 & 21.9 & 0.7025 \\
\hline GLU & $\hat{0}$ & 6.84 & 6.92 & 7.24 & 7 & 7.6 & 6.11 & 8.15 & 7.18 & 7.26 & 0.6389 \\
\hline$(\mathrm{mmol} / \mathrm{L})$ & q & 7.05 & 11.19 & 8.67 & 8.97 & 6.95 & 6.9 & 6.68 & 8.2 & 7.18 & 0.161 \\
\hline TCHO & $\hat{0}$ & 1.38 & 0.75 & 1.84 & 1.32 & 1.57 & 1.74 & 1.16 & 1.82 & 1.57 & 0.4667 \\
\hline$(\mathrm{mmol} / \mathrm{L})$ & q & 1.69 & 1.2 & 1.84 & 1.58 & 1.66 & 1.37 & 1.15 & 1.58 & 1.44 & 0.5455 \\
\hline TBIL & $\hat{0}$ & 0.33 & 0.69 & 0.6 & 0.54 & 0.49 & 0.77 & 0.62 & 0.64 & 0.63 & 0.4622 \\
\hline$(\mu \mathrm{mol} / \mathrm{L})$ & 우 & 0.47 & 0.44 & 0.14 & 0.35 & 0.5 & 0.46 & 0.57 & 0.65 & 0.55 & 0.1115 \\
\hline $\mathrm{Tg}$ & $\hat{0}$ & 0.33 & 0.26 & 0.48 & 0.36 & 0.4 & 0.43 & 0.54 & 0.71 & 0.52 & 0.1604 \\
\hline$(\mathrm{mmol} / \mathrm{L})$ & ㅇ & 0.3 & 0.37 & 0.24 & 0.3 & 0.24 & 0.34 & 0.33 & 0.36 & 0.32 & 0.7629 \\
\hline $\mathrm{CK}$ & $\hat{0}$ & 1215.8 & 1573.7 & 1316 & 1368.5 & 1406 & 1437.7 & 1328.3 & 2507.1 & 1669.8 & 0.4201 \\
\hline$(\mathrm{U} / \mathrm{L})$ & q & 1140.9 & 765 & 1668.8 & 1191.6 & 1189.8 & 568.8 & 1062.7 & 1127.8 & 987.3 & 0.4927 \\
\hline$\gamma-\mathrm{GT}$ & $\hat{\sigma}$ & 1.1 & 1.8 & 1.9 & 1.6 & 1.9 & 1.5 & 2.2 & 1.2 & 1.7 & 0.7771 \\
\hline$(\mathrm{U} / \mathrm{L})$ & q & 1.1 & 1.4 & 1.3 & 1.3 & 1.9 & 1.9 & 1.7 & 1.4 & $1.7 *$ & 0.0338 \\
\hline LDH & 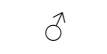 & 2165.3 & 2745.8 & 1969.4 & 2293.5 & 2110.4 & 2043.3 & 2061.7 & 1953.3 & 2042.2 & 0.262 \\
\hline$(\mathrm{U} / \mathrm{L})$ & q & 1968.9 & 1585.7 & 2636.9 & 2063.8 & 2054.9 & 1084.8 & 2097.2 & 2301.4 & 1884.6 & 0.6815 \\
\hline GLOB & $\hat{\sigma}$ & 36.2 & 33.5 & 37.8 & 35.8 & 36.6 & 33.4 & 33.6 & 36.1 & 34.9 & 0.5552 \\
\hline$(\mathrm{g} / \mathrm{L})$ & o & 38.5 .0 & 35 & 37.1 & 36.9 & 36.1 & 32.7 & 36.3 & 34.2 & 34.8 & 0.1823 \\
\hline \multirow{2}{*}{$\mathrm{A} / \mathrm{G}$} & $\hat{0}$ & 0.53 & 0.55 & 0.54 & 0.54 & 0.59 & 0.68 & 0.57 & 0.56 & 0.6 & 0.1265 \\
\hline & q & 0.58 & 0.59 & 0.66 & 0.61 & 0.63 & 0.58 & 0.61 & 0.7 & 0.63 & 0.61 \\
\hline AST & $\widehat{0}$ & 5.54 & 5.96 & 5.68 & 5.73 & 4.95 & 4.31 & 3.61 & 3.55 & $4.11^{*}$ & 0.0102 \\
\hline /ALT & q & 6.11 & 5.5 & 8.19 & 6.6 & 5.98 & 3.96 & 6.88 & 7.42 & 6.06 & 0.6525 \\
\hline
\end{tabular}

2 NOTE: $\mathrm{a}, \mathrm{p}<0.05$, vs $5 \%$ Glu group.

3 Abbreviation: ALT, Alanine Aminotransferase; AST, Aspartate Aminotransferase; ALP, Alkaline

4 Phosphatase; BUN, Blood Urea Nitrogen; Crea, Creatinine; TP, Total Protein; ALB, Albumin;

5 GLU, Glucose; TCHO, Total Cholesterol; TBIL, Total Bilirubin; Tg, Triglyceride; CK, Creatine

6 Kinase; $\Gamma$-GT, Gamma-Glutamyltransferase; LDH, Lactate Dehydrogenase; GLOB, Globulin;

7 A/G, Albumin/ Globulin. 
1 Table S9. The influence of D-TTK001 on blood electrolyte of rats

\begin{tabular}{|c|c|c|c|c|c|c|c|c|}
\hline Group & $\begin{array}{c}\text { No./ } \\
\text { Gender }\end{array}$ & $\begin{array}{c}\mathbf{K}^{+} \\
(\mathbf{m m o l} / \mathbf{L})\end{array}$ & $\begin{array}{c}\mathrm{Na}^{+} \\
(\mathrm{mmol} / \mathrm{L})\end{array}$ & $\begin{array}{c}\mathrm{Cl}^{-} \\
(\mathrm{mmol} / \mathrm{L})\end{array}$ & $\begin{array}{c}\text { No./ } \\
\text { Gender }\end{array}$ & $\begin{array}{c}\mathbf{K}^{+} \\
(\mathbf{m m o l} / \mathbf{L})\end{array}$ & $\begin{array}{c}\mathrm{Na}^{+} \\
(\mathrm{mmol} / \mathrm{L})\end{array}$ & $\begin{array}{c}\mathrm{Cl}^{-} \\
(\mathrm{mmol} / \mathrm{L})\end{array}$ \\
\hline \multirow{3}{*}{$5 \%$ Glu } & $1 \widehat{\delta}$ & 4.53 & 139.4 & 105 & 1 우 & 4.37 & 139.4 & 106.7 \\
\hline & $2 \hat{\jmath}$ & 4.4 & 139.6 & 106.1 & $2 q$ & 4.15 & 137.2 & 105 \\
\hline & $3 \hat{\circ}$ & 4.29 & 140.7 & 106 & 3 운 & 4.54 & 140.2 & 107.5 \\
\hline \multicolumn{2}{|c|}{ Mean } & 4.41 & 139.9 & 105.7 & & 4.35 & 138.9 & 106.4 \\
\hline \multicolumn{2}{|c|}{ SD } & 0.12 & 0.7 & 0.6 & & 0.2 & 1.6 & 1.3 \\
\hline \multirow{4}{*}{ D-TK } & $1 \hat{\jmath}$ & 4.22 & 141.2 & 107.2 & 1 ㅇ & 4.33 & 139.6 & 108.1 \\
\hline & $2 \hat{\jmath}$ & 4.56 & 139.9 & 106.1 & $2 q$ & 4.09 & 140.4 & 109.6 \\
\hline & $3 \widehat{\jmath}$ & 4.03 & 138.3 & 105.3 & 3 ㅇ & 4.43 & 139.9 & 109.1 \\
\hline & $40^{\pi}$ & 4.62 & 139.4 & 107.8 & $4 ㅇ$ & 4.18 & 138.9 & 107.4 \\
\hline \multicolumn{2}{|c|}{ Mean } & 4.36 & 139.7 & 106.6 & & 4.26 & 139.7 & 108.6 \\
\hline \multicolumn{2}{|c|}{ SD } & 0.28 & 1.2 & 1.1 & & 0.15 & 0.6 & 1 \\
\hline \multicolumn{2}{|c|}{$P$ value } & 0.7909 & 0.8097 & 0.2683 & & 0.4951 & 0.4018 & 0.0525 \\
\hline
\end{tabular}

2 Abbreviation: $\mathrm{K}^{+}$, Potassium ion; $\mathrm{Na}^{+}$, Sodium ion, $\mathrm{Cl}^{-}$, Chloride ion. 
1 Table S10. The influence of D-TTK001 on organ weight of rats (g)

\begin{tabular}{|c|c|c|c|c|c|c|c|c|c|c|c|}
\hline \multirow{2}{*}{ Index } & \multirow{2}{*}{$\begin{array}{c}\text { Group } \\
\text { No. }\end{array}$} & \multicolumn{3}{|c|}{$5 \%$ Glu } & \multirow{2}{*}{ Mean } & \multicolumn{4}{|c|}{ D-TK } & \multirow{2}{*}{ Mean } & \multirow{2}{*}{$P$ value } \\
\hline & & 1 & 2 & 3 & & 1 & 2 & 3 & 4 & & \\
\hline \multirow{2}{*}{ Heart } & $\hat{\sigma}$ & 1.273 & 1.059 & 1.313 & 1.215 & 1.119 & 1.269 & 1.152 & 1.109 & 1.162 & 0.534 \\
\hline & q & 0.848 & 0.917 & 0.909 & 0.891 & 0.984 & 0.878 & 0.953 & 1.06 & 0.969 & 0.169 \\
\hline \multirow{2}{*}{ Liver } & $\widehat{0}$ & 10.813 & 8.923 & 11.548 & 10.428 & 8.995 & 10.187 & 10.504 & 8.993 & 9.67 & 0.389 \\
\hline & q & 7.615 & 8.102 & 6.723 & 7.48 & 7.35 & 5.784 & 7.315 & 7.529 & 6.995 & 0.446 \\
\hline \multirow{2}{*}{ Spleen } & o & 1.199 & 1.046 & 1.135 & 1.127 & 0.916 & 1.098 & 1.251 & 0.813 & 1.02 & 0.415 \\
\hline & o & 0.971 & 0.815 & 0.8 & 0.862 & 0.754 & 0.527 & 0.817 & 0.758 & 0.714 & 0.155 \\
\hline \multirow{2}{*}{ Kidneys } & 0 & 2.557 & 2.082 & 2.369 & 2.336 & 2.402 & 2.647 & 2.537 & 2.206 & 2.448 & 0.518 \\
\hline & 우 & 1.75 & 1.752 & 1.929 & 1.81 & 1.753 & 1.432 & 1.785 & 1.866 & 1.709 & 0.448 \\
\hline \multirow{2}{*}{ Thymus } & 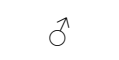 & 0.7 & 0.386 & 2.894 & 1.327 & 0.687 & 0.515 & 0.426 & 0.391 & 0.505 & 0.407 \\
\hline & q & 0.471 & 0.458 & 0.494 & 0.474 & 0.398 & 0.317 & 0.565 & 0.421 & 0.425 & 0.463 \\
\hline \multirow{2}{*}{ Testicles } & $\hat{\sigma}$ & 3.456 & 3.139 & 3.093 & 3.229 & 2.905 & 2.953 & 3.231 & 3.146 & 3.059 & 0.254 \\
\hline & q & 0.69 & 0.486 & 0.565 & 0.58 & 0.466 & 0.376 & 0.374 & 0.65 & 0.467 & 0.268 \\
\hline \multirow{2}{*}{ Epididymis } & $\hat{0}$ & 1.002 & 0.897 & 0.761 & 0.887 & 0.775 & 0.811 & 0.914 & 1.007 & 0.877 & 0.912 \\
\hline & q & 0.208 & 0.166 & 0.174 & 0.183 & 0.163 & 0.124 & 0.159 & 0.137 & 0.146 & 0.061 \\
\hline
\end{tabular}


1 Table S11. The influence of D-TTK001 on organ coefficients of rats (organ weight/body weight,

$2 \mathrm{mg} / \mathrm{g})$

\begin{tabular}{|c|c|c|c|c|c|c|c|c|c|c|c|}
\hline \multirow{2}{*}{ Index } & \multirow{2}{*}{$\begin{array}{c}\text { Group } \\
\text { No. }\end{array}$} & \multicolumn{3}{|c|}{$5 \%$ Glu } & \multirow{2}{*}{ Mean } & \multicolumn{4}{|c|}{ D-TK } & \multirow{2}{*}{ Mean } & \multirow{2}{*}{$P$ value } \\
\hline & & 1 & 2 & 3 & & 1 & 2 & 3 & 4 & & \\
\hline \multirow{2}{*}{ Heart } & 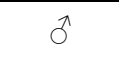 & 3.669 & 3.461 & 3.955 & 3.695 & 3.508 & 3.711 & 3.692 & 3.837 & 3.687 & 0.959 \\
\hline & 우 & 3.49 & 3.97 & 3.918 & 3.793 & 4.297 & 4.646 & 4.143 & 4.732 & $4.455^{\mathrm{a}}$ & 0.025 \\
\hline \multirow{2}{*}{ Liver } & 0 & 31.2 & 29.2 & 34.8 & 31.7 & 28.2 & 29.8 & 33.7 & 31.1 & 30.7 & 0.625 \\
\hline & q & 31.3 & 35.1 & 29 & 31.8 & 32.1 & 30.6 & 31.8 & 33.6 & 32 & 0.894 \\
\hline \multirow{2}{*}{ Spleen } & $\hat{0}$ & 3.455 & 3.418 & 3.419 & 3.431 & 2.871 & 3.211 & 4.01 & 2.813 & 3.226 & 0.512 \\
\hline & ㅇ & 3.996 & 3.528 & 3.448 & 3.657 & 3.293 & 2.788 & 3.552 & 3.384 & 3.254 & 0.156 \\
\hline \multirow{2}{*}{ Kidneys } & $\hat{0}$ & 7.369 & 6.804 & 7.136 & 7.103 & 7.53 & 7.74 & 8.131 & 7.633 & $7.759^{\mathrm{a}}$ & 0.025 \\
\hline & 우 & 7.202 & 7.584 & 8.315 & 7.7 & 7.655 & 7.577 & 7.761 & 8.33 & 7.831 & 0.717 \\
\hline \multirow{2}{*}{ Thymus } & 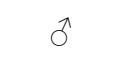 & 2.017 & 1.261 & 8.717 & 3.999 & 2.154 & 1.506 & 1.365 & 1.353 & 1.594 & 0.417 \\
\hline & q & 1.938 & 1.983 & 2.129 & 2.017 & 1.738 & 1.677 & 2.457 & 1.879 & 1.938 & 0.73 \\
\hline \multirow{2}{*}{ Testicles } & $\hat{0}$ & 9.96 & 10.258 & 9.316 & 9.845 & 9.107 & 8.635 & 10.356 & 10.886 & 9.746 & 0.887 \\
\hline & q & 2.84 & 2.104 & 2.435 & 2.46 & 2.035 & 1.989 & 1.626 & 2.902 & 2.138 & 0.42 \\
\hline \multirow{2}{*}{ Epididymis } & $\delta$ & 2.888 & 2.931 & 2.292 & 2.704 & 2.429 & 2.371 & 2.929 & 3.484 & 2.804 & 0.7877 \\
\hline & q & 0.856 & 0.719 & 0.75 & 0.775 & 0.712 & 0.656 & 0.691 & 0.612 & 0.668 & 0.0566 \\
\hline
\end{tabular}


1 Table S12. List of primers used in this paper

\begin{tabular}{|c|c|c|}
\hline \multicolumn{2}{|l|}{ Primer } & \multirow{2}{*}{$\frac{\text { Sequence }\left(\mathbf{5}^{\prime} \mathbf{- 3} \text { ') }\right.}{\text { CCTGCCAAGTATGATGACAT }}$} \\
\hline \multirow{2}{*}{ mouse-Gapdh } & Forward & \\
\hline & Reverse & GTTGCTGTAGCCGTATTCA \\
\hline \multirow{2}{*}{ GAPDH } & Forward & GAGTCAACGGATTTGGTCGT \\
\hline & Reverse & TTGATTTTGGAGGGATCTCG \\
\hline \multirow{2}{*}{$\begin{array}{c}\text { HBV X } \\
\text { (HBx/pgRNA) }\end{array}$} & Forward & ATGGCTGCTAGGCTGTGCTG \\
\hline & Reverse & TTAGGCAGAGGTGAAAAAGT \\
\hline \multirow{2}{*}{ pgRNA } & Forward & СТCCTCCAGCTTATAGACC \\
\hline & Reverse & GTGAGTGGGCCTACAAA \\
\hline HBV S & Forward & CCTGTATTCCCATCCCATC \\
\hline (HBs mRNA) & Reverse & TAGGGTTTAAATGTATACCC \\
\hline \multirow{2}{*}{$\begin{array}{c}\text { HBV e-c } \\
\text { (HBc/HBe mRNA) }\end{array}$} & Forward & TCAATCTCGGGAATCTCAATGTTA \\
\hline & Reverse & CCTAGCAGGCATAATCAATTGCAG \\
\hline \multirow{2}{*}{$\mathrm{HBV}$} & Forward & CCTAGTAGTCAGTTATGTCAAC \\
\hline & Reverse & TCTATAAGCTGGAGGAGTGCGA \\
\hline \multirow{2}{*}{ cccDNA } & Forward & CGTCTGTGCCTTCTCATCTGC \\
\hline & Reverse & GCACAGCTTGGAGGCTTGAA \\
\hline \multirow{2}{*}{ chip-cccDNA } & Forward & CTCCCCGTCTGTGCCTTCT \\
\hline & Reverse & GCCCCAAAGCCACCCAAG \\
\hline
\end{tabular}


1 Table S13. List of antibodies used in this paper

\begin{tabular}{lll}
\hline Antibody & Manufacture & Catalog Number \\
\hline HBx Polyclonal Antibody & Abcam & ab39716 \\
Ki67 Polyclonal Antibody & Proteintech & $19972-1-$ AP \\
Anti-GST-tag pAb & MBL & PM013 \\
Anti-His-tag mAb & MBL & D291-3 \\
Anti-HA-tag mAb & MBL & M180-3 \\
Anti-DDDDK-tag-mAb & MBL & M185-3L \\
Anti-HBXIP antibody & Abcam & ab157480 \\
Anti-Histone H3 antibody & Abcam & ab1791 \\
LaminB1 & proteintech & $12987-1-$ AP \\
Anti-DDB1 antibody & Abcam & ab109027 \\
Anti-KAT3B/p300 antibody & Abcam & ab14984 \\
CBP & Santa Cruz & sc-365387 \\
Anti-HDAC1 antibody & Abcam & ab1767 \\
Anti-SIRT1 antibody & Abcam & ab110304 \\
Anti-EZH2 antibody & Abcam & ab191250 \\
SMC6 Polyclonal Anbody & Abcam & ab155495 \\
APOBEC3B antibody & Abcam & ab184990 \\
MSL2 antibody & Novus & H00055167- D01P \\
SMC5 Polyclonal Anbody & Abcam & ab18038 \\
HBsAg Monoclonal Antibody & Abcam & ab68518 \\
HBcAg Monoclonal Antibody & Abcam & ab8639 \\
$\beta$-Actin Monoclonal Antibody & Sigma-Aldrich & A2228 \\
\hline
\end{tabular}




\section{Figures}

a

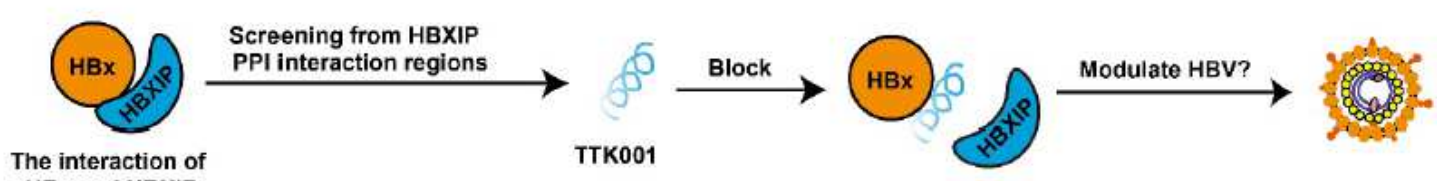

b

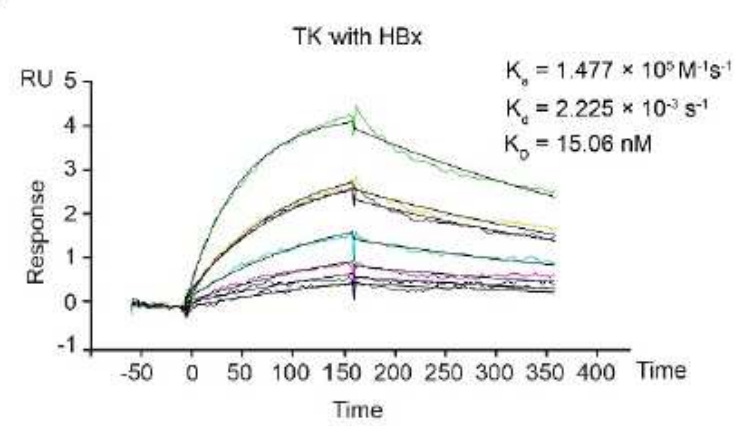

C

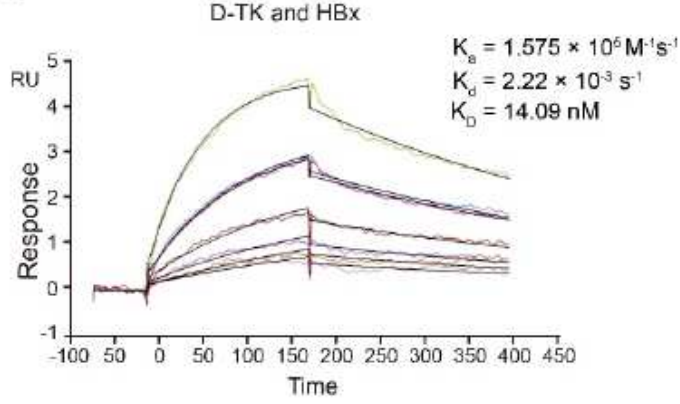

d

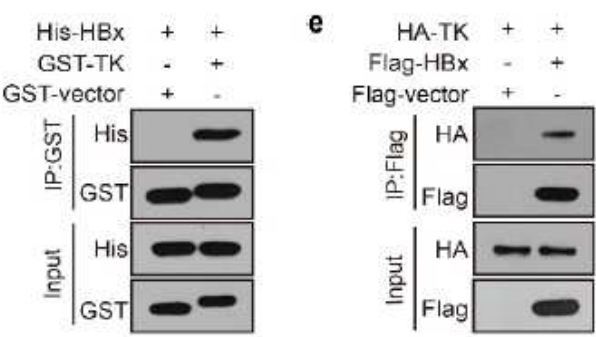

f HEK293T

g HepG2-NTCP (HBV de novo)
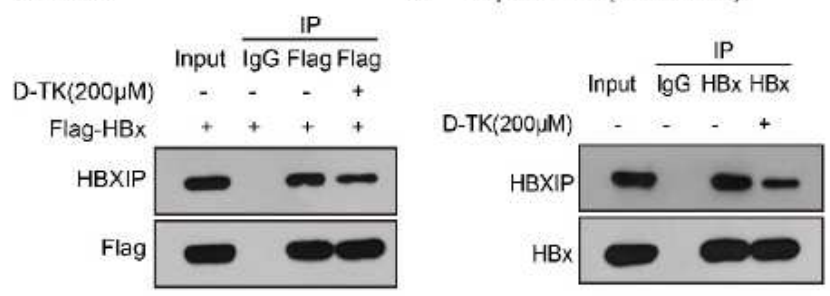

h
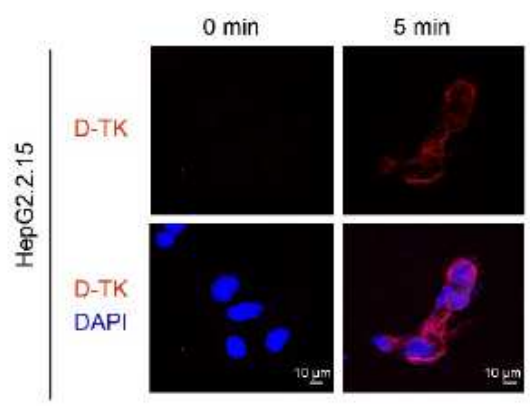

$15 \mathrm{~min}$
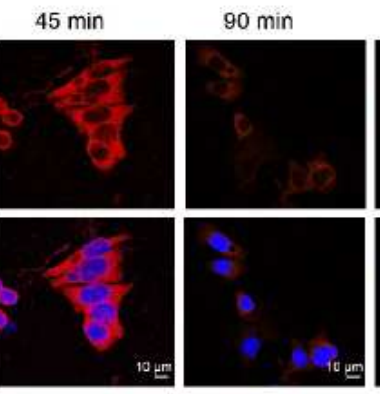

$180 \mathrm{~min}$

$240 \mathrm{~min}$
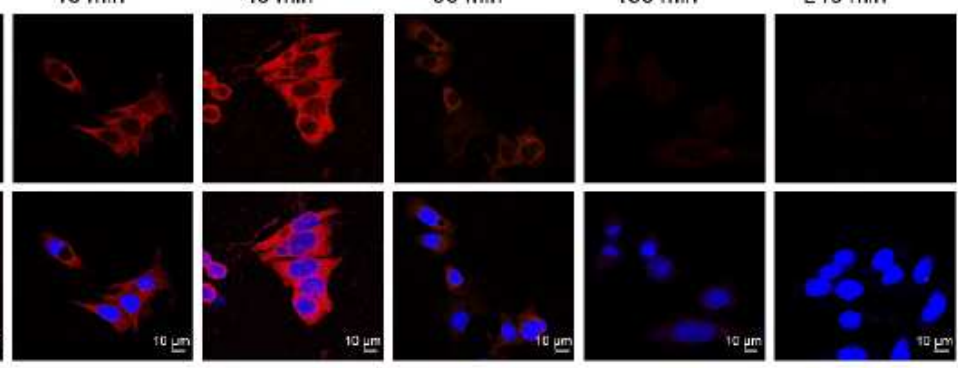

i
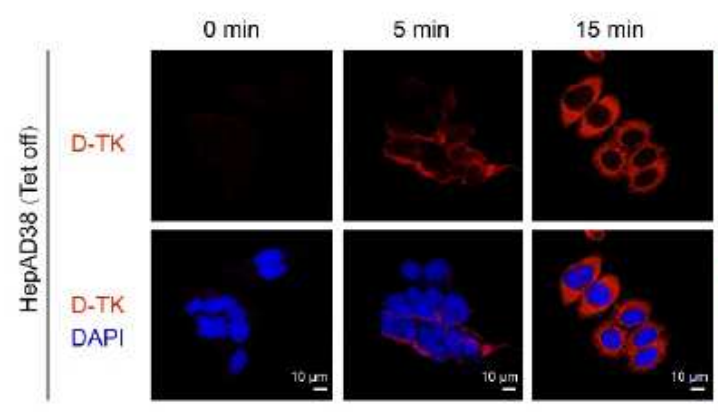

$45 \mathrm{~min}$

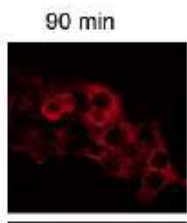

$180 \mathrm{~min}$

$240 \mathrm{~min}$
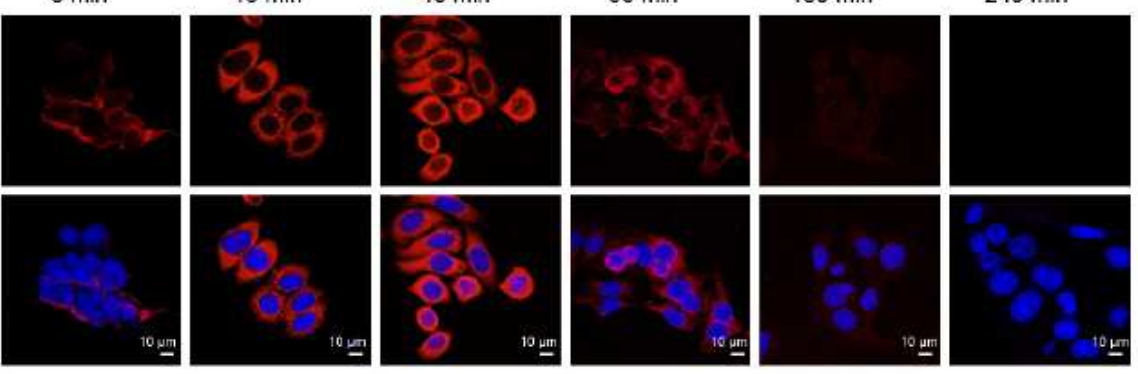

\section{Figure 1}

A new D-type polypeptide derived from HBXIP sequence is engineered. a, A model of strategy against HBV for TTK001. b, Affinity analysis of HBx binding to TTK001 using SPR. c, Affinity analysis of HBx binding to D-TTK001 using SPR. d, The interaction of HBx with D-TTK001 was tested by GST-Pull-down assays. e, 
Co-IP assays to test the binding of HBx and D-TTK001. HEK293T cells were transfected with plasmids Flag-HBX, and cells were incubated with HA-tagged TTK001 polypeptide. The interaction of HBx with TTK001 was examined by Co-IP and immunoblotting. $f$, The effect of D-TTK001 on the binding of HBXIP with exogenous HBx was measured by Co-IP assays in HEK293T cells transfected with plasmids FlagHBx and treated with D-TTK001 $(200 \mu \mathrm{M})$ for 7 days. g, The effect of D-TTK001 on the binding of HBXIP with endogenous HBx was measured by Co-IP assays in HBV de novo HepG2-NTCP cells treated with DTTK001 $(200 \mu \mathrm{M})$ for 7 days. h-i, Immunofluorescence analysis of D-TTK001 (red) in HepG2.2.15 and HepAD38 (Tet off) cells. HepG2.2.15 (h) and HepAD38 (i) cells were treated with red luciferin cy3-labeled D-TTK001 $(100 \mu \mathrm{M})$ and determined by immunofluorescence assays at different time points. DAPI (blue) stained the nuclei. Scale bars, $10 \mu \mathrm{m}$.

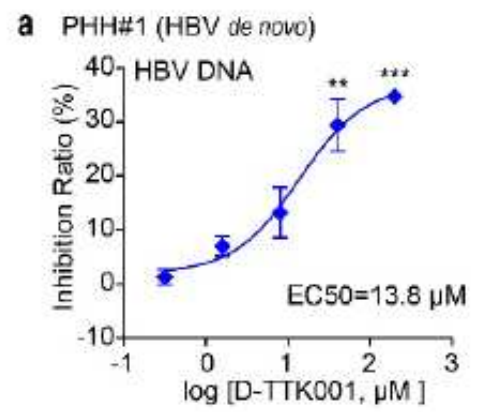

d $\mathrm{PHH \# 1} \mathrm{(HBV} \mathrm{de} \mathrm{novo)}$
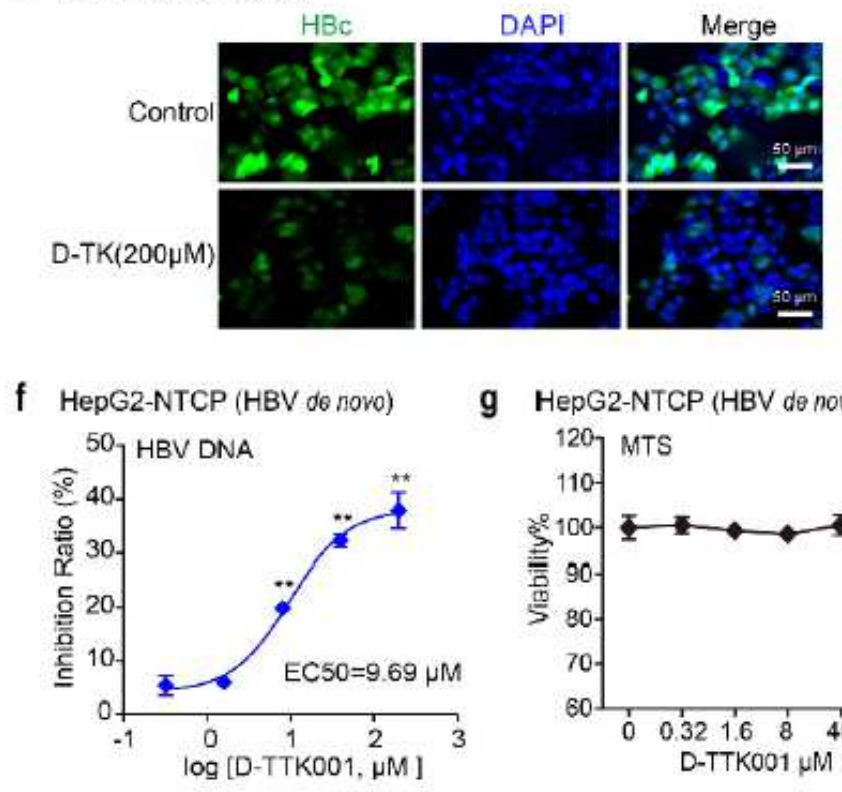

b $\mathrm{PHH \# 1} \mathrm{(HBV} \mathrm{de} \mathrm{novo)}$

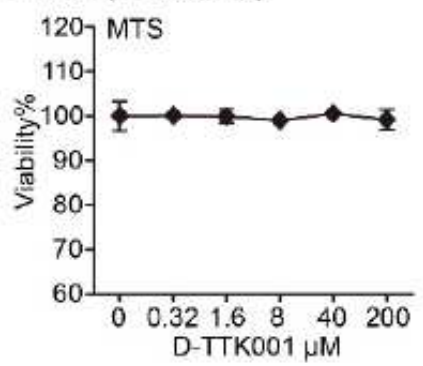

g HepG2-NTCP (HBV de novo)

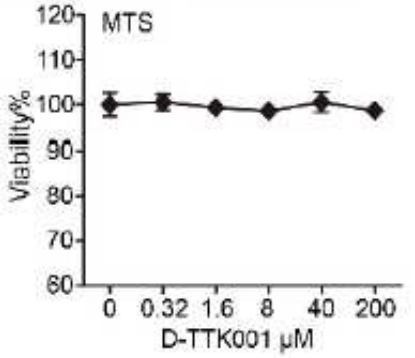

c PHH\#1 (HBV de novo)

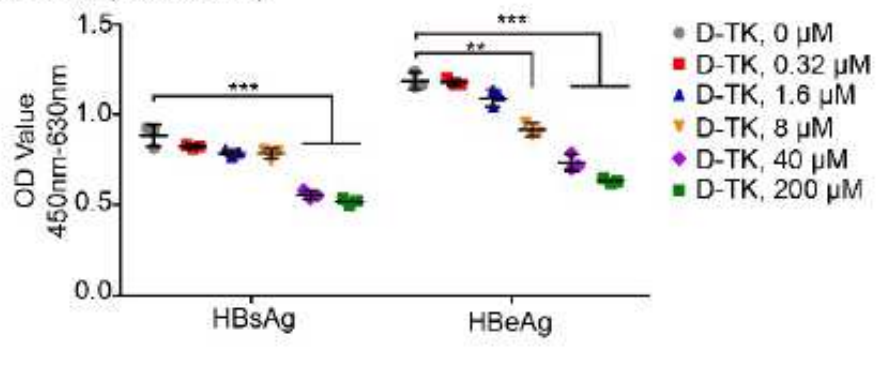

e PHH\#1 (HBV de novo)

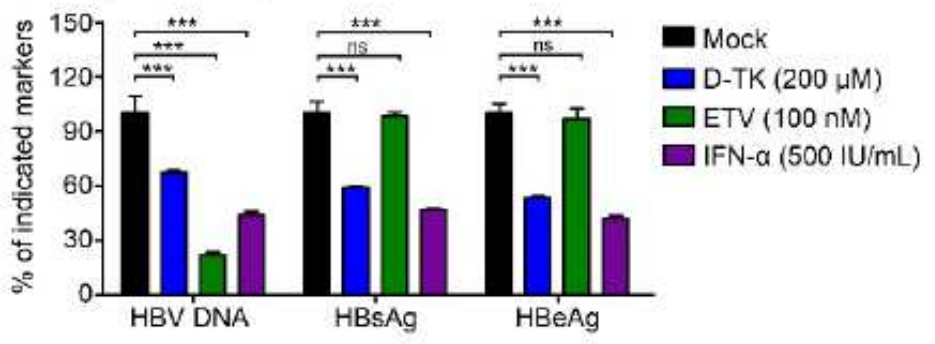

h HepG2-NTCP (HBV de novo)

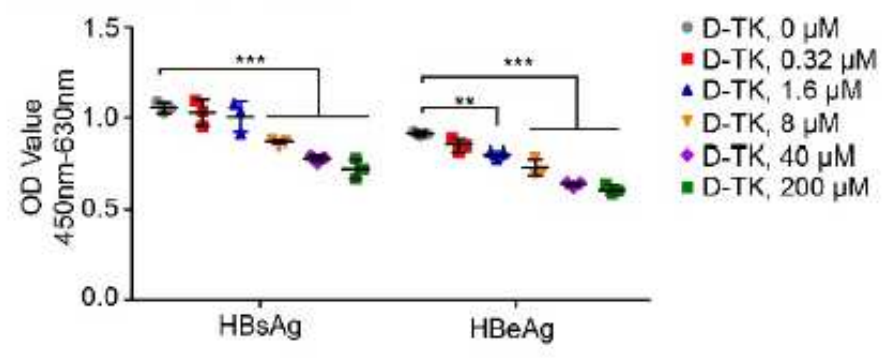

i HepG2-NTCP (HBV de nowo)

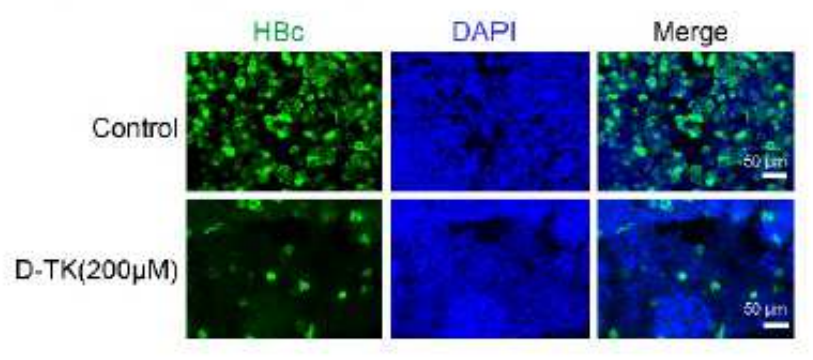

j HepG2-NTCP (HBV de novo)

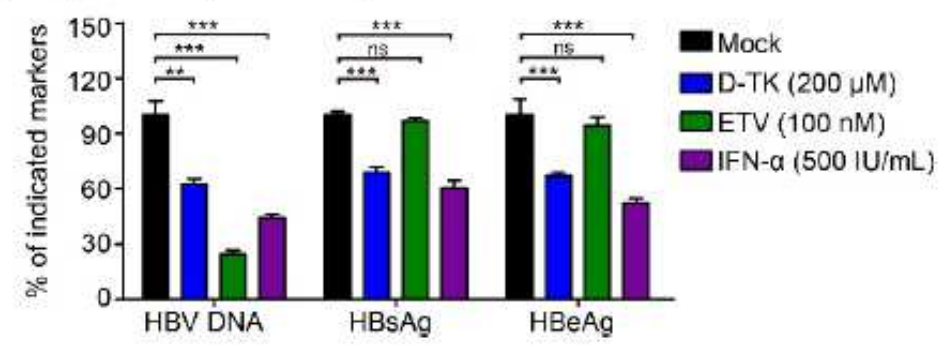

Figure 2 
Efficacy of D-TTK001 against HBV in vitro. a, The levels of HBV DNA were measured by qPCR in the supernatant of HBV de novo PHH cells. b, PHH cell viability was measured by MTS assay. c, The levels of HBsAg and HBeAg were examined by ELISA in the supernatant of HBV de novo PHH cells. $d$, The levels of $\mathrm{HBcAg}$ were determined by immunofluorescence staining in HBV de novo PHH cells. Scale bars, $50 \mu \mathrm{m}$. e, The levels of HBV DNA, HBsAg, and HBeAg were tested by qPCR and ELISA assays in the supernatant of HBV de novo PHH cells. $f$, The levels of HBV DNA were measured by qPCR in the supernatant of HBV de novo HepG2-NTCP cells. g, HepG2-NTCP cell viability was evaluated by MTS assays. $h$, The levels of HBsAg and HBeAg were examined by ELISA in the supernatant of HBV de novo HepG2-NTCP cells. i, The level of HBcAg was measured by immunofluorescence staining in HBV de novo HepG2-NTCP cells. Scale bars, $50 \mu \mathrm{m}$. j, The levels of HBV DNA, HBsAg, and HBeAg were determined by qPCR and ELISA assays in the supernatant of HBV de novo HepG2-NTCP cells. Data are represented as means $\pm S D(n=3)$. ns, no significant; ${ }^{*}<<0.05 ;{ }^{* \star} p<0.01 ; * \star \star p<0.001$ (Student's t test). 
HBV-HuHep-URG mice model

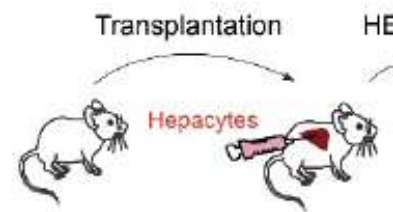

URG
$H B V$ inoculation

HBV particles

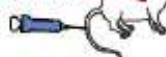

HBV-Huhep-URG b

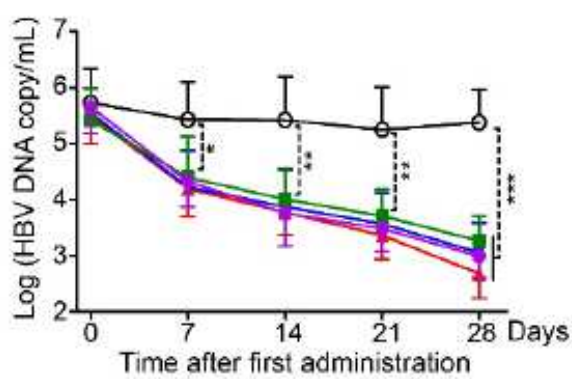

- $5 \%$ Glu

- 풀- D-TK, $2.5 \mathrm{mg} / \mathrm{kg}$

$\rightarrow$ D-TK, $5 \mathrm{mg} / \mathrm{kg}$

- D-TK, $10 \mathrm{mg} / \mathrm{kg}$

$\rightarrow-E T V, 0.076 \mathrm{mg} / \mathrm{kg}$

C

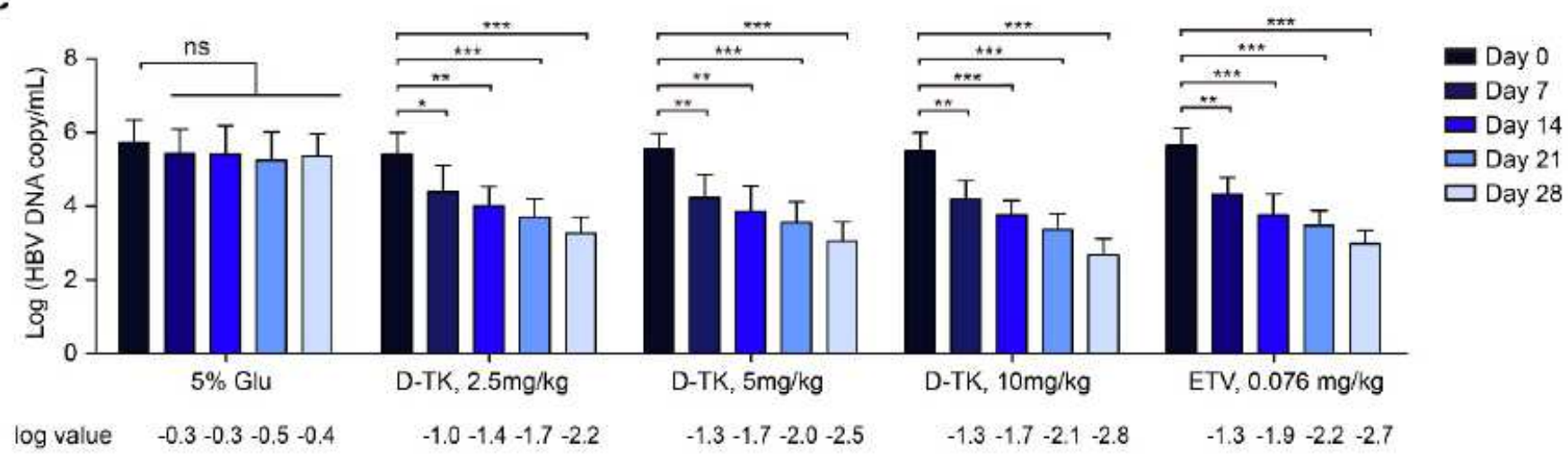

d

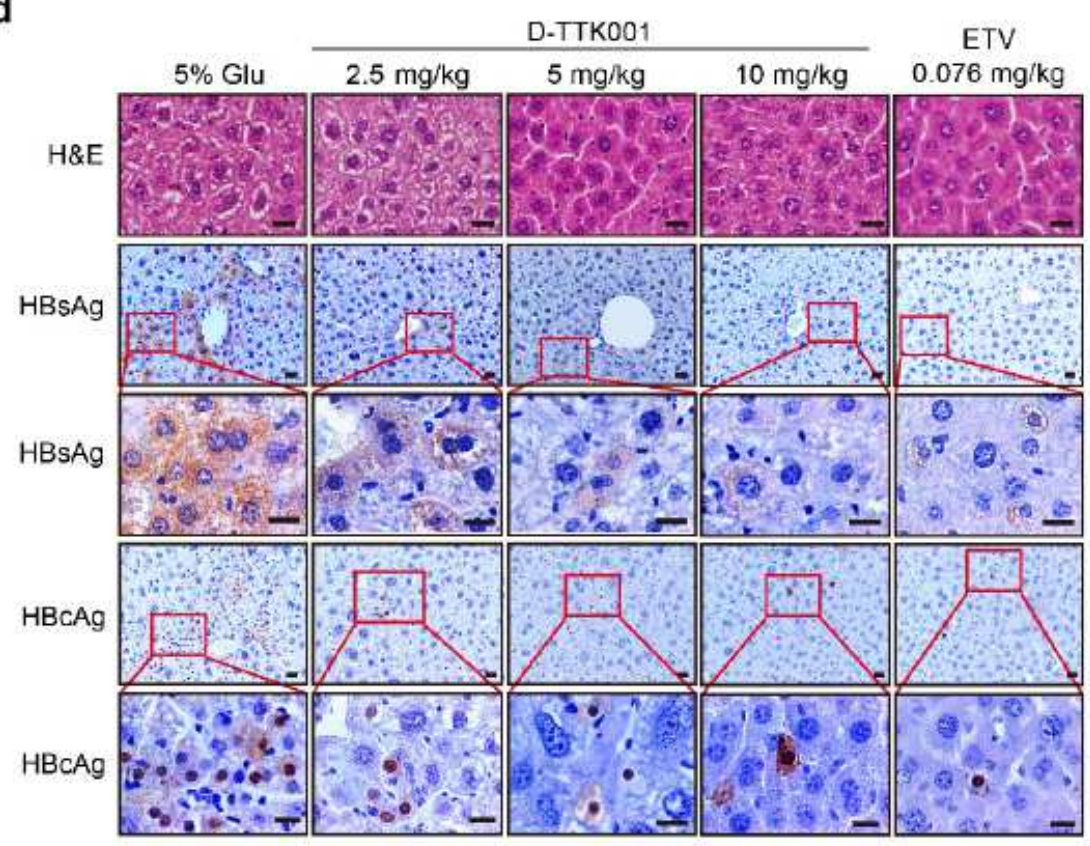

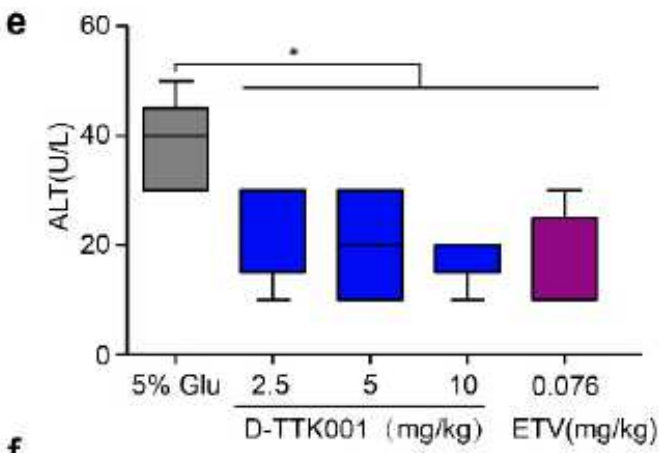

f

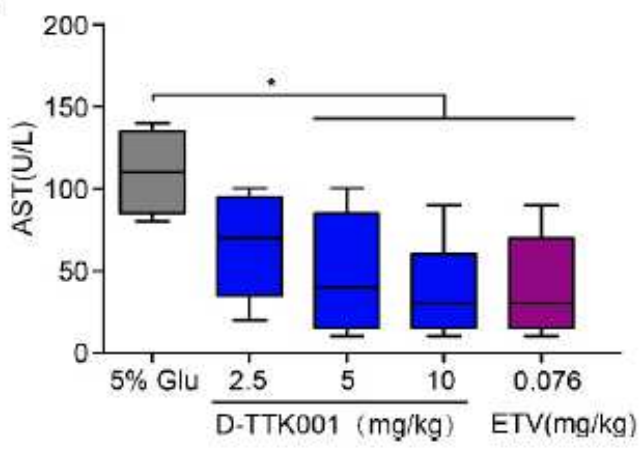

Figure 3

Efficacy of D-TTK001 against HBV in HBV-infected human liver-chimeric mice. a, A model of HBV-infected human liver-chimeric mice (HBV-Huhep-URG mice). b-c, The level of HBV DNA was tested by qPCR in the serum of human liver-chimeric mice. The HBV-Huhep-URG mice were given dose-administration $(2.5,5,10$ $\mathrm{mg} / \mathrm{kg}$ ) once a day for 4 weeks. Serum samples were collected before exposure (Day 0) and 1, 2, 3, 4 weeks post-exposure (Day 7, Day 14, Day 21, Day 28), respectively. d, Pathological observation and immunohistochemistry staining for HBsAg and HBcAg were measured in the liver tissues from HBV- 
Huhep-URG mice with different treatments. Scale bars: $20 \mu \mathrm{m}$. e-f, The levels of ALT and AST were evaluated by ALT/AST detection kits in the serum of HBV-Huhep-URG mice. The HBV-Huhep-URG mice were given dose-administration once a day for 4 weeks. Serum samples were collected after exposure (Day 28). Data are represented as means $\pm S D(n=3) .{ }^{*} p<0.05 ; * * p<0.01 ; * \star * p<0.001$ (Student's t test).

a $\mathrm{PHHH1}$ (HBV de novo)
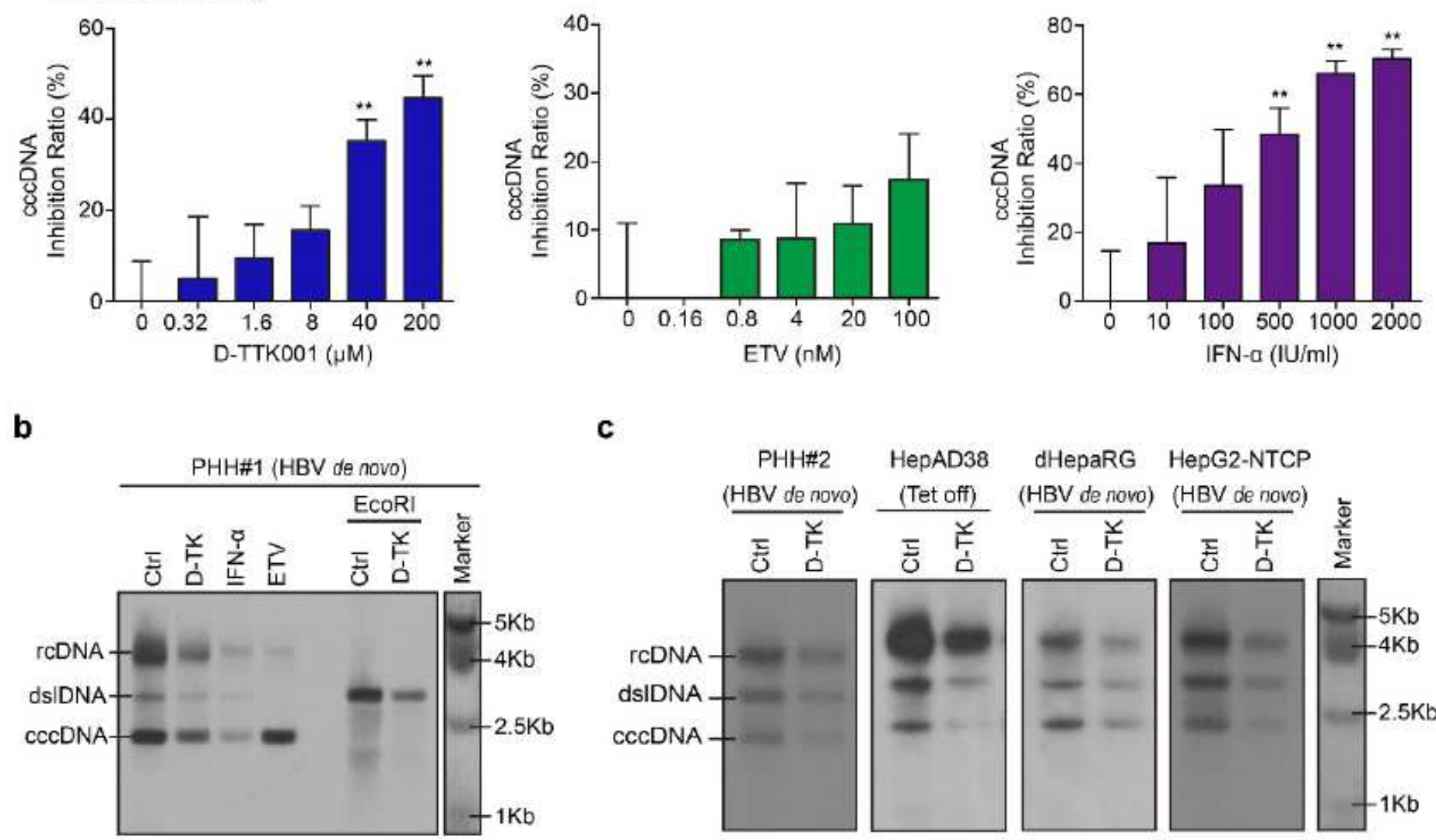

c

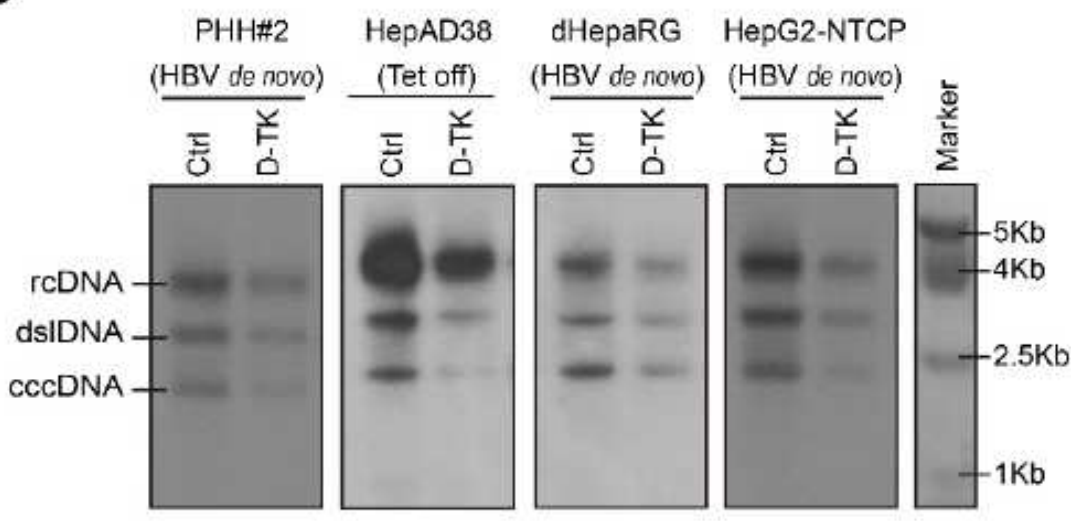

d

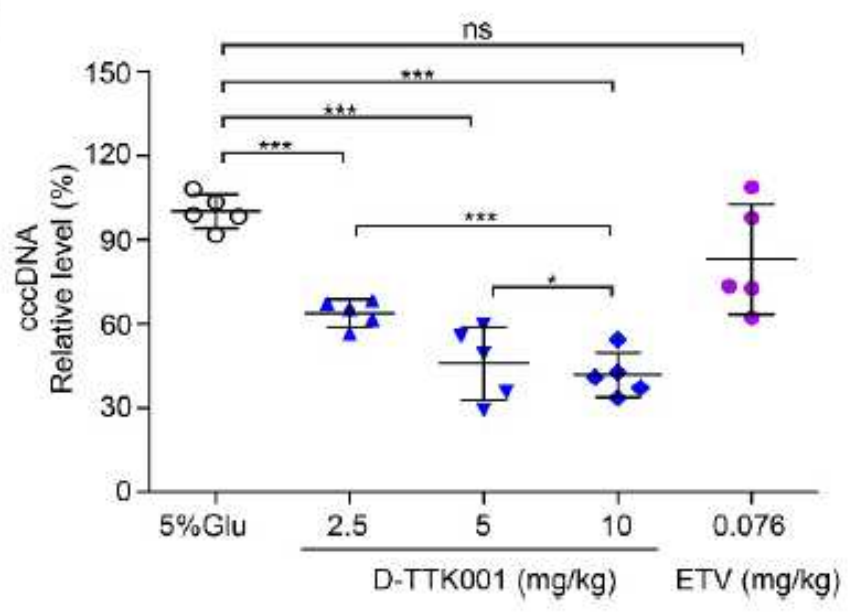

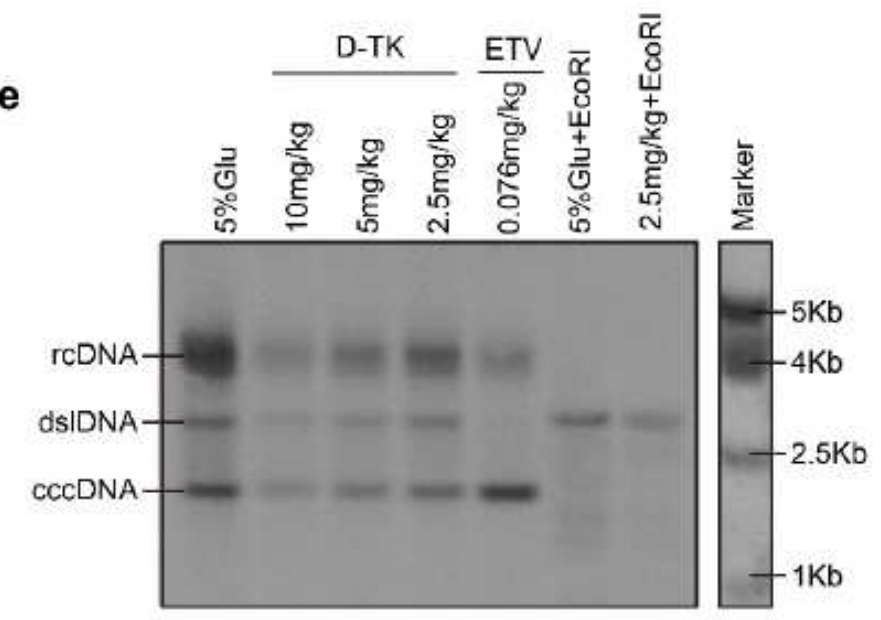

Figure 4

D-TTK001 efficiently controls the levels of HBV cccDNA in vitro and in vivo. a, The cccDNA levels were measured by qPCR assays in the nucleus of HBV de novo PHH cells treated with D-TTK001, ETV or IFN-a for 7 days. b, The cccDNA levels were examined by Southern blot analysis in the nucleus of HBV de novo 
PHH cells treated with D-TTK001 $(200 \mu \mathrm{M})$, ETV $(100 \mathrm{nM})$, and IFN-a $(2000 \mathrm{IU} / \mathrm{mL})$ for 7 days. c, The cccDNA levels were measured by Southern blot analysis in the nucleus of cells of HepAD38 (Tet off), HBV de novo PHH, dHepaRG, and HepG2-NTCP treated with D-TTK001 $(200 \mu \mathrm{M})$ for 7 days. d, The cccDNA levels were determined by qPCR assays in the liver of HBV-Huhep-URG mice treated with D-TTK001 $(10,5$, $2.5 \mathrm{mg} / \mathrm{kg})$ and ETV $(0.076 \mathrm{mg} / \mathrm{kg})$ for 28 days. e, The cccDNA levels were tested by Southern blot analysis in the liver of HBV-Huhep-URG mice. Data are represented as means $\pm S D$. ${ }^{*} p<0.05 ;{ }^{\star \star} p<0.01$; $* \star \star p<0.001$ (Student's t test).

a

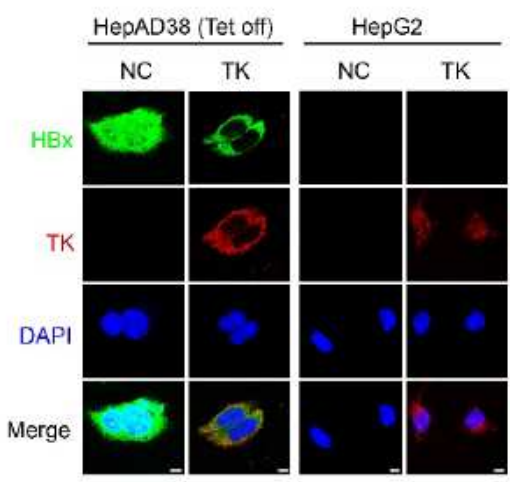

b HepAD38 (Tet off)

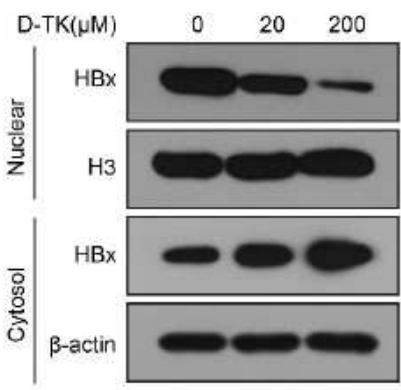

C $\mathrm{PHH}$ (HBV de novo)

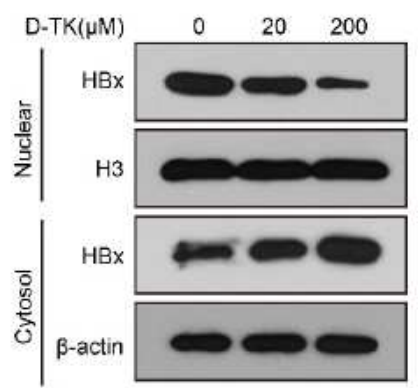

d HepAD38 (Tet off)

e HepG2-NTCP (HBV de novo)
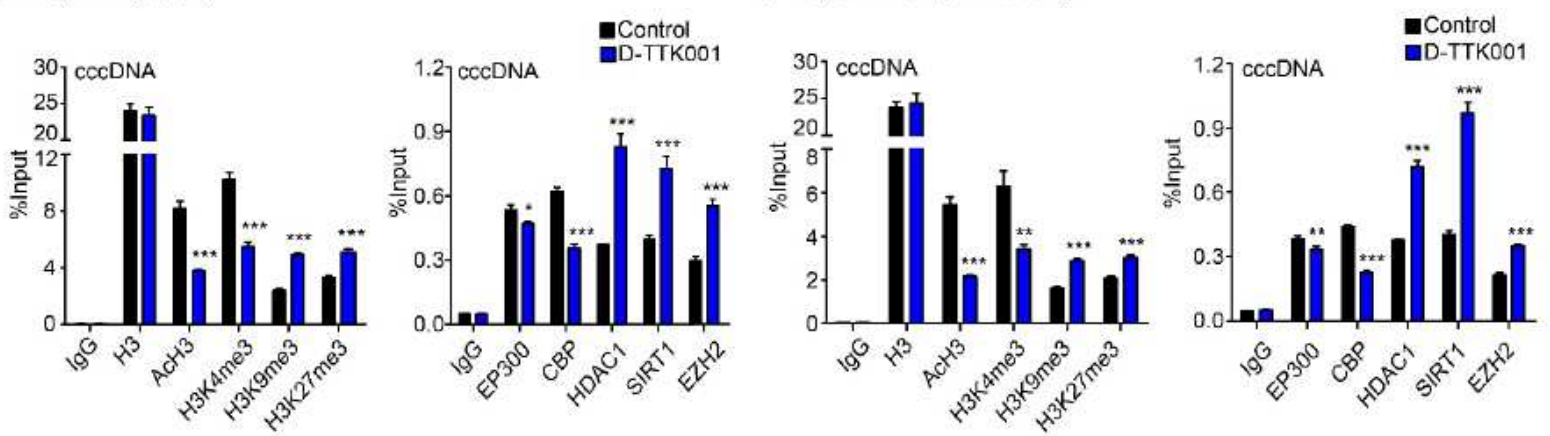

f HEK293T

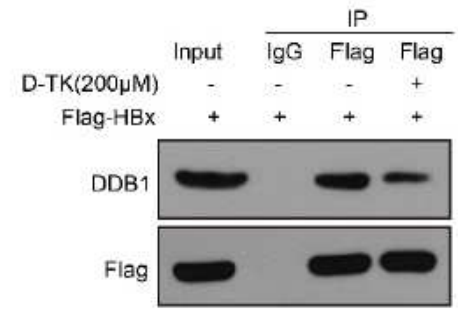

i PHH\#1 (HBV de novo)

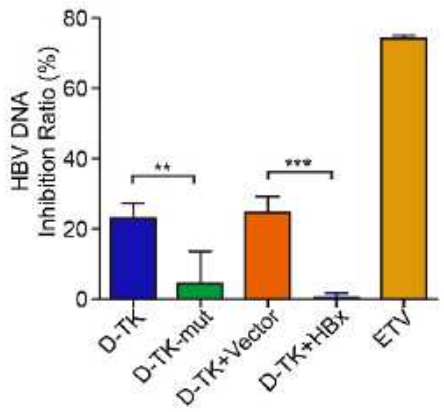

g HepG2-NTCP (HBV de novo)
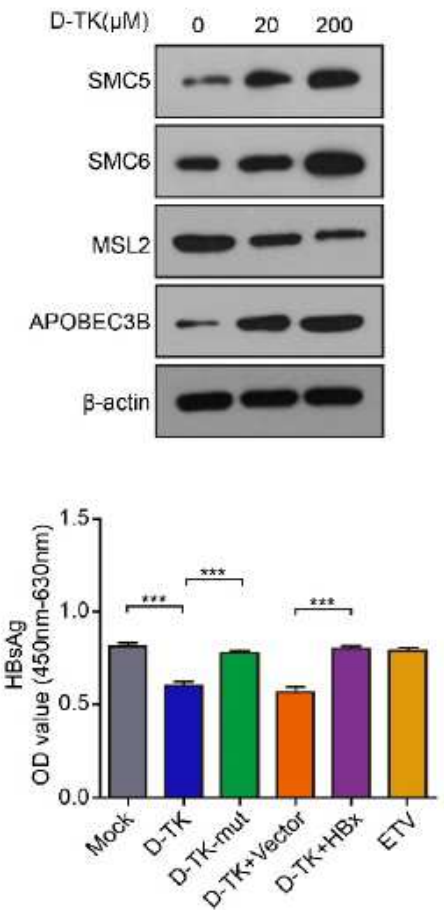

h $\mathrm{HepAD} 38$ (Tet off)
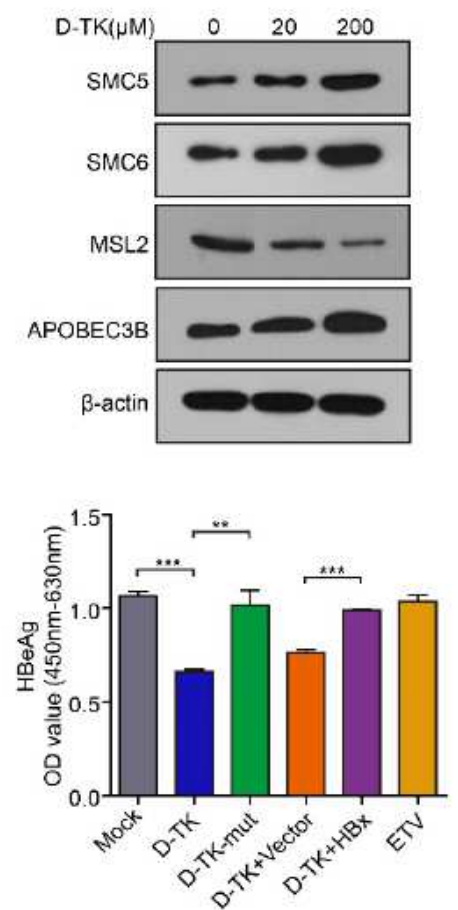


\section{Figure 5}

The mechanisms of D-TTK001 against HBV. a, Immunofluorescence staining was used to identify the location of D-TTK001 (red) and HBx (green) in HepAD38 (Tet off) and HepG2 cells treated with or without Red luciferin cy3-labeled D-TTK001 $(100 \mu \mathrm{M})$. DAPI (blue) stained the nuclei. Scale bars: $10 \mu \mathrm{m}$. b-c, The effect of D-TTK001 on the expression of HBx was tested by Western blot analysis in HepAD38 (Tet off) and HBV de novo PHH cells treated with D-TTK001 for 7 days. d-e, The assembly of histone H3, AcH3, H3K4me3, H3K9me3, H3K27me3, EP300, CBP, HDAC1, SIRT1, and EZH2 onto cccDNA was determined by ChIP-qPCR in HepaAD38 (Tet off) or HBV de novo HepG2-NTCP cells treated with D-TTK001 for 7 days, respectively. $f$, The interaction of DDB1 with exogenous HBx was examined by Co-IP assay in HEK293T cells transfected with Flag-tagged HBx and treated with D-TTK001 for 7 days. g, The effect of D-TTK001 on the expression of SMC5, SMC6, MSL2 and APOBEC3B was evaluated by Western blot analysis in HBV de novo HepG2-NTCP cells treated with D-TTK001 for 7 days. h, The effect of D-TTK001 on the expression of SMC5, SMC6, MSL2 and APOBEC3B was evaluated by Western blot analysis in HepAD38 cells treated with D-TTK001 for 7 days. i, The levels of HBV DNA, HBsAg, and HBeAg were measured by qPCR and ELISA assays in the supernatant of HBV de novo PHH cells treated with D-TTK001 (200 $\mu \mathrm{M}), \mathrm{D}$ TTK001-mut $(200 \mu \mathrm{M})$, ETV $(100 \mathrm{nM})$ for 7 days. The pcDNA3.1-HBx $(2 \mu \mathrm{g})$ and pcDNA3.1-Vector $(2 \mu \mathrm{g})$ were transfected at time points of day 0 , day 2 , and day 4 . Data are represented as means $\pm S D(n=3)$. ${ }^{*} \mathrm{p}<0.05 ;{ }^{* *} \mathrm{p}<0.01 ;{ }^{* \star *} \mathrm{p}<0.001$ (Student's t test). 
a $\operatorname{HepAD38}$ (Tet off)

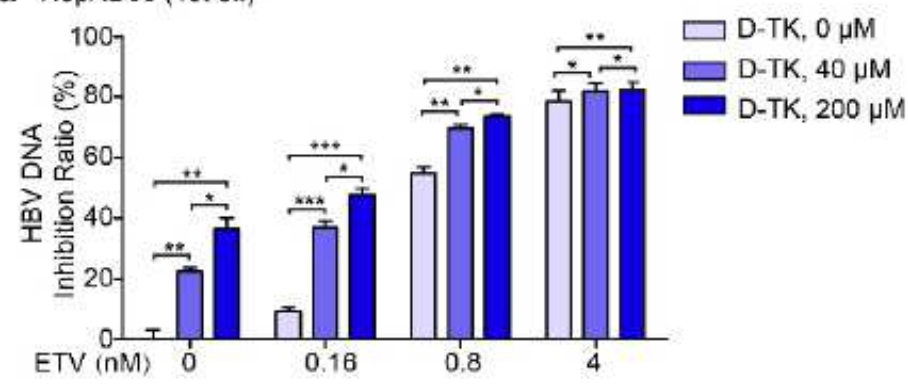

C HepAD38 (Tet off)

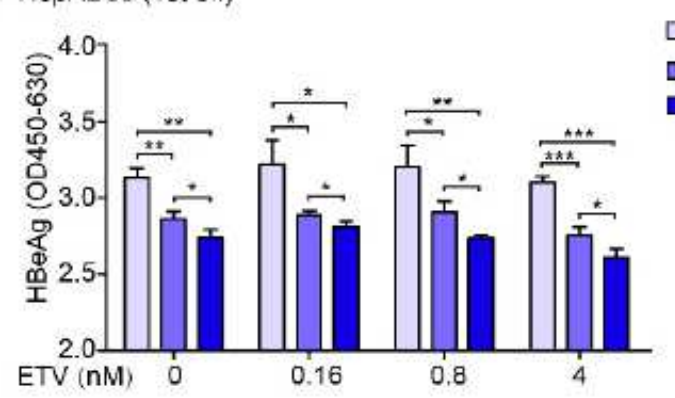

e HepAD38 (Tet off)

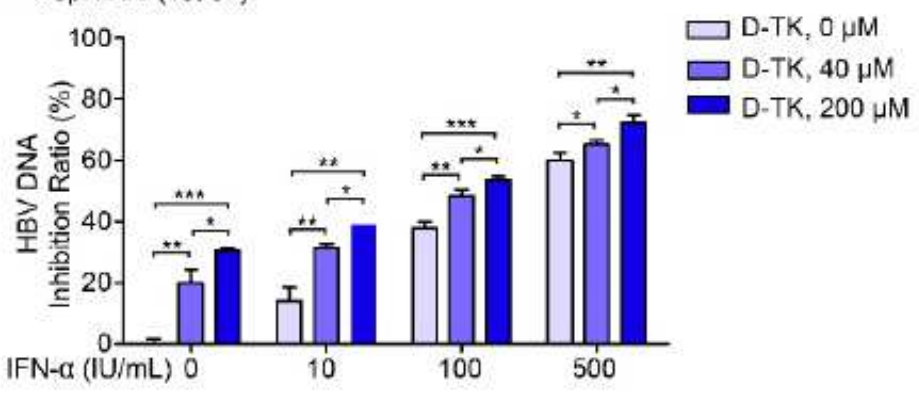

g HepAD38 (Tet off)

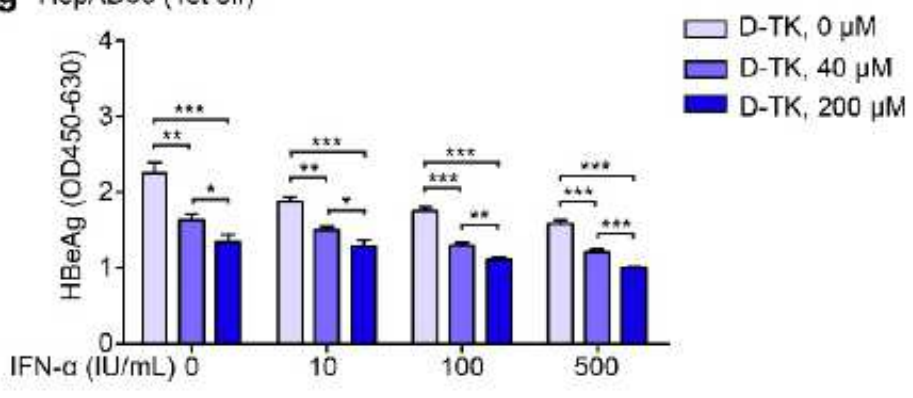

b HepAD38 (Tet off)

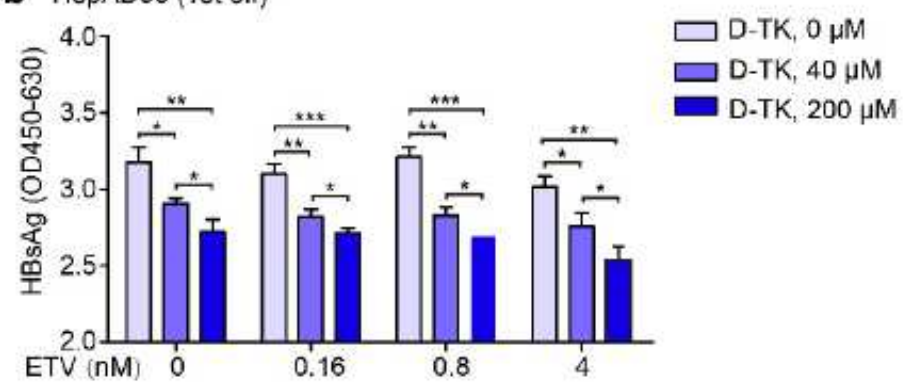

d HepAD38 (Tet off)

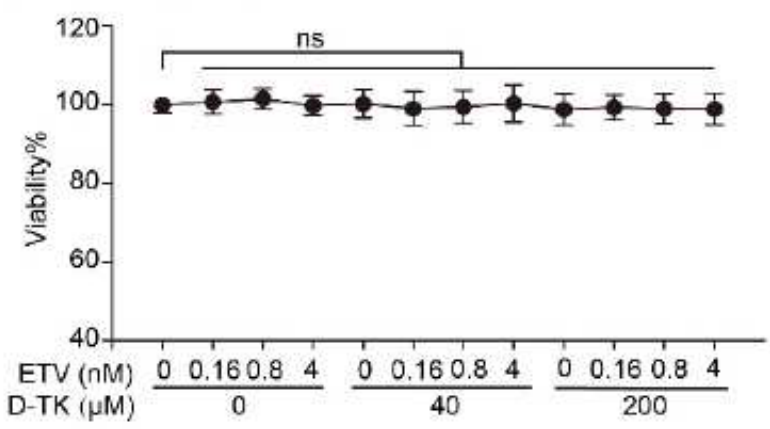

f HepAD38 (Tet off)

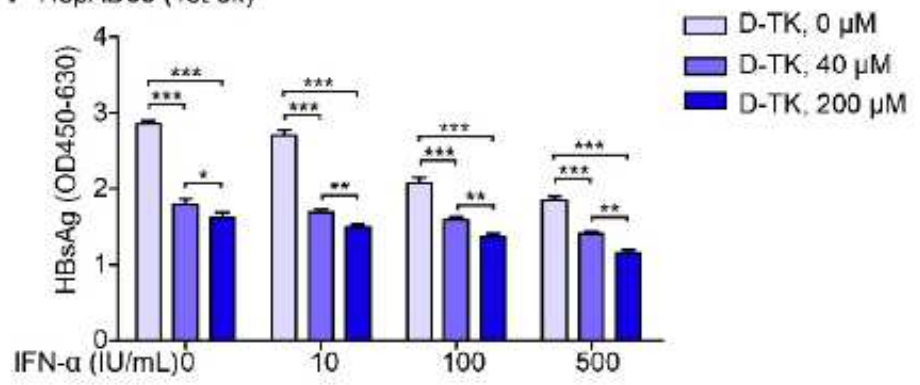

h $\operatorname{HepAD} 38$ (Tet off)

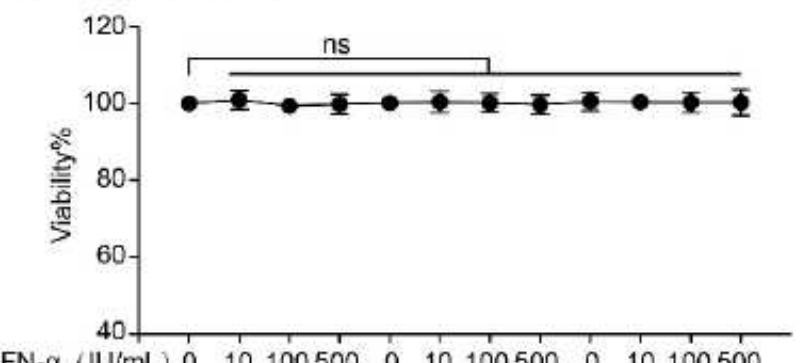

IFN- $\alpha(\mathrm{IU} / \mathrm{mL})$
D-TK $(\mu \mathrm{M})$$\frac{0 \frac{10100500}{0}}{0} \frac{010100500}{40} \frac{010100500}{200}$

\section{Figure 6}

Efficacy of the combination of D-TTK001 with ETV or IFN-a in vitro. a-c, The levels of HBV DNA, HBsAg, and HBeAg were measured by qPCR and ELISA assays in the supernatant of HepAD38 (Tet off) cells treated with both D-TTK001 and ETV for 7 days. d, HepAD38 cell viability was tested by MTS assays. e-g, The levels of HBV DNA, HBsAg, and HBeAg were evaluated by qPCR and ELISA assays in the supernatant of HepAD38 (Tet off) cells treated with both D-TTK001 and IFN-a for 7 days. (H) HepAD38 cell viability was tested by MTS assays. Data are represented as means $\pm \operatorname{SD}(n=3) .{ }^{*} p<0.05 ;{ }^{* \star} p<0.01 ;{ }^{* \star \star} p<0.001$ (Student's $t$ test). 